Aus der Abteilung Neurologie

(Prof. Dr. med. M. Bähr)

im Zentrum Neurologische Medizin

der Medizinischen Fakultät der Universität Göttingen

\title{
Analyse der Rolle des Purin-Rezeptors \\ P2X4 in der Pathophysiologie der Amyotrophen Lateralsklerose durch vergleichende Untersuchung seiner Expression im ALS-Mausmodell und humanen Gewebe
}

\author{
INAUGURAL-DISSERTATION \\ zur Erlangung des Doktorgrades \\ der Medizinischen Fakultät \\ der Georg-August-Universität zu Göttingen
}

vorgelegt von

Karoline Dorothea Ostertag

aus Hannover

Göttingen 2011 
Dekan: Prof. Dr. med. Cornelius Frömmel

I. Berichterstatter/in: Prof. Dr. med. Hülsmann

II. Berichterstatter/in: Prof. Dr. rer. nat. Keller

III. Berichterstatter/in: Prof. Dr. rer. nat. Virsik-Köpp

Tag der mündlichen Prüfung: 16.04.2012 


\section{INHALTSVERZEICHNIS}

1. EINLEITUNG 1

1.1. AMYOTROPHE LATERALSKLEROSE (ALS) [Myatrophische Lateralsklerose] 1

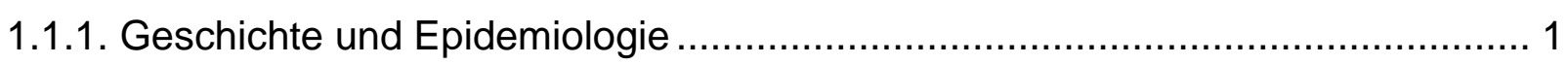

1.1.2. Pathologische und histopathologische Veränderungen................................. 3

1.1.3. Krankheitsbild ALS: Symptome, Diagnostik und Therapie ........................... 5

1.1.4. Ätiologie und pathogenetische Hypothesen ........................................... 9

1.1.5. Superoxiddismutase und transgene Tiermodelle ................................... 10

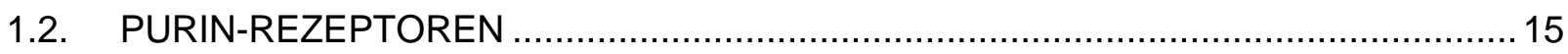

1.2.1. P2X-Rezeptoren und der P2X4-Rezeptor im Besonderen ........................... 17

1.2.2. Adenosintriphosphat (ATP) und der Purin-Rezeptor ................................. 22

1.3. DIE GLIAZELLEN DES ZENTRALEN NERVENSYSTEMS (ZNS) ...........................26

1.3.1. Gliazellen, Reiz und Immunantwort ................................................ 26

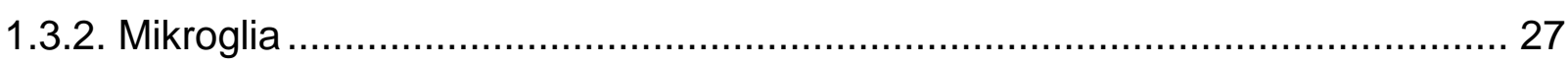

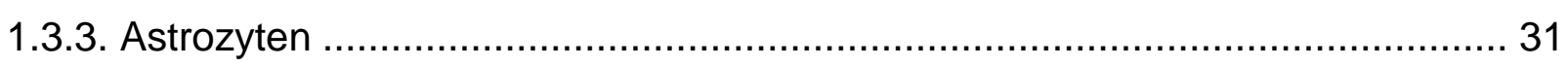

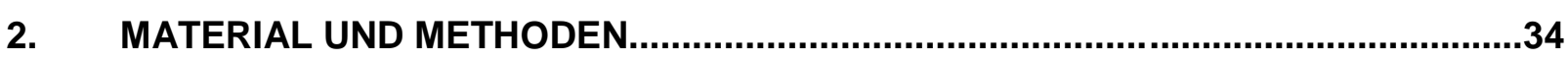

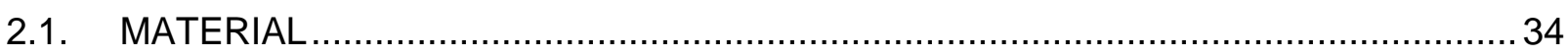

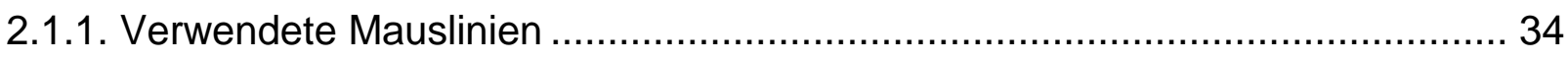

2.1.2. Verwendetes humanes Gewebe ..................................................... 36

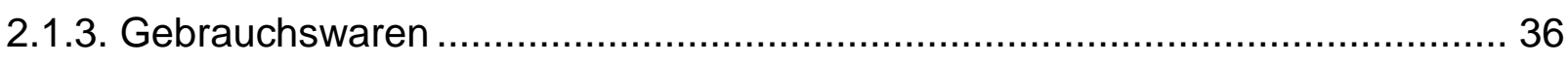

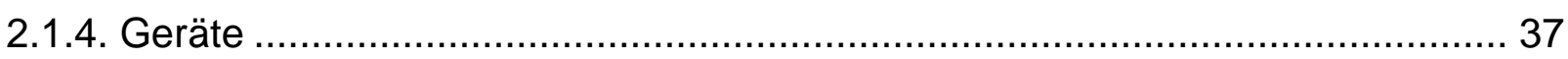

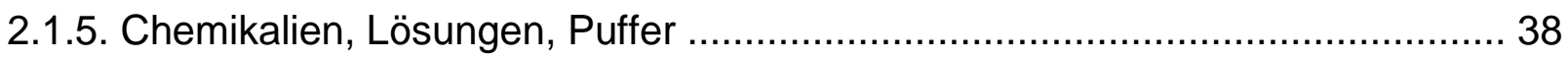

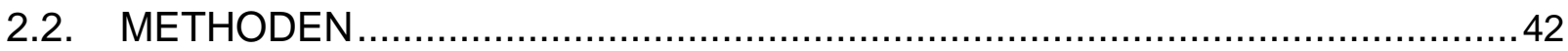

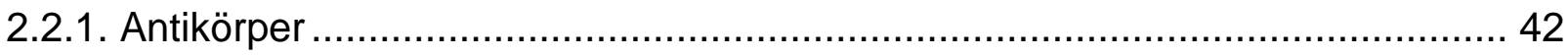

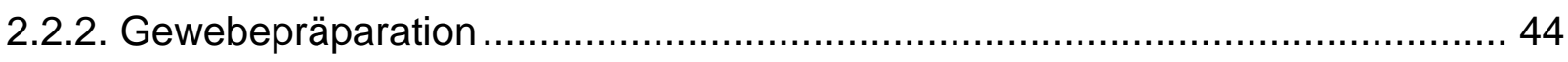

2.2.3. Paraffineinbettung der verwendeten Gewebe und Herstellung

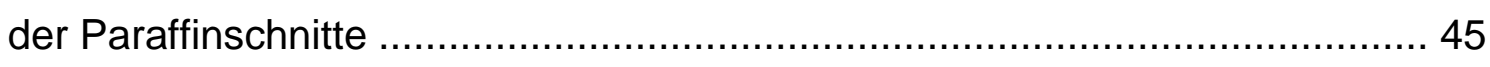

2.2.4. Herstellung von Kryoschnitten ....................................................... 46

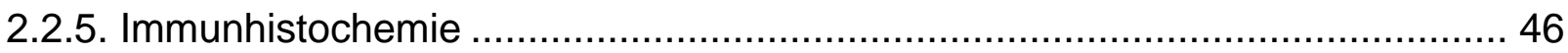




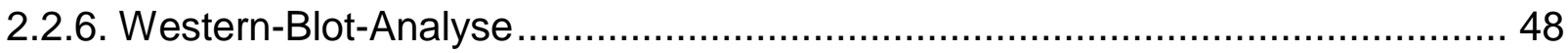

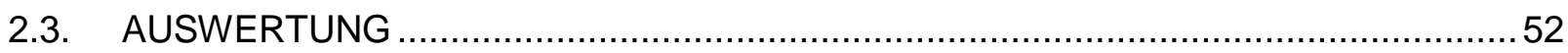

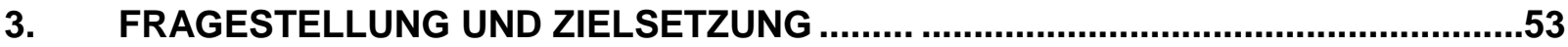

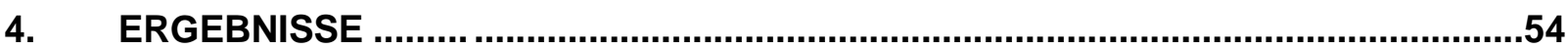

4.1. IMMUNHISTOCHEMISCHE EXPRESSIONSANALYSE DES P2X4-REZEPTORS IN WILDTYP- UND ALS-MAUSGEWEBE. 55

4.2. QUANTITATIVE ANALYSE DES P2X4-IMMUNOSIGNALS IM VERGLEICH ZWISCHEN WILDTYP- UND TRANSGEN-GEWEBE 72

4.3. WESTERN-BLOT-ANALYSE DES P2X4-REZEPTORS IN WILDTYP- UND TRANSGEN-GEWEBE 73

5. DISKUSSION. . .75

5.1. EXPRESSIONSMUSTER DES P2X4-REZEPTORS IM ALS-MAUSMODELL UND HUMANEN ALS-GEWEBE 76

5.2. ZUR ROLLE DER P2X4-EXPRESSION IN DER PATHOPHYSIOLOGIE NEUROGENER SCHÄDIGUNG 78

5.3. ZUR BEDEUTUNG DER HOCHREGULATION VON P2X4-REZEPTOREN AUF

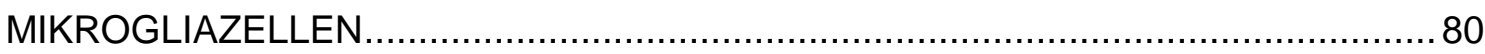

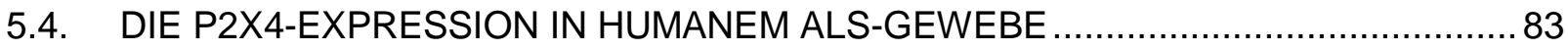

5.5. IST DIE P2X4-HOCHREGULATION MIT DER MOTONEURONALEN DEGENERATION IM RAHMEN DER ALS ASSOZIIERT?

6. ZUSAMMENFASSUNG

7. ANHANG

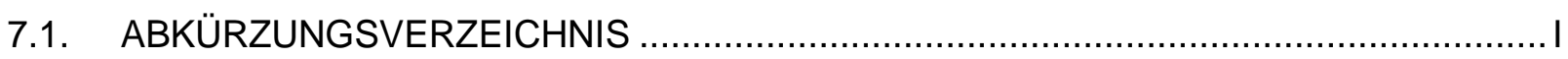

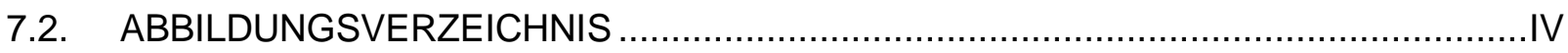

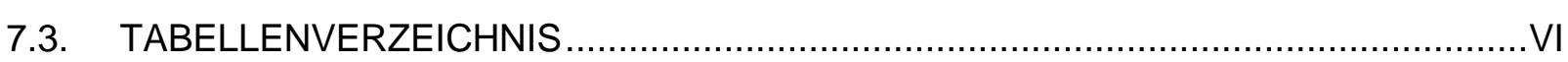

8. LITERATURVERZEICHNIS ................................................................................. 


\section{EINLEITUNG}

\subsection{AMYOTROPHE LATERALSKLEROSE (ALS) [Myatrophische Lateralsklerose]}

\subsubsection{Geschichte und Epidemiologie}

Die ALS ist eine progrediente degenerative Erkrankung des motorischen Nervensystems.

Das Krankheitsbild wurde erstmalig 1850 von François A. Aran (Aran 1850) erwähnt und 1869 von dem französischen Arzt und Begründer der klinischen Neurologie Jean-Martin Charcot als eine Kombination von spastischen Symptomen und atrophischen Paresen mit Faszikulationen beschrieben (Charcot und Joffreoy 1869).

Muskelatrophie und Degeneration der Funiculi laterales des Rückenmarks, auffallende Merkmale des Krankheitsbildes, führten zu dem Namen „Amyotrophe Lateralsklerose“ (Sclérose latérale amyotrophique - Charcot 1874).

Mit einer jährlichen Inzidenz von 1-3/100.000 und einer Prävalenz von 4-6/100.000 gilt die Amyotrophe Lateralsklerose als die häufigste Motoneuronerkrankung (Ludolph 2000).

Die Erkrankung, im angelsächsischen Raum auch als motor neurone disease benannt, ist in den USA auch unter dem Namen „Lou Gehrig's Disease“ geläufig (Namensgeber ist ein 1941 an ALS verstorbener deutschstämmiger USBaseballspieler). Sie kann in jedem Alter auftreten, manifestiert sich jedoch selten vor dem 50. Lebensjahr. Die Inzidenz ist bei Männern mit 3.0/100.000/Jahr höher als bei Frauen (2.4/ 100.000/ Jahr) (Logroscino et al. 2010).

Eine Untersuchung zum Krankheitsverlauf von Patienten, die schon im Alter zwischen 20 und 40 an ALS erkrankt waren, konnte zeigen, dass bei diesen Patienten die Männer ebenfalls häufiger als Frauen und auch früher erkranken $(5,8: 1)$. Allerdings liegt bei der sog. „young-adult-ALS“ eine Form vor, die im Gegensatz zur klassischen ALS überwiegend das obere Motoneuron betrifft 
(Sabatelli et al. 2008).

Auch endemisches Vorkommen ist bekannt, für das es bisher keine Erklärung gibt, wie z. B. die sog. Guam-Variante, benannt nach der gleichnamigen Insel im Westpazifik, auf der die jährliche Inzidenz der ALS bei den einheimischen Chamorros mit 8/100.000 wesentlich höher ist als in den USA (2.3/100.000; Rochester, MN) und Japan (0.6/100.000; Hokkaido) (Okumura 2003). Auch ein scheinbar vermehrtes Auftreten bei Fußballspielern wird beobachtet. Eine Studie der Universität Pavia wies ein 6.5fach erhöhtes Risiko im Vergleich zur Normalbevölkerung für italienische Fußballprofis auf, vor dem 49. Lebensjahr an ALS zu erkranken (Chio et al. 2005). Und bei den amerikanischen Veteranen des ersten Golfkrieges wurde ein Anstieg der Erkrankungshäufigkeit um das Doppelte mit niedrigerem Erkrankungsalter registriert (Bahron und Rowland 2002). Die USRegierung hat ALS als Kriegsfolgeschaden akzeptiert. Die der Entscheidung zugrunde liegenden Daten sind allerdings nicht erhältlich

Man unterscheidet verschiedene Formen der sporadischen ALS und ALSassoziierter Erkrankungen:

$>$ die klassische Form, die eine Inzidenz im höheren Lebensalter aufweist

$>$ die juvenile Form mit einem Krankheitsbeginn zwischen dem 20. und 40. Lebensjahr

> Demenz-assoziierte Formen (ALS mit Frontotemporaler Demenz - ALSFTD) und solche mit zusätzlichem Parkinsonsyndrom (ALS-FTDP).

> Atypische klinische Ausprägungen wie die progressive LMD (lower motoneuron disease) oder das "flail-arm-Syndrom“.

Neben der sporadischen ALS existiert eine familiäre Form (s. u.). 


\subsubsection{Pathologische und histopathologische Veränderungen}

Pathologisch-anatomisch liegt die Ursache der ALS in der kombinierten Degeneration des oberen (häufig auch als "erstes“ Motoneuron bezeichnet) und unteren („zweites“) motorischen Neurons.

Die oberen Motoneurone (MN) befinden sich hauptsächlich in der fünften Schicht des Neokortex, der sog. inneren Pyramidenschicht. Ihre Axone bilden den Großteil der Kortexefferenzen, vorwiegend über den Tractus kortikospinalis (Pyramidenbahn), die kortikobulbären Bahnen und über die motorischen Hirnnerven. Die unteren, zweiten, Motoneurone sind die Ganglienzellen des Vorderhorns im Rückenmark mit ihren Axonen. Modulierende Interneurone sind diesen Efferenzen auf Höhe des Rückenmarks zwischengeschaltet.

Je nach Lokalisation der Läsion bzw. Degeneration im ersten oder zweiten Motorneuron entwickelt sich eine spastische Parese oder eine schlaffe Parese mit Muskelatrophie bzw. einer Bulbärparalyse (Trepel 2006). Deshalb ist ein Charakteristikum der ALS das Mischbild aus zentraler und peripherer Parese.

Ein weiteres Charakteristikum ist die außergewöhnliche Selektivität des neuronalen Untergangs mit Beschränkung auf das motorische System (Strong 2004). Das sensible System bleibt meist unbeeinträchtigt, ebenso wie das vegetative Nervensystem und damit auch die Innervation des Blasen- und Rektumsphinkters. Sogar innerhalb des motorischen Systems scheint es eine Selektivität zu geben; die für die Okulomotorik verantwortlichen Neurone der Hirnnervenkerne III, IV und VI sind in der Regel nicht betroffen (Masuhr und Neumann 1996).

Auf histopathologischer Ebene sind neben der neuronalen Degeneration u. a. eine begleitende Gliose (Leigh und Swash 1991), intrazelluläre Proteinablagerungen (Leigh et al. 1991, Mourelatos et al. 1994) und ein Verlust von Myelin im Tractus kortikospinalis sowie der Vorderwurzel des Rückenmarks zu beobachten (Delisle und Carpenter 1984) (Abb. 1). 


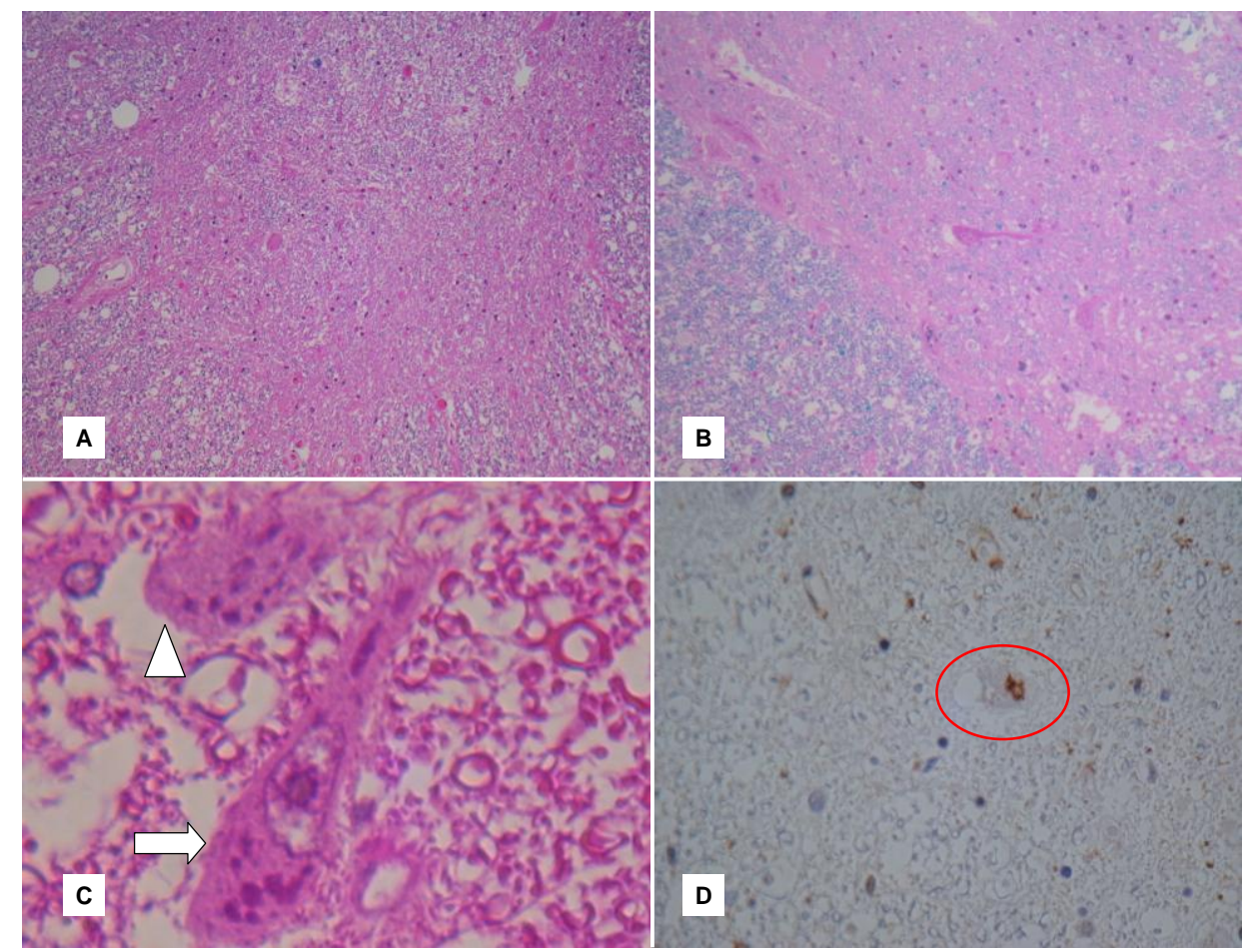

Abb. 1 Charakteristische Autopsiebefunde im Vorderhorn des Rückenmarks bei Amyotropher Lateralsklerose (79 Jahre alte Patientin, Sektion-Nr 132/92 Krankenhaus Nordstadt Hannover*)

A und B: Fortgeschrittener Verlust des zweiten Motoneurons (Färbung Luxolfastblue-HE). C: Unregelmäßiger basophiler Zytoplasmaeinschluss in einem residuellen Motoneuron (Pfeil) und eine Gruppe von perlschnurartigen Buninakörperchen (Pfeilspitze) im Zytoplasma einer Ganglienzelle (ohne angeschnittenen Kern; HE-Färbung).

D: Ubiquitin-positives knäuelartiges Aggregat (Skein) im Zytoplasma einer degenerierten Ganglienzelle (roter Kreis) - Meerrettich-Peroxidase-Technik.

(Ubiquitin, Dako, polyklonal, Verdünnung 1:1500; ZytoChem-Plus HRP-Kit von Zytomed Systems Berlin mit Diaminobenzidin als Chromogen, Kernfärbung Hämatoxilin)

* Ich danke dem Chefarzt des dortigen Institutes, Prof. Wilkens, für die Überlassung des Archivmaterials und Frau Dr. Brandis, Path. Institut der Med. Hochschule Hannover, für die Anfertigung des immunhistologischen Schnittes. 


\subsubsection{Krankheitsbild ALS: Symptome, Diagnostik und Therapie}

Der Krankheitsbeginn und -verlauf ist bei jedem Patienten unterschiedlich, sodass eine Prognose über den Verlauf der Erkrankung nur sehr vage sein kann. Der individuelle Behinderungsgrad wird allerdings wesentlich von der zuerst betroffenen Muskelregion bestimmt, denn bereits zu Beginn imponiert überwiegend eine Muskelschwäche und -atrophie. Die mittlere Überlebenszeit (ÜZ) nach Erstdiagnose beträgt 3-5 Jahre, wobei ca. 10\% der Patienten einen langsameren Krankheitsverlauf mit einer mittleren ÜZ von $>5$ Jahre aufweisen (Orrell 2007).

Bei einer geringen Anzahl von ALS-Patienten sind Verläufe von $>10$ Jahre bekannt, insbesondere bei der juvenilen form der ALS, bei der Schädigungszeichen des 1. MN im Vordergrund stehen. Da die Muskelschwäche bzw. -lähmung im Verlauf auch die Atemmuskulatur betrifft, ist die häufigste Todesursache eine progrediente Ateminsuffizienz mit Entwicklung einer Pneumonie. Bis heute ist eine Heilung der ALS nicht möglich, es bleibt ein symptomatischer bzw. palliativer Therapieansatz (Ludolph 2000, Ludolph et al. 2007).

Die einzig zugelassene Pharmakotherapie stellt das Medikament Riluzol (Rilutek®) dar (Traynor et al. 2006). Riluzol wirkt neuroprotektiv, indem es als unselektiver NMDA-Antagonist in die Glutamatstoffwechsel-Signalkette eingreift (Munch und Ludolph 2001). Daneben kommen Medikamente zum Einsatz, die die Symptome der Erkrankung lindern bzw. deren Fortschreiten verlangsamen sollen (z. B. Antispastika wie Baclofen oder Schleimlöser zur Lungenprotektion). Weiterhin stellen physiotherapeutisches Training und das Einsetzen von rehabilitativen Maßnahmen wie etwa Gehhilfen oder Schienen den Hauptteil der symptomatischen Therapie dar. Gentherapeutische Ansätze werden in Tierversuchen verfolgt (Hedlund et al. 2007) und sind in klinischen Therapiestudien geplant.

Grundsätzlich kann zwischen einem Krankheitsbeginn an den Extremitäten und einer nicht so häufigen bulbären Form (20-30\% d. F.), die mit Schluck- und Sprechstörungen einhergeht, unterschieden werden (Masuhr und Neumann 1996). Die sog. progressive Bulbärparalyse betrifft die Muskulatur, die überwiegend von 
kaudalen Hirnnerven innerviert wird, d. h. Kaumuskulatur (N. trigeminus; N. V), mimische Muskulatur (N. facialis; N. VII), Pharynx- und Larynxmuskulatur (N. glossopharyngeus; N. IX), Kehlkopfmuskulatur (N. vagus; N. X) und Zunge (N. hypoglossus; N. XII).

Diese bulbäre Form zeigt sich anfangs diskreter, oft berichten Angehörige z. B. über eine veränderte Artikulation des Betroffenen. Als besonders belastend wird häufig die durch eine zunehmende Dysphagie bedingte Unfähigkeit, den Speichel kontrolliert schlucken zu können, beschrieben (Sialorrhoe).

Bei der Mehrheit der Patienten aber treten die bulbären Symptome erst in einem späten Stadium der Krankheit zusätzlich zu der Extremitätenschwäche auf.

Die „spinale“ Form der ALS ist mit 70-80\% der Fälle die Häufigste. In der Anamnese berichten die Patienten hier am häufigsten über Muskelschwäche und krämpfe. Etwa 40\% der Patienten (Dengler et al. 2000) berichten von Frühsymptomen in Form von einer sich entwickelnden Ungeschicklichkeit beim Schreiben, Essen, Rasieren, etc. Betrifft die Muskelschwäche aber zuerst die untere Extremität, klagen wiederum 40\% über eine Gangunsicherheit. Mit fortschreitendem Krankheitsverlauf sind i. d. R. obere und untere Extremitäten betroffen.

Typischerweise tritt die Symptomatik zuerst isoliert unilateral z. B. in Unterarm und Hand auf. Inspektorisch ist eine Muskelatrophie insbesondere der kleinen Handmuskeln und der Schultermuskulatur zu erkennen. Im Verlauf ist zu beobachten, dass sich die Symptomatik auf benachbarte Muskelregionen ausbreitet (Harrison et al. 2005).

Weitere typische Frühsymptome stellen Muskelfaszikulationen dar, also unkontrollierte nicht bewegungswirksame Muskelkontraktionen, die oft besonders eindrucksvoll an der von dem Patienten herausgestreckten Zunge und/oder durch Beklopfen bzw. Kälteexposition der Muskulatur zu beobachten sind. Die Faszikulationen sind verursacht durch Erregungsstörungen an der motorischen Endplatte erkrankter zweiter Motoneurone.

Zusammenfassend sind das synchrone Auftreten von spastischen sowie schlaffen Paresen und gesteigerten bzw. abgeschwächten Reflexen beim Erwachsenen sowie der Nachweis von Muskelfaszikulationen wesentliche Diagnosekriterium für eine ALS, insbesondere wenn weder Störungen der Sensibilität, des Schmerz- und Temperaturempfindens sowie keine Einschränkung der Blasen- und 
Mastdarmfunktion vorliegen (Orrell et al. 1999).

Die Diagnosestellung soll nach festgelegten Kriterien, die als sog. „El-EscorialKriterien“ der „World Federation Neurology“ (WFN) international standardisiert wurden erfolgen:

Tab. 1: El-Escorial-Kriterien zur Diagnostik der ALS

\begin{tabular}{|c|c|}
\hline $\begin{array}{l}\text { EL-ESCORIAL- } \\
\text { KRITERIEN }\end{array}$ & BESCHREIBUNG \\
\hline Definitive/Sichere ALS & $\begin{array}{l}\text { Schädigungszeichen des } 1 \text {. und } 2 \text {. Motoneurons in } 3 \text { von } 4 \\
\text { Regionen ( bulbär, zervikal, thorakal, lumbosakral) }\end{array}$ \\
\hline Wahrscheinliche ALS & $\begin{array}{l}\text { Schädigungszeichen des } 1 \text {. und } 2 \text {. Motoneurons in } 2 \text { von } 4 \\
\text { Regionen, wobei die Schädigungszeichen des } 2 . \\
\text { Motoneurons rostral der Schädigung des } 2 \text {. Motoneurons } \\
\text { liegen müssen }\end{array}$ \\
\hline $\begin{array}{l}\text { Wahrscheinliche, } \\
\text { laborunterstützte ALS }\end{array}$ & $\begin{array}{l}\text { Schädigungszeichen des 1. und 2. Motoneurons in einer } \\
\text { von } 4 \text { Regionen (oder nur des 1. MN in einer Region) und } \\
\text { Denervierungszeichen im EMG (Elektromyogramm) in } \\
\text { mindestens zwei Extremitäten }\end{array}$ \\
\hline Mögliche ALS & $\begin{array}{l}\text { Schädigungszeichen des } 1 \text {. und } 2 \text {. Motoneurons in } 1 \text { von } 4 \\
\text { Regionen }\end{array}$ \\
\hline $\begin{array}{l}\text { Die Diagnose einer ALS } \\
\text { erfordert das } \\
\text { Vorhandensein von: }\end{array}$ & $\begin{array}{l}\text { Zeichen der Läsion des 1. MN } \\
\text { Zeichen der Läsion des 2. MN (inkl. EMG- Veränderungen } \\
\text { in klinisch nicht betroffenen Muskeln) } \\
\text { Progredienz }\end{array}$ \\
\hline $\begin{array}{l}\text { Die Diagnose einer ALS } \\
\text { erfordert das Fehlen } \\
\text { von: }\end{array}$ & $\begin{array}{l}\text { Gefühlsstörungen, Sphinkterstörungen, autonomer } \\
\text { Dysfunktion, Parkinsonsyndrom, Alzheimer-Demenz oder } \\
\text { Syndromen, die der ALS ähnlich sind }\end{array}$ \\
\hline $\begin{array}{l}\text { Die Diagnose einer ALS } \\
\text { wird gestützt durch: }\end{array}$ & $\begin{array}{l}\text { Faszikulationen in einer oder mehreren Regionen, } \\
\text { neurogene Veränderungen im EMG, normale motorische } \\
\text { und sensible Nervenleitgeschwindigkeiten, Fehlen von } \\
\text { Leitungsblöcken }\end{array}$ \\
\hline
\end{tabular}

Angepasst übernommen aus Brooks et al. 2000 
Der klinische Befund und die Verdachtsdiagnose müssen durch Zusatzdiagnostik ergänzt bzw. bestätigt werden.

Hierfür haben neurophysiologische Untersuchungen wie das Elektromyogramm (EMG) und die Messung der Nervenleitgeschwindigkeit (NLG) einen hohen Stellenwert. Des Weiteren können sowohl Muskelbiopsien als auch bildgebende Verfahren zur Diagnosefindung und -bestätigung eingesetzt werden (Grosskreutz et al. 2008, Lule et al. 2009), insbesondere wenn sich differentialdiagnostische Schwierigkeiten in der Abgrenzung z. B. zu polysegmentalen Bandscheibenvorfällen (polyradikuläre Symptomatik) oder zu seltenen Muskelerkrankungen wie der Einschlusskörperchenmyositis ergeben.

Derzeit existieren noch keine Krankheitsmarker. Jüngere Studien postulieren anhand von Verlaufsuntersuchungen körpereigener Proteine und Hormone von ALS-Patienten (u. a. Transthyretin, Fetuin-A, Erythropoetin, CD14 oder schon aus der Demenz-Diagnostik bekannte Marker wie das Tau-Protein und S100B) allerdings potentielle Zusammenhänge und beschrieben mit der Erkrankung assoziierte Schwankungen der jeweiligen Konzentrationen. Diese Faktoren könnten in der Zukunft als Marker dienen (Brettschneider et al. 2007, Brettschneider et al. 2010, Süssmuth et al. 2010). Die Diagnose einer ALS ist somit weiterhin klinisch zu stellen. Wesentliche abzuklärende Differentialdiagnosen sind v. a. andere motorisch-betonte Neuropathien (Multifokale motorische Neuropathie, polysegmentale motorische Radikulopathien), die primäre Lateralsklerose, spinale Muskelatrophie sowie in einigen Fällen auch Autoimmunerkrankungen wie die Multiple Sklerose oder myasthene Syndrome (bulbärer Beginn), paraneoplastische Syndrome sowie durch Stoffwechselerkrankungen, Infektionen oder Intoxikationen bedingte (motorische) Neuropathien (Hufschmidt und Lücking 1999). 


\subsection{4. Ätiologie und pathogenetische Hypothesen}

Die ALS ist vom pathogenetischen Standpunkt als eine komplexe, multifaktorielle Krankheit einzuordnen. Das Zusammenwirken von genetischen und umweltassoziierten Faktoren wird als Ursache der sporadischen Form angenommen (Roelofs-Iverson et al. 1984, Appel et al. 1995, Cox und Sacks 2002).

Für die bei der selteneren familiären Formen der ALS nachgewiesenen Mutationen wurden transgene Zell- und Tiersysteme entwickelt; diese sind Gegenstand der ALS-Forschung und dienen $u$. a. der Untersuchung möglicher pathogenetischer Faktoren. Schwerpunkt in diesem Bereich ist die Forschung am mSOD1Tiermodell.

Eine neue Hypothese in der ALS-Forschung ist, dass nicht eine primäre, autonome Degeneration der Motoneurone krankheitsursächlich sei, sondern eine gestörte Interaktion zwischen nicht-neuronalen Glia-Zellen und Neuronen (Boillée 2006b). Es wird angenommen, dass aus einem gestörten sog. „cross-talk“ Veränderungen des extrazellulären Milieus mit Anreicherung toxischer Substanzen resultieren können. Hierbei kommt der Störung von lonenkanälen eine wichtige Rolle zu; in Untersuchungen unserer Arbeitsgruppe konnte gezeigt werden, dass hierbei auch eine erhöhte extrazelluläre Kaliumkonzentrationen bei der neuronalen Degeneration eine Rolle spielen könnte (Kaiser et al. 2006). Die hier vorliegende Arbeit untersucht die Rolle der Purin-Rezeptoren im mSOD1-Mausmodell in der neuronalen Degeneration der ALS.

Wegen der Komplexität der Pathogenese und experimentellen Modelle wird im Folgenden näher auf das SOD-Modell, die lonenkanäle und die beteiligten Zellsysteme eingegangen. 


\subsubsection{Superoxiddismutase und transgene Tiermodelle}

Bei der ALS wird die sporadische von der erblichen, der familiären Form (fALS), unterschieden. Die sporadische Form macht etwa 90-95\% der Fälle aus (Fauci et al. 1998). 5-10\% aller ALS-Fälle haben eine familiäre Komponente. Der fALS liegt in der Regel ein autosomal-dominanter Erbgang zugrunde. Beide Formen unterscheiden sich in der klinischen Ausprägung nicht wesentlich (Gros-Louis et al. 2006).

Genetische Veränderungen werden sowohl bei der sporadischen als auch bei der familiären ALS beschrieben, allerdings ist nicht geklärt, ob die gefundenen Mutationen und/ oder genetischen Polymorphismen ursächlich für die Krankheit sind. Es wird dennoch vermutet, dass genetische Polymorphismen auch bei der sporadischen ALS an der Krankheitsentstehung beteiligt sind (Felbecker et al. 2010, Van Es et al. 2010).

Etwa 15-20\% der bekannten fALS-Fälle und 1-2\% aller ALS-Fälle (Rosen et al. 1993, Andersen et al. 2006, Birve et al. 2010, Wuolikainen et al. 2011) sind mit Mutationen auf dem Chromosom 21 assoziiert (Siddique et al. 1991).

Diese Mutationen, z. Z. der Verfassung der vorliegenden Arbeit etwa 150, befinden sich auf dem Gen, das für das Enzym Kupfer/Zink-Superoxid-Dismutase (SOD1) kodiert (Rosen et al. 1993, Wroe et al. 2008, Baek et al. 2011).

Die SOD1 ist ein homodimeres Protein mit einem Molekulargewicht von $32 \mathrm{kD}$, das ubiquitär in Zellkern, Zytosol und in den Mitochondrien exprimiert wird (Shaw 2005).

Die Monomere sind mittels einer Disulfidbrücke verbunden und jedes von innen bindet jeweils ein Zink- und ein Kupferatom. Funktion des Enzyms ist die Umwandlung von Superoxidanionen zu molekularem Sauerstoff zu Sauerstoff und Wasserstoffperoxid (Halliwell 1999), wobei das gebundene Kupfer erst reduziert und dann oxidiert wird. Das während dieser Reaktion entstandene Wasserstoffperoxid wird anschließend von der Katalase zu Wasser und molekularem Sauerstoff umgewandelt.

Die SOD1 ist damit ein wesentliches Enzym des antioxidativen Abwehrsystems (Singh et al. 1998). 
Gesamtreaktion:

$$
\begin{aligned}
& (-0,5) \quad \stackrel{(-1) \quad(0)}{(0)} \text { O-Oxidationsstufe } \\
& 2 \mathrm{O}_{2}+2 \mathrm{H}_{2} \stackrel{\text { SOD } \rightarrow \mathrm{H}_{2} \mathrm{O}_{2}+\mathrm{O}_{2}}{ } \\
& \mathrm{H}_{2} \mathrm{O}_{2}+\text { Katalase (red.) } \rightarrow \mathrm{H}_{2} \mathrm{O}+\text { Katalase (ox.) } \\
& \mathrm{H}_{2} \mathrm{O}_{2}+\text { Katalase (ox.) } \rightarrow \mathrm{H}_{2} \mathrm{O}+\mathrm{O}_{2}+\text { Katalase (red.) }
\end{aligned}
$$

Bei den bisher bekannten Mutationen auf dem SOD1-Gen handelt es sich um Punktmutationen, die zu einem Austausch einer Aminosäure im Enzym führen. Da die pathologischen Veränderungen identisch und sich die klinischen Erscheinungen ähnlich sind, bietet die Erforschung der mit der mutierten SOD1 (mSOD1) assoziierten Motoneuron-Degeneration die Möglichkeit, Rückschlüsse auf den Pathomechanismus der sporadischen Form der ALS zu ziehen. So wurden genetisch veränderte Maus- und Rattenmodelle generiert, die verschiedene SOD1Punktmutationen überexprimieren. In den letzten Jahren wurden im Wesentlichen Tiermodelle mit transgener Expression der SOD1-Mutationen $\mathrm{G}^{85 R}, \mathrm{G}^{37 \mathrm{~A}}$ und $\mathrm{G}^{93 \mathrm{~A}}$ verwendet, die eine annähernd selektive Degeneration motorischer Bahnen zeigen. Am besten etabliert ist das - auch in der vorliegenden Arbeit verwendete Maus- und Rattenmodell mit einer $\mathrm{G}^{93 \mathrm{~A}}$-Mutation. Hier liegt ein Austausch von Glycin gegen Alanin im SOD1-Gen auf Position 93 vor (Brujin und Cleveland 1996).

Die histopathologischen Veränderungen im Maus- und Rattenmodell sind vergleichbar mit entsprechenden Veränderungen im humanen postmortalen Gewebe, sodass die Maus- und Rattenmodelle in der Forschung zur Untersuchung der Pathogenese wie auch für therapeutische Strategien der ALS etabliert sind (Bruijn et al. 2004).

Es bestehen unterschiedliche Hypothesen bezüglich des Einflusses und der veränderten Wirkungsweise der mSOD1. Die naheliegende Annahme, dass die SOD1-Mutation zu einem Funktionsverlust mit daraus resultierender Anhäufung von Sauerstoffradikalen und die Radikalanhäufung zur Degeneration der Neurone führen (Estévez et al. 1999) konnte nicht aufrechterhalten werden. In der Untersuchung von Brujn et al. wurden keine erhöhten Mengen von 
Hydroxylradikalen im ZNS von SOD1-transgenen Mäusen gemessen (Bruijn et al. 1997a). In einem weiteren mSOD1-Tiermodell mit Ausschaltung des Enzymkofaktors Kupfer (Wang et al. 2003) wurde dieser Befund bestätigt.

Komplementär damit ist die Untersuchung von Reaume et al. (1996), dass die Deletion des SOD1-Gens in Mäusen (SOD1-knock-out-Mäuse) und der damit einhergehende Verlust der enzymatischen Aktivität der SOD1, nicht zu einer Degeneration motorischer Bahnen und auch nicht zum klinischen Phänotyp einer ALS führt.

Aus diesen Ergebnissen wurde geschlossen, dass die Mutation der SOD1 zelltoxisch ist, jedoch unabhängig von den katalytischen Funktionen des Enzyms (Williamson et al. 2000). Offenbar liegt eine zelltoxische Wirkung der mSOD1 vor, die nicht durch den Verlust der katalytischen Funktion („loss-of-function“), sondern durch neu erlangte - vermutlich toxische - Eigenschaften, in der Literatur in diesem Zusammenhang als „gain-of-function“-Mutation charakterisiert, vermittelt wird.

Eine weitere Theorie über die Toxizität des mutierten Enzyms zieht die im mSOD1Modell nachgewiesenen intrazellulären mSOD1-Proteinablagerungen als ursächlichen Risikofaktor in Betracht (Bruijn et al. 1997b, Bruijn et al. 1998, Watanabe et al. 2001). Diese Aggregate wurden sowohl in Nervenzellen als auch in Gliazellen gefunden (Bruijn et al. 1998). In-vitro wurde diese Ablagerung in Motoneuronen bestätigt und gezeigt, dass diese Ablagerungen die proteosomale Funktion der Zelle beeinträchtigen (Durham et al. 1997, Bruening et al. 1999).

Da viele Erkrankungen des ZNS mit intrazellulären Proteinablagerungen einhergehen, liegt die Vermutung nahe, dass dieser Zusammenhang auch bei der ALS eine Rolle spielt (vgl. z. B. Morbus Alzheimer. Hier finden sich typischerweise intrazellulär gelegene Aggregate des TAU-Proteins). Es ist jedoch weiterhin unklar, ob diese Ablagerungen die Entstehung der Krankheit bedingen oder als ihre Folge auftreten, eventuell also lediglich Epiphänomene darstellen (Ludolph et al. 2001, Münch et al. 2005, Süssmuth et al. 2003, Usarek et al. 2006).

Es sind noch weitere für degenerative Motoneuron-Erkrankungen relevante GenMutationen bekannt, für die allerdings noch kein Tiermodell entwickelt werden konnte. Es wird vermutet, dass in Folge solcher Mutationen entstandene Fehlfunktionen eine ursächliche Rolle bei der Entstehung der ALS haben könnten wie z. B. das regulatorisch im Nukleosidstoffwechsel wirksame Protein Alsin (Ludolph et al. 2001, Yang et al. 2001, Kunita et al. 2004, Teuchert et al. 2006, 
Unrath et al. 2007). Ein aufgrund von Mutationen entstandener abnormer Aufbau sowie eine Kumulation von Neurofilamenten ist ebenfalls als möglicher Risikofaktor für die Entwicklung der fALS, der sporadischen ALS (Garcia et al. 2006) und in SOD1-Tiermodellen (Bruijn et al. 1997b) beschrieben. Auch Mutationen in Genen für zytoskelettale Proteine (z. B. Dynactin) führten im Tierversuch zur Degeneration von Motoneuronen und konnten bei einer atypischen Form der ALS nachgewiesen werden (Hafezparast et al. 2003, Puls et al. 2003).

Im Zusammenhang der "gain-of-function"-Mutation der mSOD1 wird auch eine resultierende Schädigung der Mitochondrien beschrieben. Offensichtlich verlieren sie ihre Fähigkeit, ATP zu synthetisieren und Calcium aufzunehmen. Dieses führt zu einer zellschädigenden Erhöhung extrazellulären Calciums (Dal Canto und Gurney 1995, Kong und Xu 1998, Jaiswal et al. 2009, Jaiswal und Keller 2009).

Intra- und interzelluläre Prozesse werden häufig durch Calcium gesteuert (Mcburney und Neering 1985, Blaustein 1988, Neher 1995). Ein Anstieg extrazellulären Calciums und eine Erhöhung des Calciumeinstroms werden normalerweise durch sofortiges Binden der lonen an negativ geladene Bindungsstellen von intrazellulären Proteinen sowie membranständigen Phospholipiden begrenzt. Zum Beispiel kommt Calbindin die Aufgabe zu, einen übermäßigen Anstieg der intrazellulären Calciumkonzentration zu verhindern und so einer unspezifischen Aktivierung von Proteinen entgegenzuwirken (Ho et al. 1996). Diese Mechanismen dienen der Aufrechterhaltung der Calciumhomöostase. Eine dauerhaft Erhöhung der extrazellulären Calciumkonzentration wirkt neurodegenerativ (Jaiswal et al. 2009) und führt letztendlich zur Aktivierung von Enzymen, die die neuronale Apoptose einleiten (Krieger et al. 1994, Krieger et al. 1996, Morrison und Morrison 1999).

Die im Zusammenhang mit der mSOD1 außerdem beobachteten Störungen des glialen Glutamattransporters GLT1 führen zu einer erhöhten extrazellulären Glutamatkonzentration. In deren Folge kommt es zur Aktivierung synaptischer Glutamatkanäle mit der Konsequenz eines erhöhten glialen $\mathrm{Ca}^{++}$-Einstrom (Rothstein et al. 1995, Rothstein und Kuncl 1995, Trotti et al. 1999). In-vitro wurde nachgewiesen, dass die Toxizität der SOD1-Mutation abhängig ist von einem erhöhten Calcium-Einstroms in Folge dysfunktionaler spannungsabhängiger und Glutamat-Rezeptoren (Gurney et al. 1996, Roy et al. 1998). Auch klinisch gibt es dafür Hinweise mit dem Nachweis von Serum-Antikörpern gegen den L-Typ- 
Calciumkanal bei ALS-Patienten (Smith et al. 1992).

Diese Ergebnisse lassen darauf schließen, dass die neurodegenerative Wirkung bei der ALS in Relation mit Veränderungen der zentralen Calciumhomöstase stehen könnte (Appel et al. 1995, Shaw und Ince 1997).

In der vorliegenden Arbeit wurden deshalb Veränderungen des Kationenkanals P2X4 (aus der Gruppe der Purin-Rezeptoren) in Zusammenhang mit der SOD1Mutation, der fortschreitenden Entwicklung der Neurodegeneration im Mausmodell und bei humaner ALS untersucht. 


\subsection{PURIN-REZEPTOREN}

Die Wirkung der Purine Adenosin und Adenosintriphosphat (ATP) und deren Beteiligung an extrazellulären Signalkaskaden wurde erstmals 1929 von Alan Nigel Drury und Albert von Szent-Györgyi beschrieben. In experimentellen Versuchen an Myokard von Säugetieren konnten sie einen negativ chronotropen Effekt sowie eine Vasodilatation als Reaktion auf Adenosin-Gabe beobachten (Drury und SzentGyörgyi 1929).

Die folgenden Studien über den ATP-Effekt auf das kardiovaskuläre System (Bennet und Drury 1931) wurden mit zunehmender Kenntnis des ubiquitären Vorkommens von ATP durch Untersuchungen von dessen Wirkung auf Gefäße (Holton 1959, Berne 1963) und das periphere Nervensystem ergänzt.

1972 postulierte Burnstock, dass die Wirkung von ATP an der glatten Muskulatur des Gastrointestinaltrakts über "non-cholinerge" und "non-adrenerge“ Nervenzellen, sogenannte NANCS („,non-adrenergic, non-cholinergic “), vermittelt wird und gab dem Transmitter ATP und den von inm aktivierten Nervenzellen die ergänzende Bezeichnung „purinerg“ (Burnstock 1972). Forschungsergebnisse der folgenden Jahre bestätigten die „purinerge Theorie“ und die Hypothese der Rolle von ATP als Transmitter und Co-Transmitter für Acetylcholin und Noradrenalin. Extrazelluläre Rezeptoren, die mit den von Purinen vermittelten Kaskaden interagieren, Purin-Rezeptoren also, wurden 1976 erstmals erwähnt (Burnstock 1976).

Zwei Jahre später erfolgte die Unterteilung in die Subtypen P1(Adenosingesteuert) und P2-Rezeptoren (Adenosintriphosphat- bzw. Adenosindiphosphatgesteuert) (Burnstock 1978). Die P1-Rezeptoren weisen eine stärkere Reaktion auf Adenosin und AMP (Adenosinmonophosphat) auf und zeigen sich durch Methylxanthin antagonisierbar. Die Aktivierung des P1Rezeptors führt zur Abschwächung der Aktivität des Enzyms Adenylatcyklase. Dieses hat eine intrazelluläre Ansammlung des "second messenger" cAMP (zyklisches Adenosinmonophosphat) zur Folge. P2-Rezeptoren dagegen sprechen stärker auf ATP und ADP an und sind nicht durch Methylxanthin antagonisierbar. Der Aktivierung folgt hier u. a. ein Anstieg der Prostaglandinsynthese. Diese Subklassifikation wurde durch folgende pharmakologische, biochemische und 
molekular-biologische Untersuchungen bestätigt und ergänzt:

Die potentielle Wirkung von ATP, ADP, AMP und Adenosin (1); die Interaktion mit Antagonisten wie Methylxanthin (2); die Veränderungen der Adenylatcyclase durch Adenosin, jedoch nicht durch ATP (3); die Induktion der Prostaglandinsynthese durch ATP, jedoch nicht durch Adenosin (4).

Diese Klassifikation wurden im Laufe der Jahre erweitert und später vom IUPHAR (International Union of Physiological Sciences, the International Union of Pharmacology, heute „International Union of Basic and Clinical Pharmacology“) als etabliert übernommen.

Burnstock und Kennedy führten 1985 auch die erneute Unterteilung der purinergen P2-Rezeptoren in P2X und P2Y-Subtypen ein (Abbracchio und Burnstock 1994). Die Differenzierung dieser Subtypen wurde aufgrund der rezeptorvermittelten Antwort-Profile auf ATP und ATP-Analoga sowie auf Rezeptorantagonisten und aufgrund der Unterschiede in den jeweiligen Transduktionsmechanismen festgelegt.

Der P2X-Purin-Rezeptor hat $\alpha, \beta$-meATP als stärksten Agonisten und aktiviert einen intrinsischen lonenkanal, während der P2Y-Rezeptor zu der Familie der GProtein-gekoppelten Rezeptoren gehört und am stärksten durch 2-methylthio-ATP (2-MeSATP) aktiviert wird.

Von den P2Y-Rezeptoren kennt man acht Subtypen (P2Y1, 2, 4, 6, 11, 12, 13 und P2Y14); P2Y-Rezeptoren sind G-Protein-gekoppelt (Inoue 2002).

Bis heute wird der Erforschung und Kenntnisgewinnung der purinergen Signaltransduktion viel Aufmerksamkeit gewidmet. Die Kenntnis darüber, dass die Purin-Rezeptoren ubiquitär sowohl von neuronalen als auch von nicht-neuronalen Zellen exprimiert werden und dass die Rezeptor-vermittelte Signalkaskade je nach Subtyp eine langsame (long-term) oder eine schnelle Aktivität (short-term) zur Folge hat, lässt das Interesse an der Rolle der Purin-Rezeptoren in der Pathophysiologie sowie an dem therapeutischen Potential des purinergen Systems in der Behandlung von Erkrankungen des ZNS, aber auch Krankheiten wie Osteoporose, Thrombose/ Embolie, Nierenversagen oder Krebs wachsen (Burnstock und Knight 2004). 


\subsubsection{P2X-Rezeptoren und der P2X4-Rezeptor im Besonderen}

P2X-Rezeptoren sind ATP-gesteuerte Kationen-Kanäle, die ausschließlich im eukaryoten Organismus exprimiert werden (North 2002). In der Literatur werden die Begriffe „Rezeptor" und „Kanal“ oft synonym verwendet. Im Folgenden wird weitestgehend die Bezeichnung „Rezeptor" angewandt. Der Transport der Natrium $\left(\mathrm{Na}^{+}\right)$-, Kalium $\left(\mathrm{K}^{+}\right)$- sowie Calcium $\left(\mathrm{Ca}^{++}\right)$-lonen erfolgt passiv entlang des bestehenden elektrochemische Gradienten, dem Konzentrations- bzw. Potentialgefälle. Dadurch unterscheiden sich lonenkanäle von aktiven Transportproteinen, die unter Energieverbrauch den sekundär aktiven Transport durch die Membran ermöglichen.

Bis heute sind sieben Subtypen (P2X1-P2X7) des P2X-Rezeptors bekannt und benannt (North 2002, Qureshi et al. 2007, Burnstock et al. 2010) (s. Tab. 2). 
Tab. 2: Die Purin-Rezeptoren

\begin{tabular}{|c|c|c|c|c|}
\hline REZEPTOR & VERTEILUNG & AGONISTEN & ANTAGONISTEN & FUNKTION \\
\hline $\mathrm{P} 2 \mathrm{X} 1$ & $\begin{array}{c}\text { Glatte } \\
\text { Muskulatur, } \\
\text { Thrombozyten, } \\
\text { Kleinhirn, } \\
\text { Dorsalhorn des } \\
\text { Rückenmarks }\end{array}$ & $\begin{array}{c}\alpha, \beta \text {-meATP=2- } \\
\text { MeSATP } \\
\text { (schnelle } \\
\text { Desensibili- } \\
\text { sierung) }\end{array}$ & $\begin{array}{l}\text { TNP-ATP, IP51, } \\
\text { NF023 }\end{array}$ & $\begin{array}{l}\text { Intrinsischer } \\
\text { Kationenkanal } \\
\text { (Calcium und } \\
\text { Natrium) }\end{array}$ \\
\hline $\mathrm{P} 2 \times 2$ & $\begin{array}{c}\text { Glatte } \\
\text { Muskulatur, } \\
\text { ZNS, Retina, } \\
\text { chromaffine } \\
\text { Zellen, Ganglien }\end{array}$ & $\begin{array}{c}\text { ATP }>2- \\
\text { MeSATP }>>\alpha, \beta- \\
\text { meATP }(\mathrm{pH} \text { und } \\
\text { Zink-sensibel) }\end{array}$ & Suramin, PPADS & $\begin{array}{c}\text { Intrinsischer } \\
\text { Ionenkanal } \\
\text { (hauptsächlich } \\
\text { Calcium) }\end{array}$ \\
\hline P2X3 & $\begin{array}{c}\text { Sensible } \\
\text { Neuronen, } \\
\text { einige } \\
\text { Nervenzellen } \\
\text { des } \\
\text { Sympathikus }\end{array}$ & $\begin{array}{c}2- \\
\text { MeSATP }>\text { ATP }>\alpha, \\
\beta-m e A T P \\
\text { (schnelle } \\
\text { Desensibili- } \\
\text { sierung) }\end{array}$ & $\begin{array}{c}\text { TNP-ATP, } \\
\text { Suramin, PPADS }\end{array}$ & $\begin{array}{l}\text { Intrinsischer } \\
\text { Kationenkanal }\end{array}$ \\
\hline P2X4 & $\begin{array}{l}\text { ZNS, Herz, } \\
\text { Kolon, Hoden, } \\
\text { Endothel }\end{array}$ & $\begin{array}{c}\text { ATP }>>\alpha, \beta- \\
\text { meATP }\end{array}$ & - & $\begin{array}{l}\text { Intrinsischer } \\
\text { Ionenkanal } \\
\text { (hauptsächlich } \\
\text { Calcium) }\end{array}$ \\
\hline P2X5 & $\begin{array}{c}\text { Proliferative } \\
\text { Zellen der Haut, } \\
\text { Gallenblase, } \\
\text { des } \\
\text { Rückenmarks, } \\
\text { Thymus und } \\
\text { Darms }\end{array}$ & $\begin{array}{c}\text { ATP }>>\alpha, \beta- \\
\text { meATP }\end{array}$ & Suramin, PPADS & $\begin{array}{l}\text { Intrinsischer } \\
\text { Ionenkanal }\end{array}$ \\
\hline$P 2 \times 6$ & $\begin{array}{c}\text { ZNS, } \\
\text { Motoneuronen } \\
\text { des } \\
\text { Rückenmarks }\end{array}$ & - & - & $\begin{array}{l}\text { Intrinsischer } \\
\text { Ionenkanal }\end{array}$ \\
\hline P2X7 & $\begin{array}{l}\text { Apoptotische } \\
\text { Zellen des } \\
\text { Immunsystems, } \\
\text { Pankreas und } \\
\text { der Haut }\end{array}$ & $\begin{array}{c}\text { Bz-ATP }>\text { ATP-2- } \\
\text { MeSATP }>>\alpha, \beta- \\
\operatorname{meATP}\end{array}$ & $\begin{array}{l}\text { KN62, KN04, } \\
\text { Coomassie } \\
\text { Brilliant Blau }\end{array}$ & $\begin{array}{l}\text { Intrinsischer } \\
\text { Kationenkanal }\end{array}$ \\
\hline
\end{tabular}

me- ATP $=$ Methylen- Adensosintriphosphat $/ 2-M e S A T P=2-M e t h y l t h i o A T P / T N P-A T P=$ Trinitrophenol- ATP/IP5I= Diinosin Pentaphosphat/ NF023= 8,8'- (carbonylbis(imino-3,1phenylene carbonylimino)bis(1,3,5-naphthalenetrisulfonic acid)/ PPADS=

Pyridoxalphosphate- 6- azophenyl- 2',4'- disulfidsäure/ Bz- ATP= Dibenzol- ATP/ KN-62= Selective inhibitor of CaM kinase II (Ki=900 nM) (1-[N,O-bis-(5-isoquinolinesulfonyl)- $\mathrm{N}$ methyl- L- tyrosyl]- 4- phenylpiperazine) 
Diese Subtypen demonstrieren physiologische, pharmakologische und pathophysiologische Unterschiede in Aktivität, Permeabilität und Verteilung. Sie sind ubiquitär im menschlichen Organismus exprimiert, im ZNS aber auch auf Epithelzellen, Endothelzellen, Muskelzellen und immunkompetenten Zellen (s. Tab. 2) und nehmen an diversen physiologischen Prozessen teil, indem sie wasserlösliche Moleküle durch die Lipidbarriere der Zellmembran transportieren oder als zellulärer Sensor Informationen über Veränderungen im extrazellulären Milieu an das Zellinnere weiterleiten (Schwiebert et al. 2005). Im Tierversuch mit Mäusen, die eine dysfunktionale Form der P2X-Rezeptoren exprimierten, konnte beispielsweise gezeigt werden, dass diese Rezeptoren eine große Rolle bei der Blutdruck- und Gefäßregulation (Yamamoto et al. 2006) sowie eine Bedeutung im Abwehrsystem haben, indem sie die Interleukin-1ß-Produktion von Makrophagen stimulieren (Solle et al. 2001, Surprenant und North 2009). Im peripheren Nervensystem werden die P2X-Rezeptoren teilweise auf afferenten Neuronen, die auf Impulse wie Geschmack oder Schmerz reagieren, exprimiert (Surprenant et al. 1996, Chessell et al. 2005).

Im ZNS exprimieren sowohl prä- als auch postsynaptische Neurone P2XRezeptoren, die dort eine Rolle bei der Ausschüttung von Neurotransmittern wie GABA ( $y$-Aminobuttersäure) (Hugel und Schlichter 2000, Donato et al. 2008) (präsynaptisch) und Glutamat (Gu und Macdermott 1997, Khakh und Henderson 1998) haben und erforderlich bei der Aufrechterhaltung und Regulation des postsynaptischen ATP-Stoffwechsels sind (Edwards et al. 1992, Sim et al. 2006). P2X-Rezeptoren sind strukturell aus drei Untereinheiten aufgebaut und stellen somit entweder ein Hetero- oder ein Homo-Trimer dar, abhängig von den jeweils vorherrschenden Untereinheiten des Rezeptors und dem umliegenden Gewebe.

Jede der drei Untereinheiten ist aus zwei transmembranen $\alpha$-Helices, intrazellulären Termini sowie einer großen extrazellulären Domäne zusammengesetzt. Pharmakologie und Funktion variieren stark zwischen den homomeren und heteromeren Rezeptoren. Während der heteromere P2X1Rezeptor sehr stark und schnell auf Pyridoxalphosphat-6-azophenyl-2'-4'-disulfidSäure (PPADS) und Suramin reagiert, weist der homomere P2X4-Rezeptor eine geringere Sensitivität und langsamere Reaktion gegenüber diesen experimentell häufig verwendeten P2X-Rezeptor-Antagonisten auf (North und Surprenant 2000). Der homotrimere P2X4-Rezeptor setzt sich aus 388 Aminosäuren zusammen und 
ist becherartig geformt. Die große extrazelluläre Domäne ragt etwa $70 \AA$ (Angstrom) über die Membranebene hinaus. Hier sind die Untereinheiten durch eine hydrophile Kette von 270 Aminosäuren verbunden, die wiederum zwei Disulfidbrücken und drei Glykosylketten enthält. Außerdem befindet sich an dieser extrazellulären Domäne eine hydrophobe, sog. H5-Region, die nahe dem Kanalausgang liegt und evtl. nötige Modulationen des Kanals (je nach zu transportierendem lon z. B.) zu bewirken vermag, sowie die Bindungsstelle für ATP-Moleküle.

Die transmembrane Region des P2X4-Kanals weist eine Sanduhr-ähnliche Form und eine Länge von etwa $28 \AA$ auf. Die hier antiparallel zueinander angeordneten a-Helices halten so die transmembrane Pore geschlossen und definieren die Architektur des ruhenden P2X4-Kanals. Die intrazelluläre Domäne wird von den Amino (N-) und Carboxy (C-)-Termini der Untereinheiten gebildet.

Die Analyse der P2X4-Struktur brachte Katawe et al. zu dem Ergebnis, dass Ionen auf zwei verschiedenen Wegen mit dem Rezeptor interagieren bzw. den transmembranen Kanal passieren (Kawate et al. 2009). Es gelang innen der Nachweis von drei Öffnungen in der extrazellulären Domäne, deren Durchmesser von etwa $8 \AA$ die Passage von $\mathrm{Na}^{+}$-, $\mathrm{K}^{+}$- und $\mathrm{Ca}^{++}$-Ionen ermöglicht.

Außerdem entdeckten sie drei Räume, sog. Vestibüle, entlang der extrazellulären Domäne, deren Durchmesser im ruhenden Zustand allerdings mit gemessenen 2,3 $\AA$ zu gering für die Passage der lonen ist. Dennoch wird angenommen, dass die Aktivierung des Rezeptors durch Agonisten eine Konformationsänderung der Untereinheiten bewirkt, die Konstriktion der Vestibüle aufgehoben wird und Ionen so den Kanal passieren können. Der Eintritt bzw. Austritt der lonen auf der zytoplasmatischen Seite erfolgt nachgewiesenermaßen ebenfalls über ein kegelartig geformtes sog. intrazelluläres Vestibül.

Die Analyse der Architektur des P2X4-Rezeptors lässt nicht nur Schlüsse über die Mechanismen der lonenpassage, sondern auch über die lonenselektivität des Rezeptors zu. Das zentrale Vestibül der extrazellulären Domäne sowie die gesamte extrazelluläre Domäne sind reich an säurehaltigen Verbindungen. Leucin und Asparagin sind die hier vorherrschenden Aminosäuren. Diese lassen ein negatives elektronisches Potential entstehen und dienen so einerseits der Konzentration der Kationen nahe der extrazellulären Öffnung des Kanals und andererseits der direkten Bindung der Kationen. 
Des Weiteren wird vermutet, dass passierende lonen mit Sauerstoffmolekülen der Aminosäuren interagieren, bzw. diese aus ihrer Verbindung „ösen“. Es besteht die Hypothese, dass diese Sauerstoffmoleküle dann bei weiteren Interaktionen zwischen lonen und Proteinen eine Rolle spielen (Gonzales et al. 2009).

Die genaue Lokalisation der ATP-Bindungsstelle auf der extrazellulären Domäne ist noch unbekannt. Es wird angenommen, dass eine Konformationsänderung der Untereinheiten entsteht, wenn -vermutlich drei- ATP-Moleküle an den P2XRezeptor binden (Khakh und North 2006).

Die Bindung von ATP am P2X4-Rezeptor führt zu einer Aktivierung, einer Öffnung des lonenkanals. Durch elektrophysiologsche Analysen konnten Kawate et al. zeigen, dass eine Aktivierung des dort untersuchten P2X4-Rezeptors durch 1mM ATP einen lonenstrom über einen Zeitraum von etwa drei Sekunden zur Folge hat.

Der in der vorliegenden Dissertation verwendete Anti-P2X4-Antikörper ist gegen ein Epitop auf dem intrazellulär gelegenen C-Terminus gerichtet. Dieser Antikörper konnte schon in vorangegangenen Studien erfolgreich zur Detektion des P2X4Rezeptors angewendet werden (Atkinson et al. 2003, Doctor et al. 2005, Yeung et al. 2006).

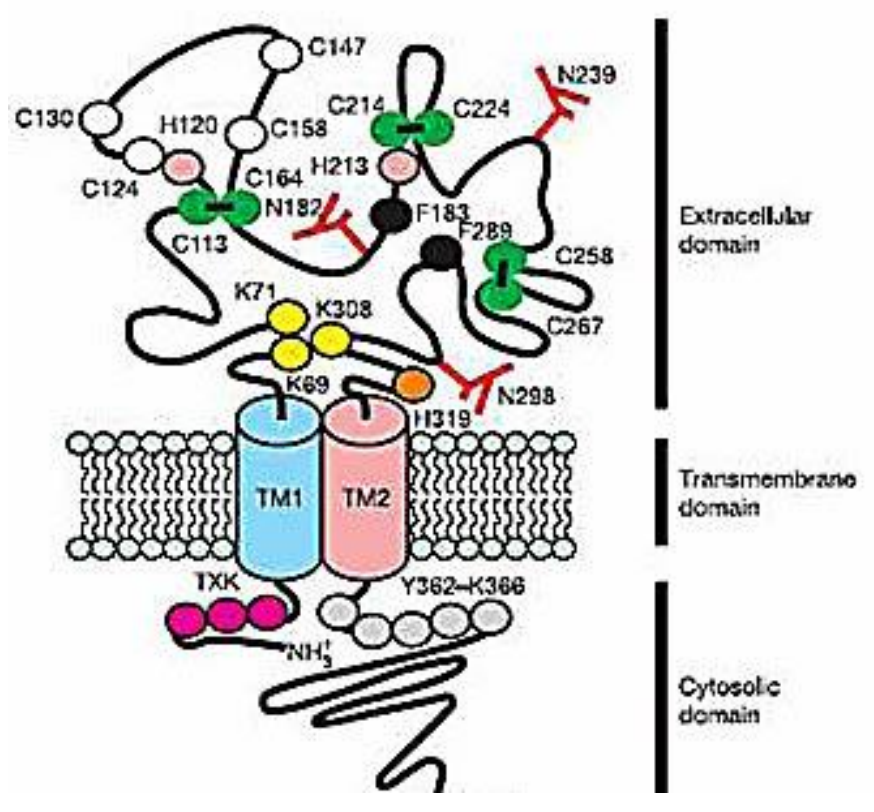

\section{C-Domäne}

\section{Zink (Zn++)- Bindungsstellen}

Disulfidbrücken
N- Glykosylierungsstellen

Proteinbindungsstelle

Abb. 2 Schematische Darstellung des P2X4-Rezeptor verändert übernommen aus Khakh und North 2006, S. 528 


\subsubsection{Adenosintriphosphat (ATP) und der Purin-Rezeptor}

Das Adenosintriphosphat (ATP)-Molekül setzt sich aus einem Adeninrest, Ribose und drei Phosphaten zusammen. Es kann bei Bedarf aus anderen Energiespeichern wie Fettsäuren oder Glykogen resynthetisiert werden. ATP dient jeder lebenden Zelle als Energiequelle für energieverbrauchende Prozesse wie Proteinsynthese, aktiver Stofftransport oder Bewegung (Muskelkontraktion). Im intrazellulären Stoffwechsel wirkt ATP u. a. als Ko-Substrat von Kinasen.

ATP fungiert außerdem als extrazellulärer (Co-)Transmitter in nicht-neuronalem und neuronalem Gewebe, wo es Liganden-gesteuerte und G-Protein-gekoppelte P2-Rezeptoren aktiviert. Im peripheren Nervensystem wirkt ATP als schneller exzitatorischer Transmitter an sympathischen, parasympathischen und enterischen Ganglien und Synapsen (Silinsky et al. 1992). Die Stimulation von sensiblen, nozizeptiven, Neuronen des sympathischen Systems führte im Versuch zu einer erhöhten ATP-Konzentration im synaptischen Spalt (Burnstock 1996).

Die Entdeckung, dass ATP einen potenten Transmitter von Neuronen im

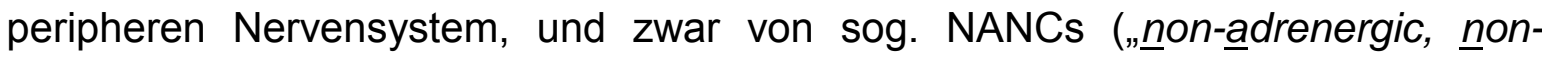
cholinergic“) darstellt, ließen Burnstock et al. den Begriff der „purinergen“ Nerven prägen (Burnstock 1972).

ATP spielt ebenfalls eine große Rolle als Neurotransmitter im ZNS. Es ist mittlerweile bekannt, dass ATP als exzitatorischer Transmitter sowohl von Neuronen als auch von Gliazellen fungiert (Bodin und Burnstock 2001). Die hier vorherrschenden P2X-Rezeptoren sind P2X2, P2X4 and P2X6 (North 2002).

Im ZNS ist die ATP-Freisetzung nicht so weitläufig und gleichmäßig verteilt wie in der Peripherie, sondern bestimmten Regionen und Zelltypen zugehörig (Potter und White 1980). Die Antwort der neuronalen P2X-Kanäle auf den Anstieg der extrazellulären ATP-Konzentration in physiologischem oder pathophysiologischem Rahmen ist vielfältig und unterscheidet sich je nach Subtyp und Lokalisation.

Wu et al. demonstrierten beispielsweise, dass die direkte elektrische Stimulation des sensomotorischen Cortex von Ratten eine erhöhte neuronale ATP-Freisetzung zur Konsequenz hatte (Wu und Phillis 1978) und einer exogenen ATP-Zugabe exzitatorische Prozesse folgten (Phillis und Wu 1981). 
Des Weiteren konnte beobachtet werden, dass ATP von afferenten Neuronen des Hinterhorns freigesetzt wurde (Fyffe und Perl 1984, Sawynok und Sweeney 1989). In in-vivo-Versuchen mit afferenten Neuronen des Rückenmarks bei Ratten wurde als Reaktion auf gesetzte Schmerzreize zusätzlich eine spontane Freisetzung von Glutamatvesikeln nachgewiesen (Gu und Macdermott 1997). Auch in Neuronen des Tractus solitarius konnte anhand nachgewiesener Erhöhung von EPSCs („excitatory postsynaptic currents“; exzitatorische postsynaptische Ströme) an neuronalen Synapsen gezeigt werden, dass der ATP-vermittelte Effekt an präsynaptisch gelegenen P2X-Rezeptoren eine spontane Freisetzung von Glutamatvesikeln war (Shigetomi und Kato 2004).

Unter Bedingungen wie Stress, Ischämie und Gewebsverletzung wurde ebenfalls eine erhöhte extrazelluläre ATP-Konzentration gemessen. Das Molekül wird in dem Fall über Vesikel oder über schon defekte Membranen untergehender oder zerstörter Zellen freigesetzt (Agteresch et al. 1999, Atkinson et al. 2003).

Außerdem konnte als Folge der Aktivierung von neuronalen P2X-Rezeptoren die Depolarisation und damit die Entstehung eines Aktionspotentials beobachtet werden. Die Aktivierung der P2X-Kanäle dient also zusätzlich der Weiterleitung und evtl. Modulation eines Reizes bzw. einer Signalkaskade (s. u.) (Gu und Macdermott 1997).

ATP vermittelt desweiteren die Synthese und Exozytose von proinflammatorischen Zytokinen, insbesondere Interleukin-1 und -6 bei Makrophagen (Solle et al. 2001, North 2002). Diese Wirkung wird über den hier vorherrschend exprimierten P2X7Rezeptor vermittelt (Surprenant et al. 1996).

Weitere Studien und Untersuchungen bekräftigten und erweiterten die These von ATP als zentral wirksamen Neurotransmitter (Edwards et al. 1992, Sperlagh et al. 1995). 
Die Freisetzung intrazellulären ATPs erfolgt also hauptsächlich als Folge von drei Mechanismen:

> vesikuläre Freisetzung: der physiologische Weg der ATP-Freisetzung von Neuronen und Gliazellen in den synaptischen Spalt als Reaktion auf Stimulation.

$>$ Zytolyse: diese nicht-physiologische Freisetzung folgt einem Schaden der Zellmembran oder des Zelltods von Neuronen und Gliazellen im Rahmen von physikalischen Traumen oder pathophysiologischen Mechanismen, wie Ischämie oder Degeneration.

$>$ Aktivierung durch ABC-Proteine, Membranproteine, die die Exozytose regulieren.

P2X2- und P2X4-Rezeptoren sind im ZNS gehäuft an exzitatorischen Synapsen lokalisiert (Rubio und Soto 2001), sowohl an der prä- als auch auf der postsynaptischen Seite.

Das und die beobachteten Reaktionen auf eine Aktivierung durch Agonisten (s. o.) lässt vermuten, dass die Rezeptoren sowohl die Modulation der postsynaptischen Antwort als auch die Vermittlung der Freisetzung von Neurotransmittern an der präsynaptischen Seite als Aufgabe haben (Gu und Macdermott 1997).

Einer Aktivierung der P2X-Rezeptoren durch ATP folgt als direkte Antwort eine Konformationsänderung des Kanals und ein $\mathrm{Ca}^{++}$-Einstrom.

Der lonen-Einstrom ist der bedeutende Prozess in der ATP-vermittelten Signaltransduktion (Khakh und Henderson 1998). Durch inn wird sowohl die Membranspannung verändert und die Depolarisation der betroffenen Zelle erreicht als auch die lokale lonenkonzentration modifizert (Postsynapse). Außerdem triggert der Anstieg der intrazellulären $\mathrm{Ca}^{++}-$Konzentration die Exozytose von transmitterenthaltenden Vesikeln (Shigetomi und Kato 2004, Khakh und North 2006).

Des Weiteren wird das extrazelluläre ATP zu ADP (Adenosindiphosphat), AMP (Adenosinmonophosphat) und Adenosin gespalten, welche wiederum als Agonisten an G-gekoppelten P2-Rezeptoren fungieren. Als Folge der Aktivierung entstehen also ein Aktionspotential und die Weiterleitung eines Reizes, die Fortführung einer Signalkaskade (Präsynapse).

Die Beobachtung, dass experimentell auf menschliche Haut appliziertes ATP 
Schmerzen verursacht (Bleehen und Keele 1977, Hamilton et al. 2000) sowie die mittlerweile gewonnene Kenntnis, dass die P2X-Rezeptoren beinahe ubiquitär im Organismus exprimiert werden, lenkte das Augenmerk der aktuellen Forschung auf die ATP-Wirkung an zentralen P2X-Rezeptoren im Rahmen von pathophysiologischen Prozessen und der Vermittlung und Empfindung von Schmerzreizen.

Die mechanische Allodynie ist in Tierversuchen mittlerweile gut erforscht. Sie ist ein etabliertes Modell für die chronische Neuropathie, wie sie z. B. bei Diabetes mellitus auftritt. Es konnte gezeigt werden, dass durch die experimentelle Blockierung der P2X4-Expression im Hinterhorn des Rückenmarks die taktile Allodynie nach Ligation eines Spinalnervs und die Aktivität der reaktiven Mikrogliazellen weniger ausgeprägt war (Tsuda et al. 2003). Durch die Blockierung der P2X3-Expression im experimentellen Tierversuch gelang die Reduktion der Allodynie (Cockayne et al. 2000, Souslova et al. 2000).

Diese Beobachtung zeigt, dass die Interaktion von ATP und zentralen P2XRezeptoren stark mit Schmerz und Verletzung in Relation steht und dass in diesem Zusammenhang die Expression der purinergen Rezeptoren auf Gliazellen eine besonders wichtige Rolle spielt.

Der Austritt von zytoplasmatischen Molekülen aus traumatisiertem Gewebe führt zu einer erhöhten Freisetzung von ATP. Dieses fungiert u. a. als sog. „find-me, eatme“-Signal apoptotischer bzw. nekrotischer Neurone gegenüber den Gliazellen (Inoue 2008). Die Aktivierung des P2X-Rezeptors durch regulär sezerniertes oder lytisch freigesetztes ATPS scheint unabdingbar für die interzelluläre Kommunikation. 


\subsection{DIE GLIAZELLEN DES ZENTRALEN NERVENSYSTEMS (ZNS)}

\subsubsection{Gliazellen, Reiz und Immunantwort}

Glia stellt den Oberbegriff für funktionell sowie strukturell von Neuronen abgrenzbare Zellen des zentralen Nervengewebes dar.

Im menschlichen Gehirn finden sich deutlich mehr Gliazellen als Neurone (das Verhältnis beträgt etwa 9:1). Ihr Entdecker Rudolf Virchow nahm an, diese Zellen hätten eine Halte- und Stützfunktion und gab ihnen den Namen „Glia“-Zellen, abgeleitet aus dem griechischen Wort für „Leim“ ( $ү \lambda i ́ a)$. Tatsächlich bilden diese Zellen ein Stützgerüst für die Neuronen. Jenseits der mechanischen Stützfunktion für die Neuronen sorgen sie für deren elektrische Isolation, sind an Stoff- und Flüssigkeitstransporten beteiligt sowie an der Aufrechterhaltung der Homöostase des extrazellulären lonenhaushalts und tragen somit maßgeblich zum Prozess der Informationsverarbeitung bei (Booth et al. 2000, Araque et al. 2001, Haydon 2001, Doetsch 2003). Die Gliazellen sind an der Bildung neuer und dem Abbau alter Synapsen beteiligt und modifizieren so neuronale Zellen in ihrer Aktivität (Allen und Barres 2005).

Gliazellen lassen sich morphologisch und funktionell in Makro- und Mikroglia unterteilen. Zu den Makroglia werden Ependymzellen, Oligodendrozyten, radiale Gliazellen und Astrozyten gezählt. Die Aufgabe der Ependymzellen ist die Auskleidung von im ZNS befindlichen Hohlräumen (Liquorzisternen, -Ventrikel und Canalis centralis). Radialzellen fungieren als Leitstruktur in der zellulären Migration während der Neurogenese. Jüngere Studien stellen außerdem die These auf, dass Radialzellen im adulten ZNS eine Funktion als neuronale Stammzellen innehaben (Fricker-Gates 2006, Bonfanti und Peretto 2007, Pinto und Gotz 2007). Oligodendrozyten bilden die Myelinscheide, die neuronale Zellfortsätze umgibt (Baumann und Pham-Dinh 2001) und sind als sog. Satellitenoligodendrozyten an der Regulation des Neuronen umfassenden extrazellulären Milieus beteiligt (Ludwin 1984, Ludwin 1997). 


\subsubsection{Mikroglia}

Mikroglia, auch als Mesoglia oder Hortega-Zellen bezeichnet, stellen ca. 20\% aller Gliazellen dar. Sie sind mesodermalen Ursprungs und man geht davon aus, dass sie von eingewanderten fetalen Monozyten oder deren Vorläufern abstammen.

Unter normalen Umständen haben sie die Funktion, die physiologische Homöostase des Extrazellulärraums zu organisieren und aufrechtzuerhalten (Nimmerjahn et al. 2005). In der sog. ruhenden Form weist die Mikrogliazelle einen heterochromatinreichen Kern und ein elektronendichtes Zellplasma auf. Neben den typischen Organellen finden sich v.a. Lysosomen und Vimentinfilamente des Zytoskeletts. Es sind bipolare Zellen mit filigranen Fortsätzen (ramifizierte Mikroglia). Sie weisen auch im physiologischen Zustand eine hohe Motilität auf und stehen in Kontakt mit den die Zelle umgebenen Strukturen (Davalos et al. 2005, Nimmerjahn et al. 2005, Dibaj et al. 2010).

Durch kontinuierliche Bewegung ihrer Ausläufer übernehmen Mikrogliazellen eine Art „house-keeping“-Funktion und besitzen so die Fähigkeit zur schnellen Aktivierung in der Beantwortung akuter pathologischer Ereignisse des ZNS im Sinne einer unspezifischen Immunabwehr. Mikroglia sind in der Lage potenziell pathogene Substanzen zu erkennen und zu phagozytieren und erfüllen damit im ZNS auch die Rolle von Makrophagen. Durch chemotaktische Signale initiieren sie die Immigration von Lymphozyten sowie durch Antigenpräsentation den Beginn derer spezifischen Abwehr (Raivich et al. 1999). Analog zur Aktivierung von Fibroblasten in anderen Geweben kommt es im ZNS durch die Mikroglia zu einer Aktivierung der Astrozyten, die verantwortlich sind für die Ausbildung einer Glianarbe (s. u.) (Raivich et al. 1995).

Ihre spontane Aktivität ermöglicht den Mikrogliazellen schnell und adäquat auf Verletzungen des umliegenden Gewebes zu reagieren.

Werden die Mikroglia mit einem pathologischen Stimulus, sei es Entzündung oder Trauma, konfrontiert ändert sich ihre Morphologie. Innerhalb von Minuten reagiert die Mikrogliazelle akut mit einer Verlängerung und gezielten Ausrichtung ihrer Fortsätze gegenüber der Läsion (Dibaj et al. 2010). Innerhalb von Stunden können die Zellen hypertrophieren sowie proliferieren und eine amöboide Gestalt annehmen. Diese sog. aktivierten Mikrogliazellen migrieren zu der Läsion und 
beginnen dort mit der Phagozytose nekrotischer Neurone und zellulärem Debris. Außerdem senden sie proinflammatorische Zytokine wie z. B. IL-1ß, IL-6, das Enzym iNOS (,induciblenitric oxide synthase”) und TNF- $\alpha$ aus (Raouf et al. 2007). In-vivo-Versuche konnten die Migration aktivierter Mikrogliazellen zum Ort einer mit Laser induzierten Läsion reproduzieren (Ohsawa et al. 2007, Dibaj et al. 2010). Auf eine akute Verletzung bzw. krankhafte Prozesse folgt also charakteristischerweise die sog. reaktive Mikrogliose, d. h. die Ansammlung von aktivierten Mikrogliazellen am Ort des Schadens. Pharmakologisch konnte durch die Gabe von ATP dieser Effekt simuliert werden. Entsprechend führte die Applikation des ATPhydrolysierenden Enzyms Apyrase bzw. von Purin-Rezeptor-Antagonisten zur Unterdrückung dieses Phänomens (Davalos et al. 2005).

P2X4, P2X7 und P2Y12 sind die dominierenden purinergen Rezeptoren auf Mikrogliazellen (Khakh und North 2006). Es konnte außerdem eine Modifikation der P2X3-Expression sowie eine vermehrte Expression aller P2X-Subtypen auf Gliazellen als Reaktion auf eine periphere Nervenverletzung beobachtet werden (Atkinson et al. 2003).

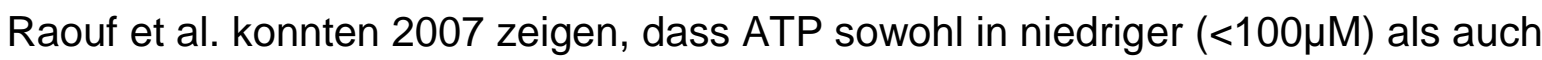
in hoher (>1mM) Dosierung einen intrazellulären loneneinstrom über den P2X4Kanal auf unbehandelten Mikrogliazellen bewirkt. Mit Hilfe der Elektrophysiologie konnten sie sogar darstellen, dass die Behandlung der Mikroglia mit bakteriellem pro-inflammatorischem Lipopolysaccharid (LPS), einem validen Modell-Stimulus zur experimentellen Aktivierung der Mikroglia, ebenfalls einen Anstieg des intrazellulären lonenstroms über den P2X4-Rezeptor zur Folge hatte. Eine PCRUntersuchung zeigte, dass der erhöhte lonenstrom die Folge einer vermehrten Expression von P2X4-Rezeptor-Untereinheiten ist. Die Aktivierung von Mikrogliazellen führt also nicht zu einer quantitativen Vermehrung des Rezeptors auf der Zelloberfläche sondern zu einer qualitativen Funktionssteigerung (Raouf 2007).

Die Interaktion von ATP an mikroglialen Purin-Rezeptoren induziert einen intrazellulären $\mathrm{Ca}^{++}$- Einstrom, eine Depolarisation und damit Aktivierung der Zelle sowie die Ausschüttung proinflammatorischer Zytokine und anderer intrazellulärer Stoffe (s. u.) (North 2002, Schwiebert et al. 2002).

Versuche der Isolation und Kultur von humaner Mikroglia post mortem zeigten, dass aktivierte Mikrogliazellen auch in nicht-perfundierten Gewebe über Stunden 
morphologisch aktiv bleiben, sie sogar den Tod des Wirts um Stunden überdauern (De Groot et al. 2000, Walker et al. 2001, Walker und Lue 2005). Die Quelle der Energie für das Überleben unter diesen Bedingungen blieb jedoch lange ungewiss. Dibaj et al. untersuchten das Verhalten der Mikroglia in verletztem Rückenmarksgewebe post mortem in situ. Abhängig von der premortalen Verfassung des Tieres wurde hier eine mikrogliale Aktivität und Motilität 5 bis 10 Stunden post mortem nachgewiesen und ATP als Energielieferant identifiziert (Dibaj et al. 2010). Die Aktivität der Gliazellen nahm mit der Zeit zwar kontinuierlich ab, doch konnte die Wiederherstellung der Motilität, eine zunehmende Migration und sogar eine gliale Proliferation als Reaktion auf die Zugabe von 1mM ATP beobachtet werden.

Der Versuch der Zugabe eines als P2-Agonist fungierenden ATP-Analogons (Adenosin 5'-[ Y-thio]triphosphat Tetralithiumsalz) erzielte dasselbe Ergebnis.

Die Aktivierung der Mikrogliazellen - sogar in nicht mehr durchblutetem Gewebe scheint also sowohl durch die Endozytose der freien Energie in Form von ATPMolekülen als auch durch die Interaktion von ATP mit P2-Purin-Rezeptoren zu erfolgen. Korrespondierend konnte auch hier nach Zugabe der ATP-Hydrolase Apyrase eine Reduzierung der mikroglialen Aktivität beobachtet werden.

Über die Aktivierung von mikroglialen P2-Rezeptoren fungiert ATP also als chemotaktischer Mediator und Energielieferant. ATP ermöglicht die Kommunikation und Interaktion zwischen Mikrogliazellen und Neuronen und die Ausübung der Rolle der Mikroglia als sog. Helferzellen (Inoue 2002, Haynes et al. 2006).

Das von verletztem Gewebe und Zellen freigesetzte ATP ist neben NO das primäre Molekül in der Induktion der Aktivierung der Mikrogliazellen (Davalos et al. 2005, Dibaj et al. 2010).

Tsuda et al. (2003) konnten zeigen, dass die Aktivierung von mikroglialen P2X4Rezeptoren durch ATP Neuropathie und taktile Allodynie entstehen lässt, genau wie es nach peripheren Nervenläsionen geschieht.

Im Versuch der pharmakologischen Blockierung bzw. des „Knockout“ des Rezeptors P2X4 durch Beeinträchtigung der RNA mit Hilfe von Lentiviren-Vektoren zeigte sich, dass die Entstehung von Allodynie gehemmt wurde sowie die mikrogliale Aktivierung und Chemotaxis nach einer Läsion ausblieb (Tsuda et al. 2003, Ohsawa et al. 2007). 
In in-vivo-Versuchen konnte weiterhin beobachtet werden, dass die Interaktion von ATP an P2X4-Rezeptoren von Gliazellen die Freisetzung von BDNF („whrainderived neurotrophic factor") verursacht. Dessen Wirkung auf umliegende Neurone ist die Expression eines Chloridkanals mit folgendem Anionen- (Chlorid-) Einstrom. An den Nervenzellen werden so ein Kollaps des transmembranen AnionenGradienten und eine anschließende Hyperexzitabilität gegenüber der aktivierenden Wirkung des Neurotransmitters GABA induziert (Inoue 2008).

Die benachbarten Neurone werden also in eine Art Erregungszustand versetzt, ihr Metabolismus angeregt. Teilweise wird vermutet, dass dies zum Schutz der Neurone geschieht (Coull et al. 2005).

Obwohl Mikroglia selbst unter Bedingungen wie unzureichender bzw. keiner Durchblutung Aktivität und Reaktion aufweisen (s. o.), ist ihre von ATP induzierte Aktivität und Funktion nicht ausreichend um nicht geschädigtes neuronales Gewebe vor sekundärer Degeneration zu bewahren (Dibaj et al. 2010). Die Verhinderung bzw. Verzögerung sekundärer Degeneration von neuronalem Gewebe nach einem primären neurodestruktivem Ereignis wie die Therapie von neuropathischen Schmerzen ist von großem Interesse in der heutigen Medizin und Forschung (Guimaraes et al. 2009).

Die Kenntnisse über die interagierenden Mechanismen zwischen ATP, PurinRezeptoren, aktivierten Mikrogliazellen und Neuronen bieten einen Angriffspunkt für die Entwicklung adäquater Therapieansätze. 


\subsubsection{Astrozyten}

Astrozyten stellen eine sehr heterogene Zellgruppe dar. Sie bilden die Mehrheit der Gliazellen im ZNS von Säugetieren. Ihr Name kommt von dem Reichtum an sternförmigen Fortsätzen (Hirllinger et al. 2004).

Aufgrund ihrer vielfältigen Eigenschaften und Funktionen ist eine Klassifikation der Astrozyten nach vielen unterschiedlichen Kriterien möglich.

Die Einteilung in protoplastische und fibröse Astrozyten basiert auf der Untersuchung des spanischen Neuroanatomen und Nobelpreisträgers Santiago Ramon y Cajal (1854-1934) und ist rein morphologisch.

Die sog. Faserglia wird von den fibrösen Astrozyten gebildet und findet sich hauptsächlich in der weißen Substanz. Sie haben wenig bis unverzweigte Zellfortsätze. GFAP (,glial fibrillarily acidic protein“) ist die Hauptkomponente der Intermediärfilamente in diesen adulten Astrozyten und wird zellspezifisch exprimiert. Aus diesem Grund dient dieses Protein auch als Marker bei immunhistologischen Färbungen.

Protoplasmatische Gliazellen dagegen sind v. a. in der grauen Substanz lokalisiert (Zenker 1994). Sie enthalten weniger von dem Intermediärfilamentprotein GFAP und weisen stark verzweigte Fortsätze auf, die über mit den Nachbarzellen in Verbindung stehen. Mit diesem Nexus-Netzwerk (Gap-Junction) können Ionen auf benachbarte Astrozyten übertragen werden.

Astrozyten sind wesentlicher Bestandteil in der Entstehung, Aufrechterhaltung und Modulation des Gewebezusammenhalts und der Blut-Hirn-Schranke (Danbolt 2001). Ihre Fortsätze bilden Grenzmembranen zur Pia mater und Blutgefäßen, Anteile der Blut-Hirn-Schranke sowie funktionelle Einheiten mit Synapsen (die sog. Tripartite-Synapse; bestehend aus drei Teilen, dem prä- sowie postsynaptischen Teil des Neurons und dem Astrozyten) (Araque et al. 1999). Die hier beschriebene Differenzierung nach morphologischen Kriterien lässt allerdings keine eindeutige Unterscheidung zu; vermutlich gibt es außerdem Übergangsformen.

Ergebnisse funktionaler Studien erlauben mittlerweile eine viel umfangreichere und differenziertere Unterscheidung und Einteilung der Astrozyten als es nur anhand morphologischer Ungleichheiten möglich war. Ihre elektrophysiologischen Eigenschaften, die Teilnahme am Kalium- und Glutamathaushalt (Matthias et al. 
2003, Wallraff et al. 2004) sowie ihre Aufgabe in der interneuronalen Kommunikation (Newman 2003, Newman und Volterra 2004) sind herausragende Attribute der Astrozyten.

Es konnte beobachtet werden, dass Astrozyten Transporter für Neurotransmitter besitzen (Largo et al. 1996, Bergles und Jahr 1997, Bergles et al. 1999) und viele Neurotransmitter-Rezeptoren, die auf Neuronen exprimiert werden sich außerdem ebenfalls auf Astrozyten befinden, wie z. B. AMPA- (a-amino-3-hydroxy-5-methyl4-isoxazol-propionic acid), NMDA- (N-methyl-D-aspartic acid), GABA- und GlycinRezeptoren (Schipke et al. 2001, Grass et al. 2004).

Die Aufnahme und der Transport von agonistischen Neurotransmittern ermöglicht den Gliazellen die Registrierung und Kontrolle der elektrischen Aktivität innerhalb von Synapsen und verleiht den Astrozyten die Fähigkeit synaptische Informationsübertragungen $\mathrm{zu}$ terminieren sowie durch Exozytose glutamatenthaltener Vesikel nahegelegene Neurone zu aktivieren (Bergles et al. 1999).

Auf von Neuronen freigesetzte Transmitter reagieren Astrozyten nachgewiesenermaßen durch eine Erhöhung der intrazellulären Calciumkonzentration (Deitmer et al. 1998, Verkhratsky et al. 1998, Araque et al. 2001, Haydon 2001,). Diese „nicht-elektrische“ Erregung ist diesen Gliazellen eigen. Über die bereits erwähnten Gap-Junctions sowie über die Freisetzung von sog. Gliotransmittern, Signalmoleküle wie Glutamat, D-Serin oder ATP (Perea und Araque 2005, Araque 2006) wird in benachbarten Astrozyten ebenfalls ein Calciumeinstrom induziert und so eine Signalweiterleitung erreicht (Cornell-Bell et al. 1990, Charles et al. 1991).

Gap-Junctions und Tripartite-Synapsen ermöglichen den Astrozyten eine schnelle Reaktion auf Veränderungen der Umgebung und lässt sie zur Leitstruktur bei der (Um-) Organisation der Synapsen werden (Araque et al. 2001, Haydon 2001, Mazzanti et al. 2001, Piet et al. 2004 sowie Zhang und Haydon 2005).

Die Astrozyten nehmen also starken Einfluss auf die neuronale Aktivität und haben einen erheblichen Anteil an der interzellulären Informationsverbreitung und verarbeitung. Sie spielen in der Kommunikation zwischen den Nervenzellen eine vermittelnde aber auch modulierende Rolle. Ihre Eigenschaft, Glykogen zu produzieren wie auch zu speichern macht sie außerdem zu wichtigen Energielieferanten für Nervenzellen. Außerdem stellen sie einigen Neuronen 
Glutamin zur Synthese des Neurotransmitters Glutamat zur Verfügung (Belin und Hardin 1991, Danbolt 2001).

Aufgrund ihrer hohen Kaliumleitfähigkeit wird den Astrozyten des Weiteren eine Kontrollfunktion des extrazellulären Milieus postuliert, denn durch passive Aufnahme extrazellulären Kaliums und Abgabe desselben in den Blutkreislauf erhalten sie die Homöostase aufrecht (Kuffler et al. 1966, Orkand et al. 1966, Kofuji und Newman 2004).

Neben ihren Funktionen unter physiologischen Bedingungen spielen Astrozyten auch eine bedeutende Rolle bei pathologischen Veränderungen des ZNS. Auf Verletzungen reagieren sie sowohl mit morphologischen als auch metabolischen Veränderungen. Die Zellen hypertrophieren und proliferieren und es kommt zu einer erhöhten Produktion von GFAP (Ridet et al. 1997). Diese Gewebeantwort wird als reaktive Gliose bzw. Astrogliose bezeichnet. Die reaktiven Astrozyten säumen den geschädigten Bereich ein und grenzen ihn so von dem umliegenden Gewebe ab, so dass dieses nicht oder nur wenig beeinträchtigt werden kann (Bush et al. 1999, Faulkner et al. 2004). Andererseits haben die Glianarben die negative Eigenschaft, die Regeneration der Neurone zu hemmen. Die Auswirkungen der Astrozyten, sowohl protektiv als auch schädigend sind in dem Artikel von Sofroniew aus 2005 zusammenfassend dargestellt.

Eine Beeinträchtigung der Neuron-Glia-Interaktion wird bei neurodegenerativen Erkrankungen wie der ALS und der Alzheimer-Erkrankung diskutiert (Leigh et al. 1991, Cotrina und Nedergaard 2002, Kaiser et al. 2006, Maragakis und Rothstein 2006), ebenso wie bei der Epilepsie (Kang et al. 2005, Tian et al. 2005) oder Schizophrenie (Hashimoto et al. 2005). Im in-vitro-Versuch eines AlzheimerModells wiesen die Astrozyten, die eine mutierte Form des Proteins Presenilin exprimierten, eine veränderte Calciumantwort auf Glutamat auf, d. h. sie reagierten mit Calciumoszillationen schon auf viel geringere ATP- und Glutamatkonzentrationen als "gesunde“ Astrozyten (Johnston et al. 2006). Es wird vermutet, dass diese Reaktion zu neuronalen Fehlfunktionen und ggf. zum neuronalen Zelltod führt.

Astrozyten exprimieren alle Subtypen der P1-Rezeptoren sowie alle bisher bekannten P2X-Rezeptoren außer P2X6. Aus der Gruppe der P2Y-Rezeptoren werden 2Y-Rezeptoren 1, 2, 4, 6, 12 und 14 exprimiert (Burnstock 2006). 


\section{MATERIAL UND METHODEN}

\subsection{MATERIAL}

\section{Gewebe}

In dieser Arbeit wurde fixiertes und in Paraffin eingebettetes sowie nativkryogefrorenes lumbales Rückenmarksgewebe verschiedenen Alters und unterschiedlicher Krankheitsstadien im murinen Tiermodell untersucht. Für die Western-Blot-Untersuchung wurde das Gewebe nativ aufgearbeitet. Ergänzend wurde autoptisch gewonnenes Gewebe von thorakalem Rückenmark von ALSPatienten sowie von rückenmarksgesund Verstorbenen als Kontrolle untersucht.

\subsubsection{Verwendete Mauslinien}

\section{Wildtypstamm B6SJL}

Diese Tiere wurden von Janvier, Le Genest-St-Isle, Frankreich bezogen. Es handelt sich bei dieser Linie um eine Kreuzung der Linien C57BI6/J und SJL F1. Die B6SJL-Linie ist fruchtbarer als die beiden Ausgangslinien. Die Linie diente als Kreuzungspartner für die $S O D^{\mathrm{G} 93 \mathrm{~A}}$-Linie, in der die transgenen Weibchen nicht fruchtbar sind.

\section{Stamm SOD1: G93A}

Die im Rahmen dieser Arbeit verwendeten Mäuse, Wildtyp als auch transgene Tiere, wurden in der Tierhaltungseinheit des Max-Planck-Institutes (MPI) für Experimentelle Medizin, Göttingen gezüchtet und den deutschen und den Richtlinien der Europäischen Union für Versuchstiere entsprechend gehalten.

Der am Max-Planck-Institut für Experimentelle Medizin, Göttingen gebräuchliche Liniencode der Arbeitsgruppe Neurogenetik (Prof. Dr. Frank Kirchhoff) für verschiedene transgene Mauslinien wurde in dieser Arbeit übernommen.

SOD1 ${ }^{\text {G93A }}$-Mäuse wurden als Versuchslinie für die ALS verwendet, da diese ein 
schon lange etabliertes und bewährtes Model in der Erforschung der familiären ALS darstellen.

Der Stamm B6.Cg-Tg(SOD1-G93A)1Gur/J wurde ursprünglich von Jackson Laboratory, Bar Harbor-Maine, USA bezogen und am Max Planck Institut gehalten (Gurney et al. 1996). Die transgenen Tiere wurden in einem hemizygoten Status erhalten, indem männliche transgene SOD1 ${ }^{\text {G93A }}$-Tiere mit B6SJL-Weibchen verpaart wurden.

Es handelt sich um Tiere, die eine mutierte Form der humanen Cu/Zn-SuperoxidDismutase (hSOD1) exprimieren, in der Glyzin durch Alanin im Codon 93 substituiert wurde. Diese Tiere entwickeln eine Degeneration von Motoneuronen und adäquate klinische Symptome, die ebenfalls im Krankheitsprogress der ALS beim Menschen zu beobachten sind. Die Mäuse wurden anhand ihres Krankheitsstadiums und der entsprechenden Symptome klassifiziert, d. h. die Stadieneinteilung beruhte auf den klinisch festgestellten phänotypischen Veränderungen.

Als präsymptomatisch (presymptomatic, Stadium 0) wurden Mäuse bezeichnet, die phänotypisch noch keine Anzeichen motorischer Beeinträchtigung demonstrierten, aber bereits histopathologische Schädigungszeichen von Motoneuronen zeigten (P60-P90).

Frühsymptomatisch (early symptomatic, Stadium 1) wurden Tiere benannt bei denen sich eine beginnende motorische Störung der Hinterbeine in Form einer Gangataxie zeigte.

Mäuse mit deutlicher Parese von mindestens einem Hinterbein wurden als symptomatisch (symptomatic, Stadium 2) bezeichnet und Tiere mit einer kompletten Lähmung beider Hinterbeine und Lähmung mindestens eines Vorderbeines (Verlust des Aufrichtreflexes) wurden als Endstadium (endstage, Stadium 3) klassifiziert.

Tiere, die für die vorliegende Arbeit verwendet wurden, zeigten erste Krankheitssymptome mit $\mathrm{P}$ (postnataler Tag) 85 bis P90 und erlangten das Endstadium der Erkrankung mit etwa P120-P140. Tiere im Endstadium (Verlust des Aufrichtreflexes) sowie Tiere mit einem Gewichtsverlust von $>15 \%$ des Eingangskörpergewichts, wurden getötet. 


\subsubsection{Verwendetes humanes Gewebe}

Für die Analyse der P2X4-Expression in humanem Rückenmark wurden Gewebsschnitte des thorakalen Rückenmarks von zwei an ALS verstorbenen Patienten und zwei Kontrollen, jeweils im Alter zwischen 44 und 78 Jahren, verwendet.

Die kryokonservierten Proben wurden von der Neurologischen Klinik der Medizinischen Hochschule Hannover zur Verfügung gestellt.

Gewebsschnitte von Formalin-fixiertem, in Paraffin-eingebetteten Rückenmarksgewebe von einem Patienten mit ALS und einem rückenmarkgesunden Verstorbenen wurden mit freundlicher Genehmigung von Herrn PD Dr. Schulz-Schaeffer, Institut für Neuropathologie in Göttingen, bereitgestellt. Das Gewebe wurde in der Neuropathologie Göttingen im Rahmen des Brain Net-Projekts 068/00 bearbeitet, das durch die Ethikkommission der medizinischen Fakultät, LMU München, genehmigt worden war.

\subsubsection{Gebrauchswaren}

Verbrauchsmaterial und Gebrauchswaren wurden, falls nicht gesondert erwähnt, von regionalen Laborbedarfslieferanten oder den Firmen direkt bezogen (z.B. BD Falcon, Heidelberg; Eppendorf, Hamburg; Greiner, Solingen; Nunc, Wiesbaden; Menzel-Gläser, Braunschweig; Sartorius, Göttingen; Schott AG, Mainz, Schütt Göttingen, VWR Darmstadt).

Tab. 3: verwendete Verbrauchsmaterialien

\begin{tabular}{||l|l||}
\hline \multicolumn{1}{|c|}{ VERBRAUCHSMATERIAL } & \multicolumn{1}{c|}{ HERSTELLER } \\
\hline Hyperfilme ECL & Amersham, Buckinghamshire, UK \\
\hline $\begin{array}{l}\text { Nitrocellulose-transfer-membran } \\
\text { PROTRAN (Porengröße 0,45 } \mu \mathrm{m})\end{array}$ & Whatman, Dassel, D. \\
\hline Objektträger SUPERFROST PLUS & Menzel-Gläser, Braunschweig, D. \\
\hline Deckgläser & Menzel-Gläser, Braunschweig, D \\
\hline
\end{tabular}




\subsubsection{Geräte}

Soweit nicht anders angegeben wurden Standardlaborgeräte der Firmen Biometra GmbH Göttingen; Eppendorf, Hamburg; Haraeus, Hanau; Sartorius, Göttingen; Schütt, Göttingen; VWR, Darmstadt; Zeiss, Jena verwendet.

Tab. 4: verwendete Geräte

\begin{tabular}{|c|c|c|}
\hline GERÄTE & MODELL & HERSTELLER \\
\hline Feinwaage & BL 210S & Sartorius, Göttingen, D. \\
\hline $\begin{array}{l}\text { Hamilton-Mikroliter- } \\
\text { Spritze }\end{array}$ & Microliter ${ }^{\mathrm{TM}}$ Syringes, 702N & $\begin{array}{l}\text { Hamilton Bonaduz AG, } \\
\text { Bonaduz, Ch }\end{array}$ \\
\hline Kryomikrotom & CM3050S & $\begin{array}{l}\text { Leica, Microsysteme, } \\
\text { Wetzlar, D. }\end{array}$ \\
\hline Magnetrührer & Combimag RCO & IKA Labortechnik, Staufen, \\
\hline Mikroskop & Zeiss Axioplan 2 imaging & $\begin{array}{l}\text { Carl Zeiss Microlmaging, } \\
\text { Jena/ Göttingen, D. }\end{array}$ \\
\hline Mikroskop & $\begin{array}{l}\text { Zeiss Axiovert 200M/LSM } 510 \text { Meta } \\
\text { confocal laser-scanning microscope }\end{array}$ & $\begin{array}{l}\text { Carl Zeiss Microlmaging, } \\
\text { Jena/ Göttingen, D. }\end{array}$ \\
\hline Mikrotom & SM 2000R & $\begin{array}{l}\text { Leica, Microsysteme, } \\
\text { Wetzlar, D. }\end{array}$ \\
\hline Peristaltik-Pumpe & Heraeus SR70, Flussrate 0,2- $0,5 \mathrm{ml} / \mathrm{s}$ & Heraeus, Hanau, D. \\
\hline $\mathrm{pH}$ Meter & PB-20 & Sartorius, Göttingen, D. \\
\hline $\begin{array}{l}\text { Reinstwasser- } \\
\text { Anlage }\end{array}$ & SARTOPORE 2, arium, $611 \mathrm{VF}$ & Sartorius, Göttingen, D. \\
\hline Schüttler & WT17 & $\begin{array}{l}\text { Biometra GmbH, Göttingen, } \\
\text { D. }\end{array}$ \\
\hline Sterilbank & Hera safe & Heraeus, Hanau, D. \\
\hline Ultramikrotom & EM UC6 & $\begin{array}{l}\text { Leica, Microsystems, } \\
\text { Wetzlar, D. }\end{array}$ \\
\hline Vortex Mixer & $7-2020$ & neoLab, Heidelberg, D. \\
\hline Waage & BL 3100 & Sartorius, Göttingen, D. \\
\hline
\end{tabular}




\begin{tabular}{||l|l|l||}
\hline \multicolumn{1}{|c|}{ GERÄTE } & \multicolumn{1}{|c|}{ MODELL } & \multicolumn{1}{|c|}{ HERSTELLER } \\
\hline Wärmeplatte & HI 1220 & $\begin{array}{l}\text { Leica, Microsystems, } \\
\text { Wetzlar, D. }\end{array}$ \\
\hline $\begin{array}{l}\text { Western-Blot- } \\
\text { System }\end{array}$ & Mini-PROTEAN TetraCell System & BioRad, München, D. \\
\hline Zentrifugen & Centrifuge 5415 C + R & $\begin{array}{l}\text { Eppendorf; Vertrieb } \\
\text { Wesseling-Berzdorf, D. }\end{array}$ \\
\hline
\end{tabular}

\subsubsection{Chemikalien, Lösungen, Puffer}

Standardlaborchemikalien wurden bei handelsüblichen Firmen wie Amersham Biosciences, Freiburg; BD Falcon, Heidelberg; BioRad, München; Biozym, Hessisch Oldendorf; Carl Roth, Karlsruhe; Eppendorf, Hamburg, Invitrogen, Karlsruhe; Merck, Darmstadt; Roche, Penzberg; Serva, Heidelberg; Sigma-Aldrich, Taufkirchen bestellt.

Außerdem wurden Zellkulturmedien, Seren und andere Medienzusätze sowie gebrauchsfertige Puffer von PAA, Cölbe und Invitrogen, Karlsruhe bezogen.

Standardlösungen und -puffer wie PBS, TBS, TBST oder Ringerlösung wurden aus den jeweiligen Chemikalien stets selber hergestellt.

Tab. 5: verwendete Chemikalien

\begin{tabular}{||l|l||}
\hline \multicolumn{1}{|c|}{ CHEMIKALIEN } & \multicolumn{1}{|c|}{ HERSTELLER } \\
\hline Acrylamid (40\%) / Bisacryl (0,8\%) & Merck, Darmstadt, D. \\
\hline Ammoniumpersulfat (APS) & USB / Amersham, Ohio, USA \\
\hline BSA (Bovines Serum-Albumin) & Sigma-Aldrich, München, D. \\
\hline $\begin{array}{l}\text { di-Natriumhydrogenphosphat-Dihydrat } \\
\left(\mathrm{Na}_{2} \mathrm{HPO}_{4}{ }^{*} 2 \mathrm{H}_{2} \mathrm{O}\right)\end{array}$ & Merck, Darmstadt, D. \\
\hline Film-Entwickler & Kodak, Stuttgart, D. \\
\hline Film-Fixierer & Kodak, Stuttgart, D. \\
\hline
\end{tabular}




\begin{tabular}{|c|c|}
\hline CHEMIKALIEN & HERSTELLER \\
\hline Glycin $(1.04201 .1000)^{*}$ & Merck, Darmstadt, D. \\
\hline Kaliumchlorid (1.04936.1000) & Merck, Darmstadt, D. \\
\hline Kaliumdihydrogenphosphat $99 \%\left(\mathrm{KH}_{2} \mathrm{PO}_{4}\right)$ & Sigma-Aldrich, München, D \\
\hline (Mager-)Milchpulver & Sigma-Aldrich, München, D. \\
\hline Methanol (8.22283.2500) & Merck, Darmstadt, D. \\
\hline Natriumchlorid (fest) (1.06400.100) & Merck, Darmstadt, D. \\
\hline Natriumdodecylsulfat (SDS) & Merck, Darmstadt, D \\
\hline Normal goat serum (NGS) & PAA Laboratories $\mathrm{GmbH}$, Pasching, Ö. \\
\hline Paraformaldehyd (PFA) & Merck, Darmstadt, D. \\
\hline Ponceau S & Sigma-Aldrich, München, D. \\
\hline Salzsäure $(\mathrm{HCl})$, rauchend $37 \%$ & Merck, Darmstadt, D. \\
\hline Sudanschwarz B & Sigma-Aldrich, München, D. \\
\hline Tetramethylethylendiamin (TEMED) & Sigma-Aldrich, München, D. \\
\hline Tris (hydroxymethyl)-aminomethan & Merck, Darmstadt, D. \\
\hline Triton $\mathrm{X}-100$ & Sigma-Aldrich, München, D. \\
\hline TWEEN 20 (Polysorbat) & Merck, Darmstadt, D. \\
\hline Wasserstoffperoxid $30 \%\left(\mathrm{H}_{2} \mathrm{O}_{2}\right)$ & Merck, Darmstadt, D. \\
\hline Xylol (Isomere) & Roth, Karlsruhe, D. \\
\hline
\end{tabular}

* Katalognummer in Klammern 
Tab. 6: verwendete Lösungen

\begin{tabular}{|c|c|}
\hline \multicolumn{2}{|c|}{ LÖSUNGEN } \\
\hline Blocklösung & $5 \%$ Magermilch bzw. $5 \%$ BSA, in TBST \\
\hline ECL-Lösung 1 (10ml) & $\begin{array}{l}100 \mu \mathrm{l} \text { Luminol } \\
44 \mu \mathrm{l} \mathrm{p} \text {-Courmarsäure } \\
1 \mathrm{ml} \text { Tris pH } 8,5 \\
8,85 \mathrm{ml} \mathrm{Aq.} \mathrm{dest}\end{array}$ \\
\hline ECL-Lösung 2 (10ml) & $6 \mu \mathrm{l} 30 \%$ Wasserstoffperoxid $\left(\mathrm{H}_{2} \mathrm{O}_{2}\right)$ \\
\hline Paraformaldehyd (PFA) & $4 \%$ in PBS; $\mathrm{pH} 7,4$ \\
\hline Ponceau S & $\begin{array}{l}\text { 0,5\% (w/v) Ponceau S } \\
1 \%(v / v) \text { Essigsäure }\end{array}$ \\
\hline Sudanschwarz B $(0,5 \%)$ in $70 \%$ Ethanol & $\begin{array}{l}0,5 \mathrm{~g} \text { Sudanschwarz B } \\
100 \mathrm{ml} 70 \% \text { Ethanol } \\
\text { bis zum Siedepunkt erhitzen, in Dunkelheit } \\
\text { über Nacht stehen lassen und anschließend } \\
\text { filtrieren. }\end{array}$ \\
\hline
\end{tabular}

Tab. 7: verwendete Reaktionssysteme

\begin{tabular}{||l|l||}
\hline \multicolumn{1}{||}{ KIT } & \multicolumn{1}{|c|}{ HERSTELLER } \\
\hline Diaminobenzidin (DAB) - Kit & Vector, Burlingame, CA, USA \\
\hline ECL-Lumiglo & $\begin{array}{l}\text { Cell Signaling } \\
\text { Technology, Beverly, MA, USA }\end{array}$ \\
\hline Vectastain ABC -Kit & Vector, Burlingame, CA, USA \\
\hline BCA-Kit & Pierce, Rockford, IL, USA \\
\hline
\end{tabular}


Tab. 8: verwendete Puffer

\begin{tabular}{|c|c|}
\hline \multicolumn{2}{|r|}{ PUFFER } \\
\hline Citrat-Puffer (10mM) & $\begin{array}{l}\text { 2,1014g Citronensäure-Monohydrat } \\
1 \text { I Aq. dest., } \\
\text { pH 6,0 }\end{array}$ \\
\hline Elektrophorese-Puffer & $\begin{array}{l}250 \text { mM Tris-(hydroxymethyl)aminomethan } \\
1,9 \text { M Glycin } \\
1 \% \text { (v/v) SDS }\end{array}$ \\
\hline OKANO-Puffer & $\begin{array}{l}1 \text { M Tris- (hydroxymethyl)aminomethan } \\
1,9 \text { M Natriumchlorid } \\
0,5 \text { M EDTA } \\
5 \%(v / v) \text { Triton } X-100 \\
10 \%(v / v) \text { SDS }\end{array}$ \\
\hline Lysepuffer & $\begin{array}{l}50 \mathrm{mM} \text { Tris-Base } 0,605 \mathrm{~g} \\
150 \mathrm{mM} \text { Natriumchlorid }(\mathrm{NaCl}) \quad 0,87 \mathrm{~g} \\
1 \% \text { Triton X-100 } 1 \mathrm{ml} \\
\text { auf } 100 \mathrm{ml} \text { Aq. dest. } \\
\text { auf } 50 \mathrm{ml} \text { LB } 1 \text { Tablette Proteaseinhibitoren }\end{array}$ \\
\hline PBS & $\begin{array}{l}138 \mathrm{mM} \text { Natriumchlorid }(\mathrm{NaCl}) \\
2,7 \mathrm{mM} \text { Kaliumchlorid }(\mathrm{KCl}) \\
10 \mathrm{mM} \text { di-Natriumhydrogenphosphat-Dihydrat }\left(\mathrm{Na}_{2} \mathrm{HPO}_{4} 2 \mathrm{H}_{2} \mathrm{O}\right) \\
2 \mathrm{mM} \text { Kaliumdihydrogenphosphat } 99 \%\left(\mathrm{KH}_{2} \mathrm{PO}_{4}\right)\end{array}$ \\
\hline SDS-Ladepuffer & $\begin{array}{l}70 \%(\mathrm{v} / \mathrm{v}) 4 x \text { Tris }(\mathrm{pH} 6,8) \\
30 \%(\mathrm{v} / \mathrm{v}) \text { Glycerin } \\
0,01 \%(\mathrm{v} / \mathrm{v}) \text { SDS } \\
600 \mathrm{mM} \text { DTT } \\
8,33 \%(\mathrm{w} / \mathrm{v}) \text { Bromphenolblau }\end{array}$ \\
\hline TBS & $\begin{array}{l}0,9 \%(w / v) \text { Natriumchlorid }(\mathrm{NaCl}) \\
0,3 \%(w / v) \text { Tris-(hydroxymethyl)aminomethan } \\
0,1 \%(w / v) ~ H C l\end{array}$ \\
\hline TBS-T & 0,01\% (w/v) TWEEN 20 in TBS \\
\hline $\begin{array}{l}\text { Transfer- Puffer } \\
\text { (pH 8,3) }\end{array}$ & $\begin{array}{l}25 \text { mM Tris-(hydroxymethyl)aminomethan } \\
192 \text { mM Glycin } \\
20 \%(v / v) \text { Methanol }\end{array}$ \\
\hline
\end{tabular}




\subsection{METHODEN}

\subsubsection{Antikörper}

Gegenstand dieser Analyse ist die Expression und Regulation des P2X4Rezeptors und das Verhalten der Mikroglia im Rückenmark der Maus und humanen Gewebe im Krankheitsverlauf.

Folgende Antikörper wurden verwendet:

\section{Anti-P2X4-Rezeptor}

Anti-P2X4-Rezeptor-AK ist ein polyklonaler Antikörper aus dem Kaninchen und detektiert den P2X4-Purinrezeptor. Er richtet sich gegen die intrazellulär gelegene C-Domäne des Purin-Kanals P2X4 (Aminosäurencode (C) KKYK YVEDY EQGLS GEMNQ, entsprechend den Aminosäuren 370-388 des P2X4-Kanals in der Ratte). Er kann in Mensch, Maus, Huhn und Ratte in der Immunohistochemie sowie Western-Blot-Analyse verwendet werden.

\section{$\underline{\text { Anti-GFAP }}$}

Anti-glial fibrillary accidic protein-AK ist ein monoklonaler Antikörper aus der Ratte. Er stellt Astrozyten aus verschiedenen Spezies dar.

\section{Isolectin B4}

IB4 ist ein biotinyliertes Lektin-Konjugat und wird als einziger hier verwendeter Antikörper aus einer Pflanze gewonnen (GRIFFONIA (BANDEIRAEA) SIMPLICIFOLIA). Er stellt endotheliale Zellen wie auch Gliazellen dar.

\section{$\underline{K i-M 1 P}$}

Dieser Antikörper ist ein monoklonaler IgG-Antikörper aus der Maus Ki-M1P (hybridoma culture supernatant, diluted 1: 2000).

Ki-M1P detektiert Monozyten, Makrophagen, „Sternhimmelzellen“, Mastzellen.

Er wird in der vorliegenden Arbeit zur Detektion humaner Mikrogliazellen 
verwendet, da der dazu im Mausmodell angewandte Isolectin B4-Antikörper nicht im humanen Gewebe detektiert.

\section{Proteolipid Protein (PLP)}

Anti-Proteolipid Protein ist ein monoklonaler Antikörper aus der Maus, der Proteolipide in Säugetieren detektiert und damit zur Markierung von Myelin geeignet ist.

\section{SMI32}

SMI32 ist ein monoklonaler Antikörper gegen nicht-phosphoryliertes Neurofilament, er demaskiert neuronale Somata, Dentriten und Axone im ZNS und peripheren Nervensystem. Der Antikörper stammt aus der Maus.

Die für die immunohistochemische Analyse verwendeten Primär- sowie Sekundärantikörper sind zur Übersicht in den folgenden Tabellen aufgeführt.

Tab. 9: Primär-Antikörper für die Immunhistochemie

\begin{tabular}{||l|l|l|l||}
\hline \multicolumn{1}{|c|}{ ANTIKÖRPER } & $\begin{array}{l}\text { HERKUNFTS- } \\
\text { SPEZIES }\end{array}$ & \multicolumn{1}{|c||}{ HERSTELLER } & VERDÜNNUNG \\
\hline P2X4 & Kaninchen & $\begin{array}{l}\text { Alomone labs, } \\
\text { Jerusalem, Israel }\end{array}$ & $1: 200$ \\
\hline $\begin{array}{l}\text { GFAP (Glial Fibrillary } \\
\text { Acidic Protein) }\end{array}$ & Ratte & $\begin{array}{l}\text { Zytomed Systems, } \\
\text { Berlin, D. }\end{array}$ & $1: 100$ \\
\hline ISOLECTIN B4 & $\begin{array}{l}\text { Biotinylated } \\
\text { Bandeiraea } \\
\text { Griffonia }\end{array}$ & $\begin{array}{l}\text { Vector.; Burlingame, } \\
\text { CASA }\end{array}$ & $1: 25$ \\
\hline Ki-M1P & Maus & $\begin{array}{l}\text { UMG, Göttingen, D. } \\
\text { (Prof. Radzun) }\end{array}$ & $1: 5000$ \\
\hline $\begin{array}{l}\text { PLP (Anti-Myelin Proteo- } \\
\text { lipid Protein) }\end{array}$ & Maus & Chemicon MA, USA & $1: 100-200$ \\
\hline SMI32 & Maus & $\begin{array}{l}\text { Covance, Princeton } \\
\text { NJ, USA }\end{array}$ & $1: 1000$ \\
\hline
\end{tabular}


Tab. 10: Sekundär-Antikörper für die Immunhistochemie

\begin{tabular}{||l|l|l|l||}
\hline \multicolumn{1}{||}{ BEZEICHNUNG } & $\begin{array}{c}\text { HERKUNFTS- } \\
\text { SPEZIES }\end{array}$ & \multicolumn{1}{|c||}{ HERSTELLER } & VERDÜNNUNG \\
\hline $\begin{array}{l}\text { Alexa 488-gekoppelter } \\
\text { anti-Maus IgG }\end{array}$ & Ziege & $\begin{array}{l}\text { Invitrogen } \\
\text { Molecular Probes, } \\
\text { Darmstadt, D. }\end{array}$ & $1: 500$ \\
\hline $\begin{array}{l}\text { Alexa 488-gekoppelter } \\
\text { anti-Ratte IgG }\end{array}$ & Ziege & $\begin{array}{l}\text { Invitrogen } \\
\text { Molecular Probes, } \\
\text { Darmstadt, D. }\end{array}$ & $1: 500$ \\
\hline $\begin{array}{l}\text { Cy3-gekoppelter anti- } \\
\text { Kaninchen-IgG } \\
\text { (Meerrettich-Peroxidase- } \\
\text { gekoppelt) }\end{array}$ & Ziege & $\begin{array}{l}\text { Jackson } \\
\text { ImmunoResearch } \\
\text { Laboratories, } \\
\text { PA, USA }\end{array}$ & $1: 1000$ \\
\hline
\end{tabular}

\subsubsection{Gewebepräparation}

\section{Perfusionsfixierung}

Nach Inhalationsanästhesie des Tieres mit Ether erfolgte die Thorakotomie und Platzierung einer Kanüle in den linken Ventrikel sowie Inzision des rechten Atriums. Durch eine sog. Peristaltikpumpe (Heraeus SR70, Flussrate 0,2- 0,5 ml/s; Heraeus, Hanau) wurde das Blut mit HBSS (Hanks buffered Saline-Solution) ausgespült und Paraformaldehyd (PFA, 4\%(w/v) in PBS, pH 7,4) infundiert. Die vollständige Fixation dauerte bei adulten Tieren ca. 10 Minuten. Anschließend wurde die Wirbelsäule freipräpariert und über Nacht bei $4^{\circ} \mathrm{C}$ nachfixiert. Die Perfusionsfixierung erfolgte nicht durch die Doktorandin, das perfusionsfixierte Material wurde für diese Arbeit bereitgestellt.

Am folgenden Tag wurde das Rückenmark freipräpariert, mehrfach mit PBS gewaschen sowie in PBS bei $4^{\circ} \mathrm{C}$ maximal 7 Tage bis zur Einbettung (Kryomatrix bzw. Paraffin) gelagert. 


\section{Immersionsfixierung}

Nach Anästhesie (s. o.) wurden die Mäuse durch Dekapitation getötet, die Wirbelsäule freipräpariert und das präparierte Gewebe über Nacht bei $4^{\circ} \mathrm{C}$ in PFA (10\% (w/v) in PBS) fixiert. Am folgenden Tag wurde das Rückenmark freipräpariert, mehrfach in PBS gewaschen sowie bei $4^{\circ} \mathrm{C}$ maximal 7 Tage bis zur endgültigen Einbettung (Kryomatrix bzw. Paraffin) gelagert. Diese Methode wurde bei P0-P10Tieren angewandt. (Die Gewebeentnahme erfolgte nicht durch die Doktorandin; das Gewebe wurde zur Weiterverarbeitung für diese Doktorarbeit bereitgestellt.)

\subsubsection{Paraffineinbettung der verwendeten Gewebe und Herstellung der Paraffinschnitte}

Nachdem das Gewebe eine Stunde gewässert und in 70\% EtOH gebracht wurde erfolgte die Einbettung in einem Gewebeeinbettautomat (Shandon-Elliott; Frankfurt) wie folgt:

EtOH (80\%), EtOH I (96\%) - 60 Min.; EtOH II (96\%) -60 Min.; EtOH I (100\%) - 60 Min.; EtOH II (100\%) - 60 Min.; Chloroform I - 45 Min.; Chloroform II - 45 Min; Chloroform III - 45 Min.; Paraffin I 120 Min.; Paraffin II - 120 Min.; Paraffin III - 120 Min. (jeweils Paraplast Plus, Roth; Karlsruhe)

Unmittelbar nach dieser Prozedur wurde das Gewebe in flüssigem Paraffin in einem Metallrahmen eingeblockt, bei $5^{\circ} \mathrm{C}$ erkaltet und bei Raumtemperatur gelagert.

Die so hergestellten Paraffinblöcke wurden zur Anfertigung der Schnitte auf Holzklötzchen gebracht und mit dem Mikrotom (1130 Biocat, Reichert u. Jung/Cambridge Instruments; Nussloch) geschnitten.

Die gefertigten Schnitte hatten eine Dicke von $8 \mu \mathrm{m}$ und wurden in einem warmen Wasserbad geglättet und auf Objektträger gezogen.

Die Trocknung erfolgte auf einer Wärmeplatte bei ca. $45^{\circ} \mathrm{C}$. Die fertigen Schnitte konnten bei Raumtemperatur gelagert werden. 


\subsubsection{Herstellung von Kryoschnitten}

Das nach der Entnahme in Flüssigstickstoff schockgefrorenes Gewebe wurde in einem Kryomikrotom (CM3050S, Leica; Wetzlar) auf einen Schneideaufsatz gelegt und -von Luftblasen frei- in Kryomatrix (Thermo Shandon; Pittsburgh, USA) eingebettet. Die $12 \mu \mathrm{m}$ dicken Gewebeschnitte wurden auf Objektträger (SuperFrostRPlus, Menzel; Braunschweig) gezogen, auf einer Wärmeplatte bei $40^{\circ} \mathrm{C}$ eine Stunde getrocknet und anschließend bei $-80^{\circ} \mathrm{C}$ gelagert.

\subsubsection{Immunhistochemie}

\section{Immunhistochemische Untersuchung an Paraffinschnitten; Standardprotokoll}

Der erste Schritt war jeweils die Entparaffinierung und Rehydration der Schnitte. Dazu durchliefen diese eine absteigende Xylol-Et-Alkoholreihe und zwar zweimal 10 Minuten Xylol-100\% und dann jeweils 2 Minuten EtOH-100\%, EtOH-96\%, $\mathrm{EtOH}-70 \%$ und $\mathrm{EtOH}-50 \%$; anschließend folgten 2 Minuten in Aqua dest. Zur Antigendemaskierung wurden die Schnitte in Citratpuffer $(10 \mu \mathrm{M} ; 0,2 \%, \mathrm{pH} 6.0)$ in einer Mikrowelle (Bauknecht MWS 2891) gekocht; 5 mal 3 Minuten bei 800 Watt mit zwischenzeitlichem Auffüllen des Puffers.

Mit dem Abkühlen der Schnitte auf Raumtemperatur (ca.15 bis 30 Minuten) war die Entparaffinierung und Antigendemaskierung beendet und es folgte das Umranden und Abgrenzen der einzelnen Schnitte eines Objektträgers mithilfe eines Fettstiftes (DAKO Cytomation Pen, Dako, Hamburg) und das Waschen der Schnitte in PBS bei RT.

Der nächste Schritt, die einstündige Behandlung der Schnitte mit 10\% NGS in 0,3\% Triton - PBS, diente zur Blockade unspezifischer Bindungsstellen. Dem folgte die Inkubation mit dem bzw. den Primärantikörper(n)(1: 200) in 10\% NGS in PBS über Nacht bei $4^{\circ} \mathrm{C}$.

Am folgenden Tag wurden die Schnitte dreimal 5 und einmal 15 Minuten in PBS gewaschen und anschließend für eine Stunde bei RT mit dem Sekundärantikörper 
$(1: 500)$ in $10 \%$ NGS in PBS inkubiert. Für die Konfokale Immunfluoreszenzuntersuchung war der Antikörper mit dem Fluorochrom Akexa488 gekoppelt; zur Visualisierung der Zellkerne folgte eine 5minütige Behandlung mit DAPI $(2 \mu \mathrm{g} / \mathrm{ml})$ in PBS. Für die Immunhistochemische Untersuchung im Lichtmikroskop war der Sekundär-Antikörper mit MeerrettichPeroxidase markiert. Die Kernfärbung erfolgte mit Hämalaun.

Zum Abschluss wurden die Schnitte ein letztes Mal in PBS gewaschen- dreimal 5 Minuten- und mit wasserlösliches Einbettmedium (ImmuMount; Hersteller: Thermo Shandon, Pittsburgh, USA) eingedeckt und bei $4^{\circ} \mathrm{C}$ gelagert.

Die Behandlung der humanen Paraffinschnitte unterschied sich nur in der Zeit des Blockens (20 Min. bei RT statt 1 Stunde) und der Konzentration des Zweitantikörpers (hier: 1:200) und dessen Inkubationszeit von 2 1/2 Stunden.

Zur Supression der für humanes (zentrales) Nervengewebe charakteristischen aber unspezifischen von Lipofuszinablagerungen hervorgerufenen Autofluoreszenz wurden die humanen Schnitte nach Beendigung der eigentlichen Immunfärbung für eine Minute in 0,5\% Sudanschwarz B in 70\% Ethanol gefärbt.

\section{Immunhistochemische Untersuchung an Kryoschnitten}

Die bei $-80 \mathrm{C}^{\circ}$ gelagerten Kryoschnitte wurden zunächst eine Stunde bei $37 \mathrm{C}^{\circ}$ aufgetaut und erwärmt. Anschließend wurden die einzelnen Schnitte eines Objektträgers mit einem Fettstift (DAKO Cytomation Pen, Dako, Hamburg) umrandet.

Es folgte die Bearbeitung der Schnitte nach dem o. g. immunhistochemischen Protokoll.

Die digitale Analyse der Schnitte erfolgte an einem Zeiss Axiovert 200M LSM 510 (Zeiss, Jena/ Göttingen) durch konfokale Mikroskopie (Gerät des Max-PlanckInstituts für Experimentelle Medizin, Göttingen). 


\subsubsection{Western-Blot-Analyse}

\section{Grundlagen}

Das Prinzip des Western Blots (engl. blotting= Übertragung) ist der Transfer von Proteinen auf eine Trägermembran, auf der diese weiter untersucht und dargestellt werden können. Vor dem eigentlichen Western Blot wird das zu untersuchende Proteingemisch in einer Gel-Trägermatrix mittels der SDS-Gelelektrophorese (SDS-PAGE $=$ SDS-PolyAcrylamidGelElektrophorese) entsprechend der molaren Masse, also der Größe und Ladung in Proteinbanden aufgetrennt.

\section{Herstellung der Proteinextrakte}

Die Tiere wurden zunächst mit 7\% Chloralhydrat durch intraperitoneale Injektion anästhesiert und nach Ausfall der Schmerzreflexe dekapitiert. Anschließend erfolgte die Freipräparation des Rückenmarks und Entnahme des Gewebes wobei zervikales und lumbales Mark separiert gesammelt wurde. Das Gewebe wurde zur Weiterverarbeitung direkt der Doktorandin zur Verfügung gestellt.

Mithilfe eines Glashomogenisators wurde das Gewebe anschließend im eiskalten Lysepuffer homogenisiert und für 30 Minuten auf Eis inkubiert. Anschließend konnten die Lysate entweder bei $-80^{\circ} \mathrm{C}$ gelagert oder gleich für 15 Minuten bei $4^{\circ} \mathrm{C}$ und $13.000 \mathrm{rpm}$ zentrifugiert werden. Der Überstand wurde in neue Eppendorfgefäße pipettiert, aliquotiert und bei $-80^{\circ} \mathrm{C}$ gelagert; das von Proteinen freie Sediment wurde verworfen.

\section{Bestimmung des Proteingehalts der Gewebeproben}

Die Proteinkonzentration der gewonnenen Mausgewebeproben wurde photometrisch mit dem BCA-Kit bestimmt.

Die Erstellung der Reaktionslösungen erfolgte nach Angaben des Herstellers und die Bestimmung an sich in einem Volumen von 200 $\mu$ lin einer 96-well-Platte.

In einem dreifachen Ansatz wurde je $1 \mu l$ der Gewebeprobe in je ein well der vorbereiteten Platte gegeben und mit der Reaktionslösung vermischt. Für den Erhalt des Blindwertes wurde jeweils $1 \mu$ des WBP verwendet.

Nach Verstreichen von 30 Minuten erfolgte die photometrische Erfassung der 
Extinktion bei 530nm.

Der Proteingehalt wurde anhand einer Eichreihe $(0,625 ; 1,25 ; 2,5 ; 5 ; 10 ; 20 ; 40 \mu \mathrm{g}$ BSA) ermittelt, welche bei jeder Analyse analog mitbestimmt wurde.

So wurde der Einsatz von gleichen Mengen Protein für die Western-Blot-Analyse ermöglicht.

Tab. 11: Primär-Antikörper für den Western Blot

\begin{tabular}{||l|l|l|l||}
\hline \multicolumn{1}{||c|}{ BEZEICHNUNG } & AUS SPEZIES & \multicolumn{1}{|c|}{ HERSTELLER } & VERDÜNNUNG \\
\hline P2X4 & Kaninchen & $\begin{array}{l}\text { Alomone labs, } \\
\text { Jerusalem, Israel }\end{array}$ & $1: 1000$ \\
\hline Tubulin & Maus & $\begin{array}{l}\text { Sigma-Aldrich. } \\
\text { St. Louis, MO, USA }\end{array}$ & $1: 5000$ \\
\hline
\end{tabular}

Tab. 12: Sekundär-Antikörper für den Western Blot

\begin{tabular}{||l|l|l|l||}
\hline \multicolumn{1}{|c|}{ BEZEICHNUNG } & AUS SPEZIES & HERSTELLER & VERDÜNNUNG \\
\hline $\begin{array}{l}\text { ECL tm-labeled anti- } \\
\text { rabbit antibody }\end{array}$ & Ziege & $\begin{array}{l}\text { Santa Cruz } \\
\text { Biotechnology, } \\
\text { Santa Cruz, CA, } \\
\text { USA }\end{array}$ & $1: 2500$ \\
\hline $\begin{array}{l}\text { ECL tm-labeled anti- } \\
\text { mouse antibody }\end{array}$ & Ziege & $\begin{array}{l}\text { Santa Cruz } \\
\text { Biotechnology, } \\
\text { Santa Cruz, CA, } \\
\text { USA }\end{array}$ & $1: 5000$ \\
\hline
\end{tabular}

\section{Präparation der Gewebeproben für die Elektrophorese}

Für die folgende Western-Blot-Analyse wurden die zu vergleichenden Proben (TG=Stadium1; WT P120) zunächst auf den gleichen Proteingehalt eingestellt und

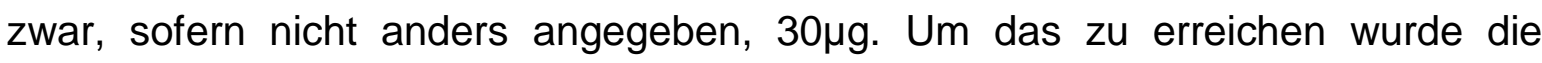
einzusetzende Probenmenge mit 6-fach konzentriertem SDS-Ladepuffer (LP) versetzt und mit Aqua dest. auf identische Volumina aufgefüllt.

Anschließend wurden die so präparierten Proben für sieben Minuten bei $95^{\circ} \mathrm{C}$ 
gekocht und kurz abzentrifugiert.

\section{Gelelektrophorese und Western Blot (Transfer)}

Die Acrylamidkonzentration des Trenngels (12\%), welches zuerst gegossen wird, richtet sich nach dem Molekulargewicht des zu analysierenden Proteins.

Das Trenngel wurde mit einem 4\%igen Sammelgel überschichtet.

Tab. 13: Chemikalien zur Herstellung der Western-Blot-Gele

\begin{tabular}{|c|c|c|c|c|c|}
\hline \multirow[t]{2}{*}{ CHEMIKALIE } & \multirow{2}{*}{ SAMMELGEL } & \multicolumn{4}{|c|}{ TRENNGEL } \\
\hline & & $8 \%$ & $10 \%$ & $12 \%$ & $15 \%$ \\
\hline $\begin{array}{l}\text { Acrylamid }(40 \%) \text {, } \\
\text { Bisacrylamid }(0,8 \%)- \\
\text { Mischung }\end{array}$ & $0,5 \mathrm{ml}$ & $2 \mathrm{ml}$ & $2,5 \mathrm{ml}$ & $3 \mathrm{ml}$ & $3,75 \mathrm{ml}$ \\
\hline $\begin{array}{l}\text { 1,5 M Tris/HCl pH 8,8; } \\
\text { SDS (0,4\%) }\end{array}$ & - & $2,5 \mathrm{ml}$ & $2,5 \mathrm{ml}$ & $2,5 \mathrm{ml}$ & $2,5 \mathrm{ml}$ \\
\hline $\begin{array}{l}0,5 \mathrm{M} \text { Tris/HCl pH } 6,8 \\
\text { SDS }(0,4 \%)\end{array}$ & $1,25 \mathrm{ml}$ & - & - & - & - \\
\hline Aqua dest. & $3,25 \mathrm{ml}$ & $5,5 \mathrm{ml}$ & $5 \mathrm{ml}$ & $4,5 \mathrm{ml}$ & $3,75 \mathrm{ml}$ \\
\hline APS (10\%) & $30 \mu \mathrm{l}$ & $60 \mu \mathrm{l}$ & $60 \mu \mathrm{l}$ & $60 \mu \mathrm{l}$ & $60 \mu \mathrm{l}$ \\
\hline TEMED & $15 \mu l$ & $30 \mu l$ & $30 \mu l$ & $30 \mu \mathrm{l}$ & $30 \mu l$ \\
\hline
\end{tabular}

Die Proben wurden mit einer Hamilton-Mikroliter-Spritze in die Taschen des Trenngels überführt und elektrophoretisch durch ein senkrecht zum Gel angelegtes elektrisches Feld bei einer Spannung von 100-140 Volt bei RT in Elektrophoresepuffer aufgetrennt. Als Molekulargewichtsmarker diente der Precision Plus Protein Standards-Kaleidoscope-Marker.

Anschließend wurden die Proteine durch Anlegen eines elektrischen Feldes (100 Volt, 55mA) für erneut 1,5 Stunden bei $4 \mathrm{C}^{\circ}$ in Transferpuffer auf eine Nitrozellulosemembran Protean TM $(0,45 \mu \mathrm{M}$, Whatman) durch das Prinzip der hydrophoben Wechselwirkungen übertragen. Dabei bleibt das Muster der elektrophoretischen Auftrennung erhalten aber das an den Proteinen angelagerte 
SDS ausgewaschen. So können die Proteine renaturieren und sogar teilweise ihre Sekundär- und Tertiärstruktur wiedererlangen, jedoch nie die Quartärstruktur. Das ist die Vorraussetzung dafür, dass sie in der folgenden Immunfärbung von den Antikörpern erkannt werden können. Der Transfer wurde durch die reversible Färbung der polymeren Membran mit Ponceau S kontrolliert und der Farbstoff mit den üblichen Waschschritten (dreimal fünf und einmal 15 Minuten) in TBS-T ausgewaschen. Zur Sättigung freier, d. h. unspezifischer Bindungsstellen wurde die Membran eine Stunde bei RT mit 5\%Milchpulverlösung blockiert und daraufhin mit dem Primärantikörper ebenfalls in Milchpulverlösung über Nacht bei $4 \mathrm{C}^{\circ}$ inkubiert.

Am nächsten Tag wurde zuerst ungebundener Primärantikörper durch Waschen der Membran mit TBS-T (dreimal fünf Minuten; einmal 15 Minuten) entfernt bevor die einstündige Behandlung mit dem Sekundärantikörper in 5\% Milchpulverlösung erfolgte.

Nach erneutem Waschen der Membran mit TBS-T (dreimal fünf und einmal 15 Min.) wurden die Proteinbanden bzw. das Antigen-Antikörper-Konjugat mit Hilfe des ECL-Systems (Enhanced Chemiluminescent Detektionssystem, Amersham Biosciences) nach Angaben des Herstellers auf einem Film (Hyperfilm ECL, Amersham) visualisiert, d.h., je nach Inkubationsdauer (zwei sec oder 10 min) erfolgte eine Schwärzung des verwendeten photographischen Films.

Die Western-Blot-Zellulosemembran wurde in einem speziellen Western-BlotScanner (Multi ImagerTM, Light Cabinet System Alpha Innotech Corp.,San Leandro, USA) eingescannt und die Datei im Tiff-Format gespeichert und mit dem Programm Adobe Photoshop zu Abbildungen zusammengestellt. 


\subsection{AUSWERTUNG}

Die Quantifizierung der Immunhistochemischen P2X4-Expression im mSOD1Mausmodell erfolgte mittels Intensitätsmessung von definierten Regionen (region of interest, ROI). Als ROI wurden motoneuronale Zellkörper ohne Zellfortsätze gewählt ( $n=70$ für Wildtyp und $n=100$ für transgene Tiere, Stadium 2; $n=4$ vier unterschiedliche Tiere jeweils). Es wurden konfokale Laseraufnahmen der zu untersuchenden Gewebsschnitte erstellt (Zeiss Axiovert 200M, LSM 510; Zeiss, Jena). Die Lasermikroskopischen Einstellungen wurden standardisiert: Scan mode:

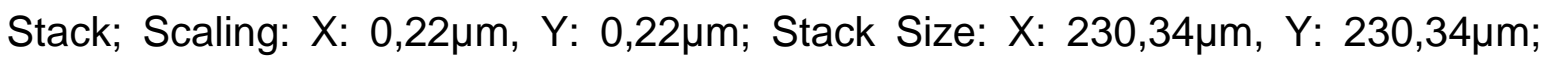
Plan-Neofluar 40x/1,3 Ölimmersionsobjektiv; Average: Line 16; Pinhole: Ch3. 125 $\mu \mathrm{m}$; Filters: Ch3: LP560; Beam Splitters: MBS: HFT UV/488/543/633; DBS1: Mirror; DBS2: NFT 545; DBS3: None; FW1: None; Wavelenght: 543nm 40,0\%. Gegenstand der Untersuchung waren mit Anti-P2X4-Antikörper angefärbte Motoneurone von Wildtyp- und Transgen-Gewebe.

Anschließend erfolgte eine Überarbeitung der Aufnahmen mit Hilfe des ComputerGrafik-Programms Irfanview 4.25. Die Messung der Pixelintensität erfolgte mit dem Programm Scion Image.

In Scion Image wurden 70 Wildtyp-Motoneurone und 100 transgene Motoneurone vermessen (Somata ohne Zellfortsätze). Es wurden Pixel/ Area (inch) analysiert und die Ergebnisse als Mittelwert \pm Standardabweichung angegeben. Im Programm GraphPad Prism erfolgte die statistische Analyse der Daten mittels unpaired T-Test, sowie die Erstellung und Bearbeitung des in Abbildung 15 dargestellten Graphen. 


\section{FRAGESTELLUNG UND ZIELSETZUNG}

Der Amyotrophen Lateralsklerose liegt eine progrediente Degeneration von Motoneuronen im ZNS zugrunde. Im Mausmodell der fALS sind v.a. Motoneurone im Vorderhorn des Rückenmarks betroffen. Die Pathomechanismen, die zur neuronalen Degeneration führen, beinhalten eine gestörte Interaktion zwischen Gliazellen und Neuronen sowie Störungen der extrazellulären Homöostase.

Gegenstand dieser Arbeit ist

$>$ der Vergleich der zeitlichen und topographischen Expression von P2X4Rezeptoren im Rückenmarksvorderhorn zwischen Wildtyp- und TransgenGewebe im Mausmodell

$>$ die Untersuchung der zellspezifischen Expression von P2X4-Rezeptoren auf neuronalen versus nicht-neuronalen Zellen (Mikroglia)

$>$ der Vergleich der im Tiermodell gewonnenen Daten mit humanem ALSGewebe.

$>$ die Analyse der Bedeutung der erhobenen Befunde im Ablauf des neuroinflammtorischen und -degenerativen Prozesses

Die Untersuchung der Expression des P2X4-Rezeptors und seiner Funktion in der interzellulären Kommunikation sowie auf der individuellen Nervenzelle soll Rückschlüsse auf eine Beteiligung des Neurotransmitters ATP an der Neuroinflammation und der Neurodegeneration im ALS-Modell ermöglichen.

Außerdem wurde in der vorliegenden Arbeit das P2X4-Immunosignal als Marker dysfunktionaler, degenerierender Motoneurone vorgestellt, der es ermöglicht den Krankheitsverlauf im Tiermodell genauer beobachten und beurteilen zu können. Ziel ist durch die spezifische Detektion, die genaue Darstellung der von der ALS betroffenen Regionen des ZNS, die Erarbeitung eines Diagnosesystems für Ausprägung und Verlauf der Krankheit sowie die bessere Beurteilbarkeit von Therapien aufgrund der Messung des Rezeptorverhaltens an Motoneuronen und Mikroglia zu erhalten. Das weitere Ziel kann die Entwicklung inflammatorisch bezogener Therapieansätze sein. 


\section{ERGEBNISSE}

In dieser Arbeit wurden Paraffinschnitte von Wildtyp- und SOD1 ${ }^{\text {G93A-Mäusen auf }}$ die Expression des ligandengesteuerten P2X4-Purin-Rezeptors zu unterschiedlichen Zeitpunkten des Krankheitsverlaufs untersucht. Bei den an ALS Verstobenen Patienten handelt sich einmal um natives gefriergeschnittenes Material mit entspr. Kontrolle und einmal um Paraffineingebettets Gewebe mit entsprechender Kontrolle.

Die Quantifizierung der P2X4-Expression erfolgte in der Western-Blot-Analyse und durch die Messung der Fluoreszenzintensität über dem histologischen Schnitt.

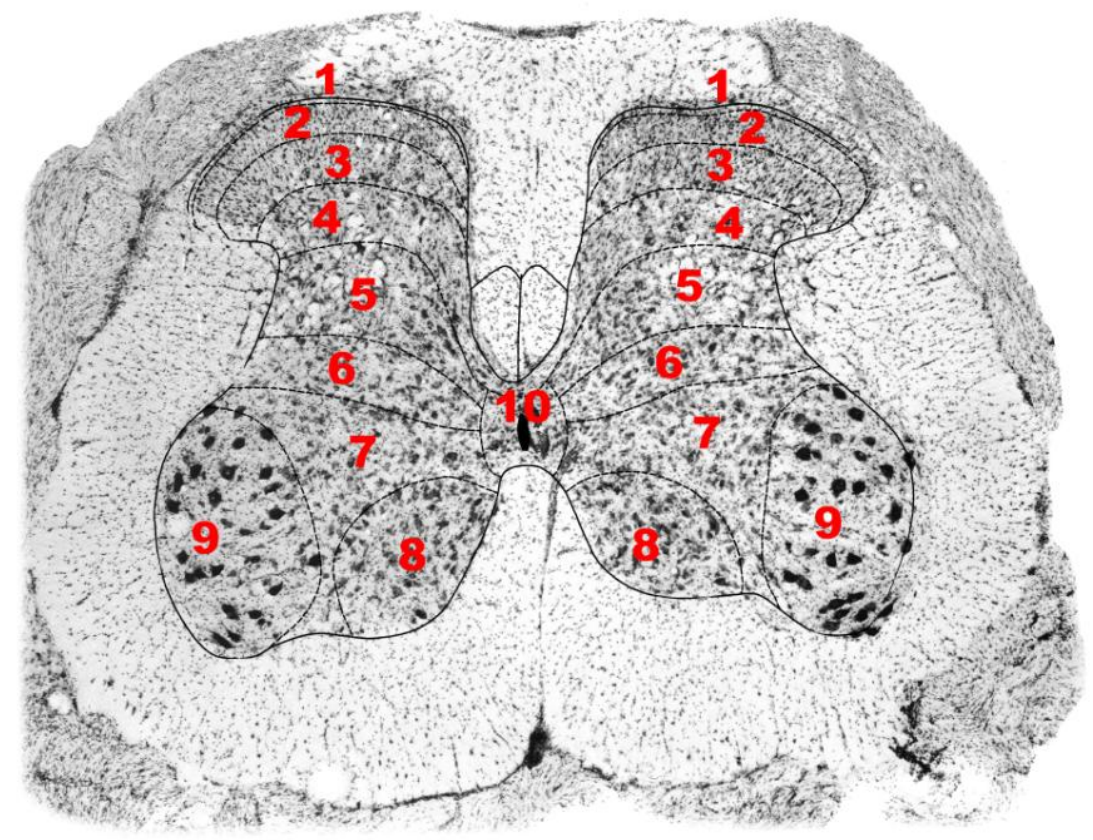

Abb. 3 Mikroskopischer Rückenmarkquerschnitt (L5) der Ratte mit schematischer Darstellung der Laminae 1-10 (Kryostatschnitt, Kresylviolett); Lamina $9=$ „Region of interest"

verändert übernommen aus Paxinos und Watson (1986), Plate 117 


\subsection{IMMUNHISTOCHEMISCHE EXPRESSIONS- ANALYSE DES P2X4-REZEPTORS IN WILDTYP. UND ALS-MAUSGEWEBE}

Um zu erkennen, ob und inwiefern der P2X4-Rezeptor im Prozess der Zelldegeneration bei ALS involviert ist, wurde zuerst die physiologische Expression des P2X4-Rezeptors im Rückenmarksvorderhorn von Kontroll-Tieren unterschiedlichen Alters untersucht.

\section{Wildtyp}

Die Analyse der Kontroll-Tiere zeigte eine P2X4-Rezeptor-Expression auf Axonen und Dendriten der grauen Substanz während der postnatalen Entwicklung. Bei adulten Tieren hingegen war die Expression des P2X4-Rezeptors fast ausschließlich auf den Somata von Motoneuronen lokalisiert während auf Neuriten kein spezifisches P2X4-Signal nachgewiesen wurde (Abb. 4). Die Spinalwurzeln wurden vereinzelt und schwach markiert.

\section{Transgen}

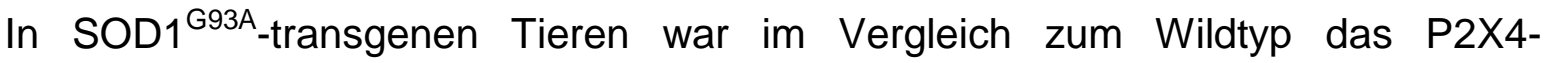
Immunosignal stärker. P2X4-positive Strukturen waren hier Somata der Motoneurone und ihre Axone (Abb. 6).

Ab dem Alter von P90 (Stadium 1) ist die Expression des P2X4-Rezeptors auf den Motoneuronen in der Immunhistochemie schon deutlich nachvollziehbar (Abb. 6J, K). Die Motoneurone wiesen im Vergleich zum Wildtypgewebe adulter Mäuse ein stärkeres P2X4-Signal auf. Im Vergleich zu präsymptomatischen Tieren (Stadium 0) hatte ebenfalls eine Hochregulation des P2X4-Rezeptors stattgefunden. Somata, die schon im Stadium 1 eindeutige morphologische Schädigungszeichen demonstrierten, wiesen eine Überexpression von P2X4 auf. Außerdem wurden hier Axone und Dendriten stärker von dem Anti-P2X4-Antikörper detektiert einschließlich der axonalen Strukturen der Vorderwurzel. Zu diesem Zeitpunkt sind im Gewebe leichte Zeichen der Zellschädigung, tatsächlich v. a. an den Zellfortsätzen und weniger an den Somata, wie degenerative Schrumpfung und 
Vakuolisierung sowie vereinzelt auch Debris zu erkennen.

Im Stadium 2 zeigte sich das P2X4-Signal auf den oben beschriebenen Strukturen im Vergleich zu Stadium 1 und 3 deutlich intensiver (Abb. 6L).

Im transgenen Gewebe des Stadium 3, d. h. im Endstadium, zeigte sich, dass das P2X4-Signal auf den Motoneuronen zwar vorhanden war, allerdings im Vergleich zum Stadium 2 wieder abgenommen hatte (Abb. 6M).

Als durchgehender Befund war die Signalstärke des P2X4-Rezeptors auf Axonen und Dendriten im Mausmodell während des gesamten Verlaufs stärker als auf den Somata. Sogar im Stadium 3 der Einteilung zeigten o. g. Strukturen trotz deutlicher Zeichen der Degeneration im Gegensatz zu den Somata der EndstadiumMotoneurone, deren Signalstärke im Vergleich zu früheren Stadien schwächer geworden war, nach wie vor ein deutliches P2X4-Signal.

Das Maximum der P2X4-Rezeptor-Hochregulation war im mittleren Stadium des Kranlheitssverlaufs am stärksten.

Man kann annehmen, dass die Abnahme des P2X4-Signals im Stadium 3 durch die fortschreitende Degeneration bzw. den Verlust der kranken Motoneurone verursacht ist.

Tab. 14 Verteilung der P2X4-Expression im WT- und TG-Mausgewebe

\begin{tabular}{|c|c|c|c|c|c|c|}
\hline & Postnatal & adult & 0 & 1 & 2 & 3 \\
\hline MN & $(+)$ & ++ & ++ & +++ & ++++ & + \\
\hline Fortsätze & ++ & $(+)$ & +++ & ++++ & ++++ & +++ \\
\hline Spinalwurzel & $(+)$ & $(+)$ & +++ & ++++ & ++++ & + \\
\hline
\end{tabular}




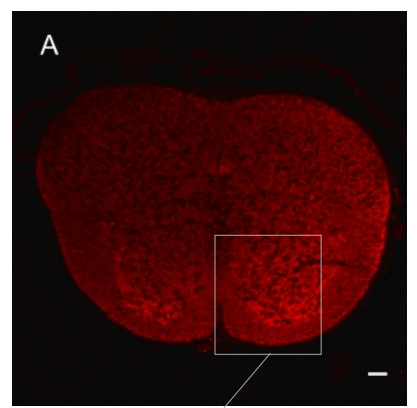

Abb. 4 Zeitverlauf der P2X4-Expression (rot) im Rückenmark von Wildtyp-Mäusen (WT).

Im postnatalen Stadium $(A=P 3, C=P 10)$ zeigt sich eine diffuse Verteilung im Vorderhorn, während im adulten Gewebe ( $D=P 90, E=P 120)$ eine überwiegend motoneurale Expression beobachtet wird. In Abb. 4D wurde zur Illustration der spezifischen Anfärbung durch Anti-P2X4-Antikörper eine motorische Nervenzelle vergrößert dargestellt (Inset).

WS= weiße Substanz

GS= graue Substanz
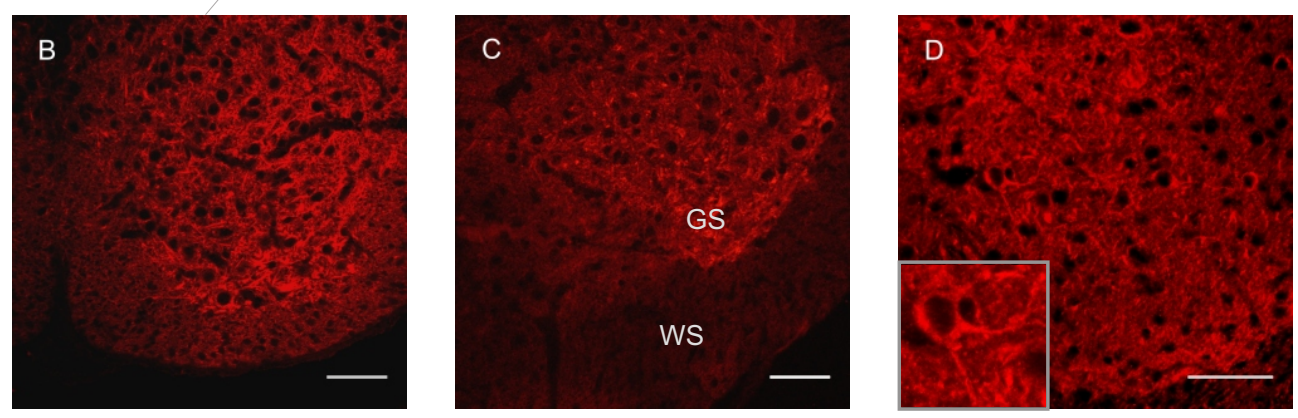

Skalierung $=50 \mu \mathrm{m}$

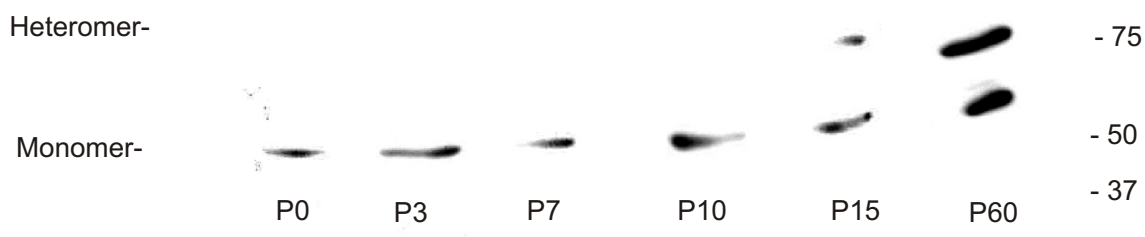

Abb. 5 Western-Blot-Analyse von fraktioniertem und mit Anti-P2X4-Antikörper inkubierten Rückenmarksgewebe (lumbal) des Wildtyps im Verlauf.

Hier wurde eine deutliche Hochregulation des bei ca. $58 \mathrm{kD}$ gelegenen Immunosignals in postnatal präparierten Tieren (P0- P10) beobachtet sowie ein hochmolekulares Signal bei 75kD im adulten (P15, P60) Gewebe.

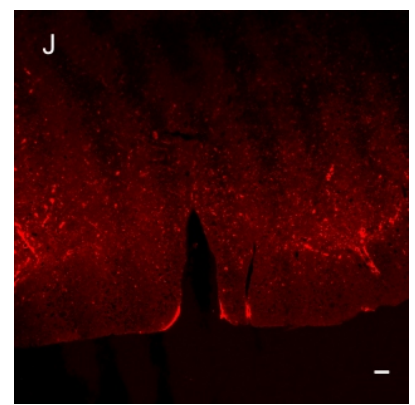

Abb. 6 Zeitverlauf der P2X4-Expression im Rückenmark von transgenen (SOD1G93A; TG) Mäusen im Stadium 1 (J, K), 2 (L) und 3 (M).

Es ist deutlich die Hochregulation des P2X4-Immunosignals im Krankheitsverlauf zu erkennen, wobei die Detektion des P2X4-Kanals im Stadium 2 am stärksten ist. Im Stadium 3 ist das Gewebe schon so weit von Degeneration geprägt, dass ein Verlust der Signalstärke im Vergleich zu früheren Stadien deutlich wird.

Skalierung $=50 \mu \mathrm{m}$
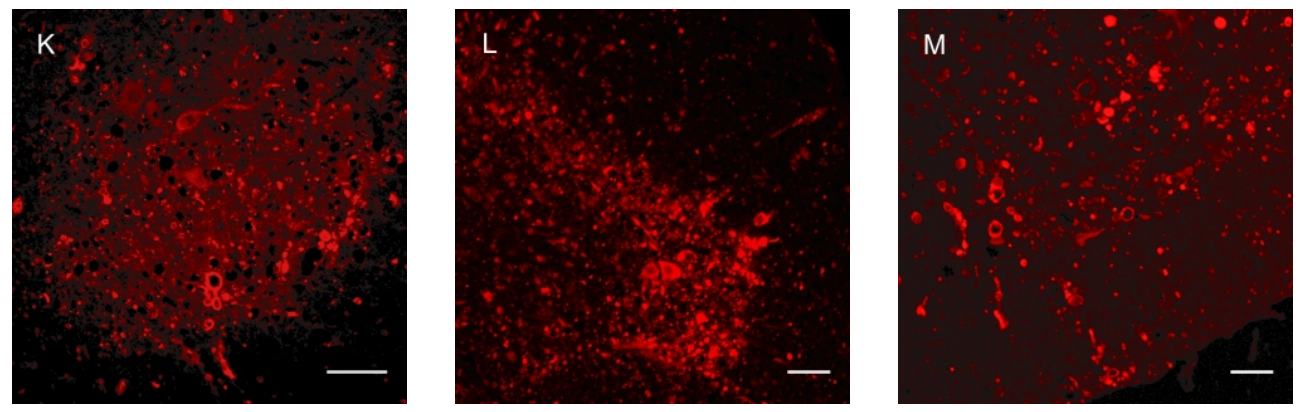
Erweiterte Untersuchung der P2X4-Expression durch immunhistochemische Doppelmarkierung

Zur Absicherung der neuronalen Zugehörigkeit des hochregulierten Rezeptors im Transgen-Gewebe erfolgten zusätzliche Doppelfärbungen zur zellspezifischen Zuordnung der P2X4-Expression. Die mit dem Antikörper PLP (Proteo lipid protein) markierten Myelinscheiden waren komplett negativ (Abb. 7G).

In der Doppelfärbung mit dem Astrozytenmarker GFAP (glial fibrillary acidic protein) wiesen nur vereinzelte astrogliale Zellen ein P2X4-Immunsignal auf (Abb. I).

Die Doppelfärbung mit dem neuronalen Antikörper SMI32 zeigte die Kolokalisation des P2X4-Rezeptors auf neuronalen Strukturen. Mit dieser Methode wurde auch die neuronale Degeneration als sog. Axonbulbs (in ihrer Kontinuität unterbrochene axonale Strukturen) hervorgehoben, die schon im Stadium 1 nachzuweisen war (Abb. $7 \mathrm{H})$. Trotz frühzeitig einsetzender axonaler Degeneration findet sich dennoch eine Hochregulation des P2X4-Rezeptors. 

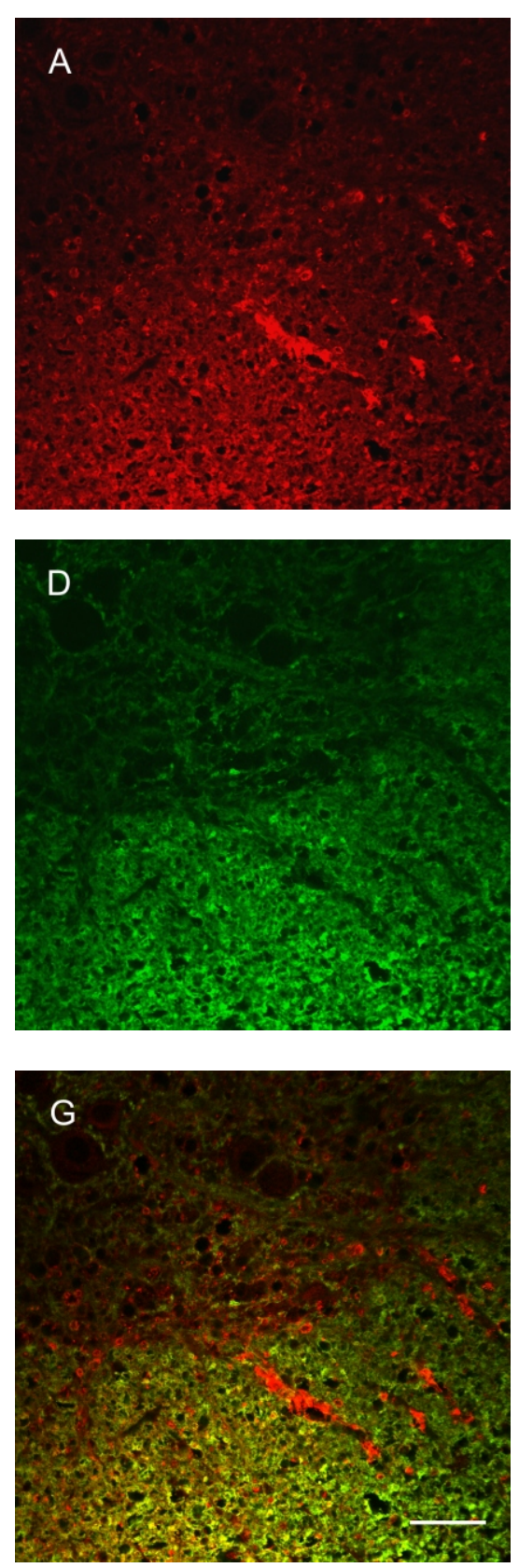

PLP
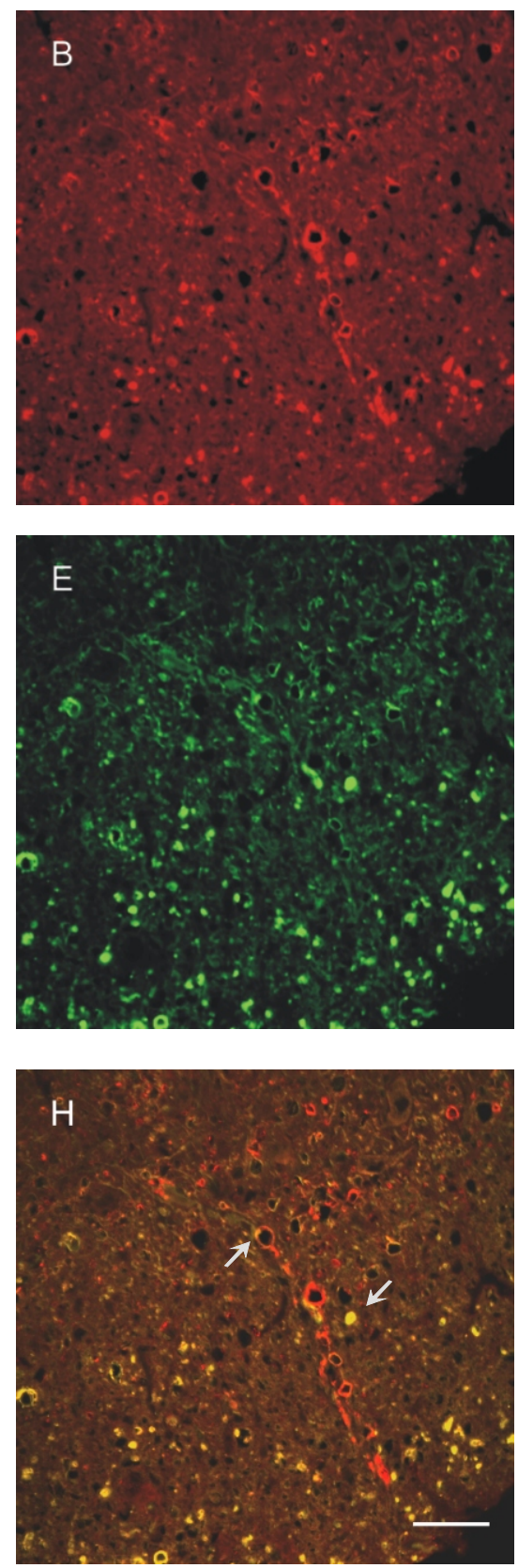

SMI32
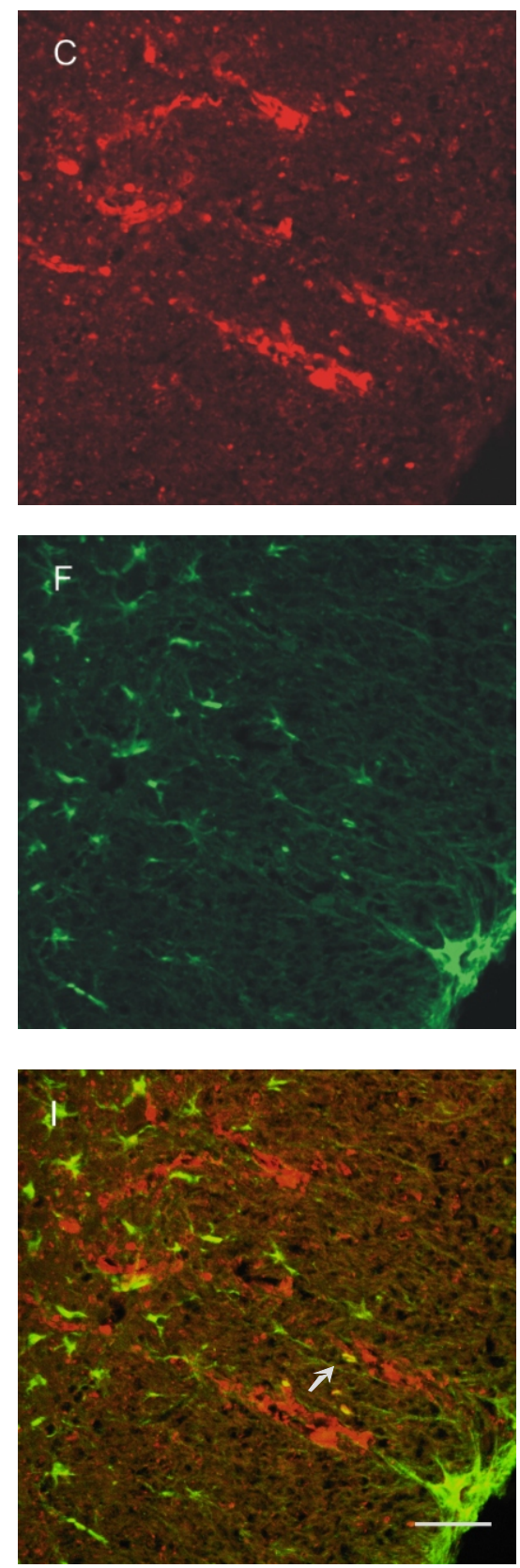

GFAP

Abb. 7 Zweifach-Immunfärbung des P2X4-Antikörpers (rot) mit Anti-Myelin Proteolipid Protein (PLP), Smi32 und GFAP (jeweils grün dargestellt) im transgenen Mausgewebe (PLP- und GFAP-Färbung= Stadium3; SMI32- Färbung= Stadium1).

Darstellung der Hochregulation des P2X4-Rezeptors auf Fasern der ventralen Rückenmarkswurzel und Identifikation sowie Illustration der Kolokalisation auf neuronenzugehörigen Fasern durch die Doppelfärbung mit dem neuronalen Marker Smi32 (B, E, H; s. Pfeil). Abb. A zeigt ein mit Anti-P2X4-markiertes Axon, in Abb. D ist die zentrale Aussparung des Axons zu erkennen.

Eine Kolokalisation des Purin-Rezeptors auf Myelin liegt nicht vor. Dagegen konnte auf vereinzelten Astrozyten eine Detektion durch Anti-P2X4-Antikörper, also eine partielle Kolokalisation, nachgewiesen werden.

Darstellung als Overlay-Bild in G, H, I

Skalierung $=50 \mu \mathrm{m}$ 


\section{Verlaufsuntersuchung der neuronalen Degeneration}

Die Markierung mit dem neuronenspezifischen Antikörper SMI32 detektiert spezifisch den Verlust der Motoneurone sowie auch degenerative/ morphologische Veränderungen von Motoneuronen im Verlauf des ALS-Mausmodells (Abb. 8).

Der Verlust des SMI32-Signals ging mit dem neuronalen Untergang im Krankheitsverlauf einher (Abb. 8D, E, F).

Die Doppelfärbung mit Anti-P2X4-Antikörper demonstrierte die zelluläre Hochregulation auf SMI-positiven Motoneuronen im frühen und mittleren Krankheitsstadium. Nervenzellen des Endstadiums dagegen boten im Vergleich meist eine schwächere aber deutliche Anfärbung durch die beiden Antikörper, während in den frühen Krankheitsstadien die Markierung durch den SMI32Antikörper dominierte (Abb. 8H, I).

Es fanden sich auch Motoneurone, die sich in dieser Doppelfärbung SMI32-negativ aber P2X4-positiv darstellten. Diese Zellen zeigten deutliche morphologische Schädigungszeichen sowie eine räumliche Assoziation zu Mikrogliazellen, die "clusterförmig" diese Motoneurone umlagerten. Wir gehen hierbei von frühzeitig und stark geschädigten Motoneuronen aus (s. u.). Dieser Befund war der Ausgangspunkt für weitere Untersuchungen der Rolle der Mikroglia in der Pathophysiologie der ALS. 

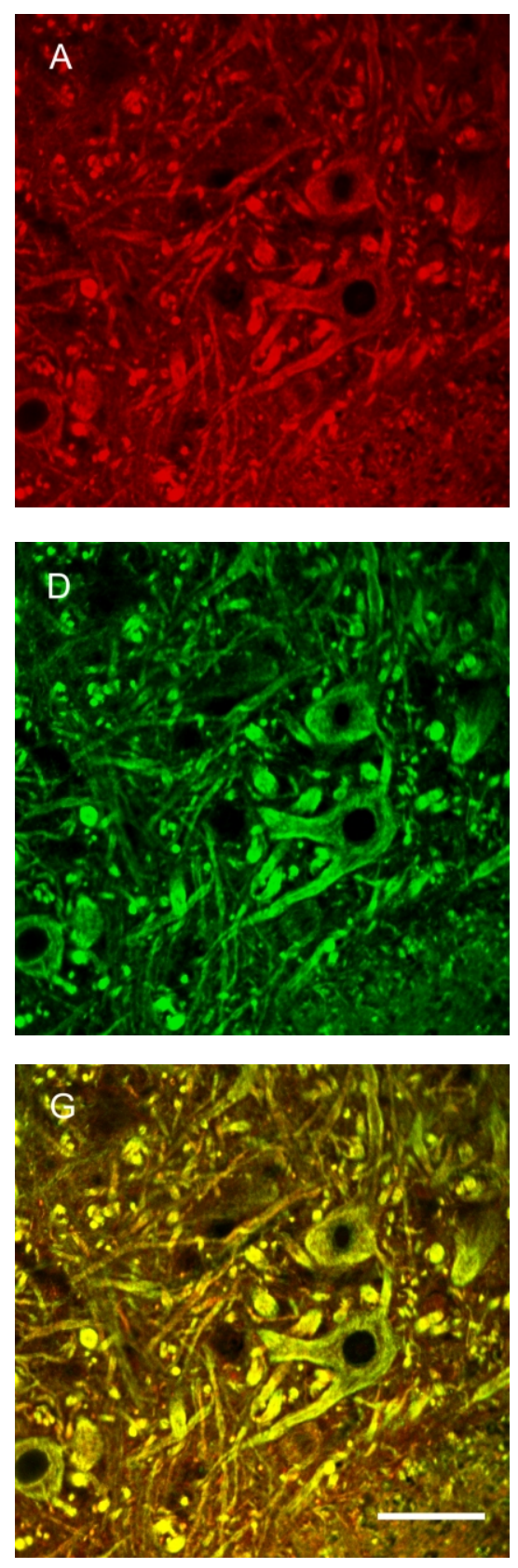
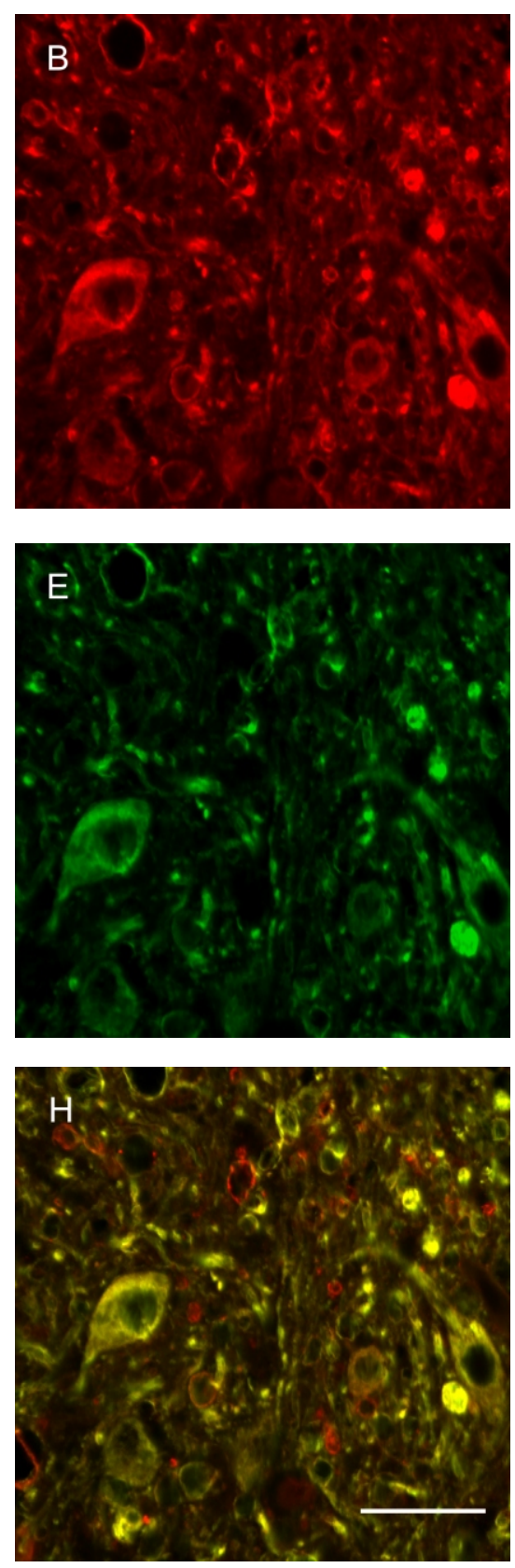
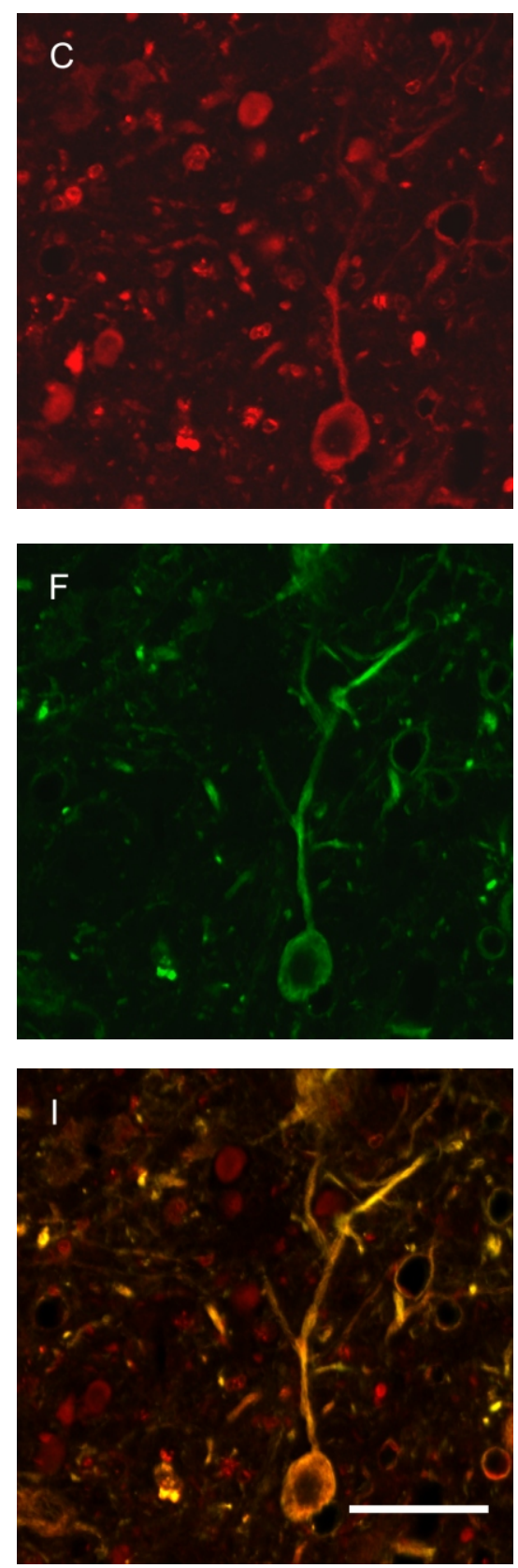

Abb. 8 Nachweis der zellspezifischen Expression des P2X4-Rezeptors auf Motoneuronen in Wildtyp- (G= P90) und Transgen-Vorderhorn des frühsymptomtischen Stadiums $1(\mathrm{H})$ sowie des Endstadiums $3(\mathrm{I})$.

Es ist die Kolokalisation von P2X4 und SMI32(grün) dargestellt. Der Verlust der Signalstärke des neuronalen Markers im Krankheitsverlauf $(\mathrm{H}, \mathrm{I})$ sowie im Vergleich zum gesunden Gewebe ist deutlich zu erkennen und als Anzeichen des Neuropilverlusts sowie des Proteinverlusts der individuellen Nervenzelle zu interpretieren. Zudem ist in der Abbildung $\mathrm{H}$ die Vakuolenbildung als Beginn der Gewebedegeneration dargestellt.

Trotz der individuellen Hochregulation des Purin-Rezeptors auf der individuellen Zelle, ist im Stadium 3 durch den Verlust des Neuropils die allgemeine Abnahme der Signalstärke beider Antikörper nachvollziehbar. Einzig in Zellrändern apoptotischer Neurone scheint eine verbleibende Hochregulation des P2X4-Kanals vorzuliegen.

Skalierung $=50 \mu \mathrm{m}$ 


\section{P2X4 und Mikroglia}

Die Detektion der Mikrogliazellen im Mausgewebe erfolgte durch den Antikörper Isolectin B4. In der Doppelfärbung ließen sich P2X4-Rezeptoren nur auf aktivierten Mikroglia nachweisen. Entsprechend zeigte das Wildtypgewebe keine spezifische Markierung durch den I-B4-Antikörper.

Es zeigte sich auch eine zunehmende räumliche Beziehung dieser Zellen zu den Motoneuronen im Verlauf. Im Stadium 1 des Krankheitsverlaufs haben Mikrogliazellen noch keine räumliche Verbindung zu Motoneuronen bzw. stellten sich deutlich weniger Gliazellen im Gewebe dar als in den folgenden Stadien 2 und 3 (Abb. 9A, B, C). Hier fanden sich aktivierte Mikoglia in clusterförmiger Verteilung in der Nähe morphologisch geschädigter Nervenzellen.

Die Zellen zeigten ein spezifisches P2X4-Signal; diese Doppelfärbung belegt die Lokalisation des Purin-Rezeptors P2X4 auch auf der Mikroglia (Abb. 9I). 

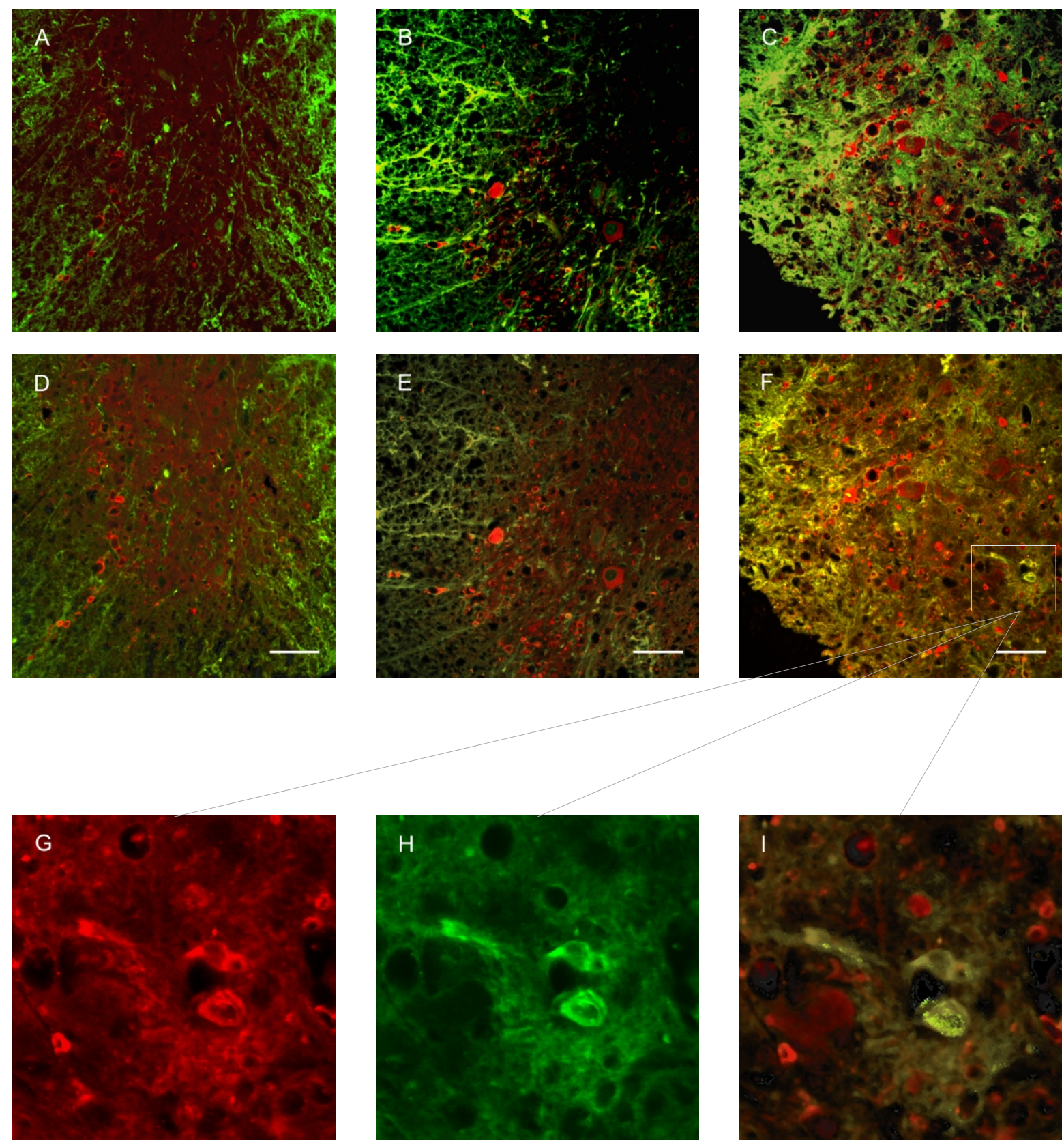

Abb. 9 Doppelfärbung von P2X4/ Isolectin B4 (grün) mit Mikrogliazellen im Rückenmarksgewebe von transgenen Mäusen.

Die Darstellung zeigt die Entwicklung der Mikrogliose im Verlauf der Stadien ( $D=1, E=2, F=3$ ). In den Bildern A-C ist das Vorkommen und die Verteilung der Mikroglia zusätzlich exemplarisch durch die übertriebene Betonung durch Hochregulation der Fluoreszenzintensität des grünen Kanals in der Bildbearbeitung dargestellt.

Die Abb. 8 G-I bieten den Nachweis der Kolokalisation des P2X4-Rezeptors auf der Mikrogliazelle.

Skalierung $=50 \mu \mathrm{m}$ 
P2X4 und Astrozyten

In der Markierung mit dem Antikörper GFAP konnte mit der Detektion von Astrozyten eine weitere zelluläre Reaktion nicht-neuronaler Zellen auf den neuronalen Untergang immunhistochemisch nachgewiesen werden.

Schon im Stadium 1 waren die Astrozyten deutlich und in großer Zahl im transgenen Gewebe zu finden. Eindeutig darzustellen war die mengenmäßige Zunahme ebenso wie die morphologisch sichtbare Aktivierung dieser Zellen im Verlauf der drei Stadien (Abb. 10D, E, F).

In der Doppelmarkierung ließen sich einige Astrozyten mit P2X4-Signal nachweisen (Abb. 10G, H, I). 

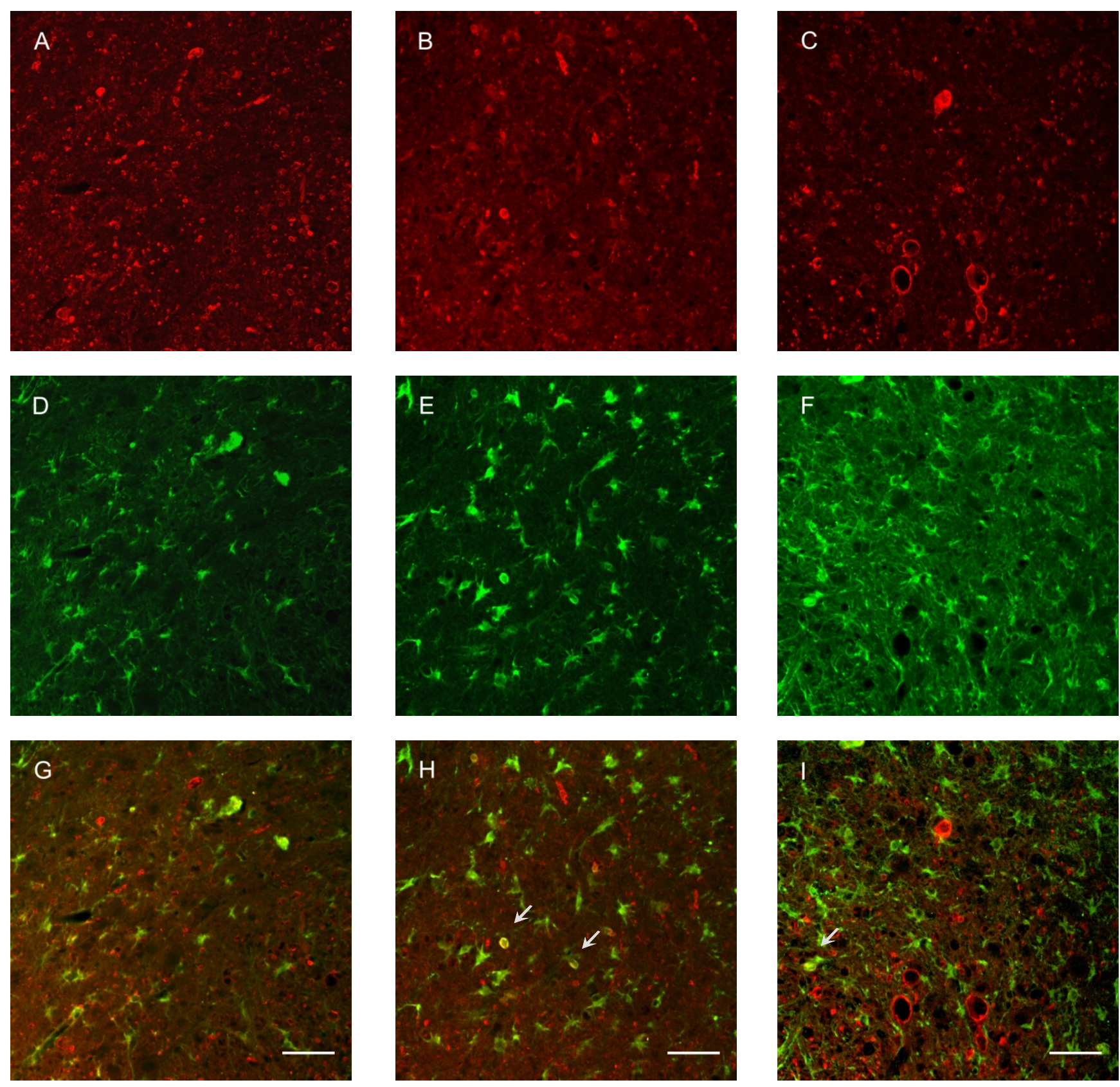

Abb. 10 Doppelfärbung mit P2X4/ GFAP (grün) von transgenem Mausgewebe in den Stadien 1 (G), 2 (H) und 3 (I).

Die Abbildung zeigt die zunehmende Astrogliose im Krankheitsverlauf. Außerdem liegt der Nachweis einer partiellen Kolokalisation des Purin-Rezeptors P2X4 auf einzelnen Astrozyten vor (s. Pfeil). Bemerkenswert ist ebenfalls die räumliche Nähe derAstrozyten zu offensichtlich geschädigtem Gewebe.

Skalierung $=50 \mu \mathrm{m}$ 


\section{Untersuchung an humanem Gewebe - Motoneurone}

Die Analyse des menschlichen Rückenmarks folgte bei ausschließlicher Doppelmarkierung dem Versuchsaufbau im Mausmodell. Auch hier wurde gesundes mit krankem Gewebe verglichen. Die Expression von P2X4 auf motorischen Nervenzellen sowie die Kolokalisation des Rezeptors auf Gliazellen im humanen kranken Gewebe im Vergleich zur gesunden Kontrolle waren Gegenstand der Untersuchung. Die "Region of Interest" war auch hier das Rückenmarksvorderhorn; untersucht wurde das thorakale Segment.

Das humane ALS-Gewebe zeigte das Bild einer fortgeschrittenen Erkrankung mit Verlust der Motoneurone und Zeichen der zellulären Degeneration wie Rarifizierung von Zellfortsätzen.

Die Färbung der Paraffin- sowie Kryoschnitte mit Anti-P2X4-Antikörper zeigte ein häufigeres und stärkeres Immunosignal auf motorischen Nervenzellen (Abb. 12A) im Vergleich zu Kontrollgewebe trotz reduzierter Zellpopulation. Dort präsentierten sich Motoneurone morphologisch intakt, das P2X4-Immunosignal war nur schwach ausgeprägt.

Im gesunden Gewebe war das P2X4-Signal auf den Nervenzellen nur schwach ausgeprägt, während hier die Anfärbung der Neurone durch SMI32-Antikörper sehr deutlich war (Abb. 11A, B, E).

Im ALS-Gewebe stand das kräftige Immunsignal durch den Anti-P2X4-Antikörper im Kontrast zur schwach ausgeprägten Signalstärke des neuronalen Markers (Abb.11 C, D, F). Die P2X4-Expression auf Motoneuronen nahm mit zunehmenden morphologischen Schädigungszeichen, einhergehend mit einem abnehmenden SMI32-Immunosignal, ab. 

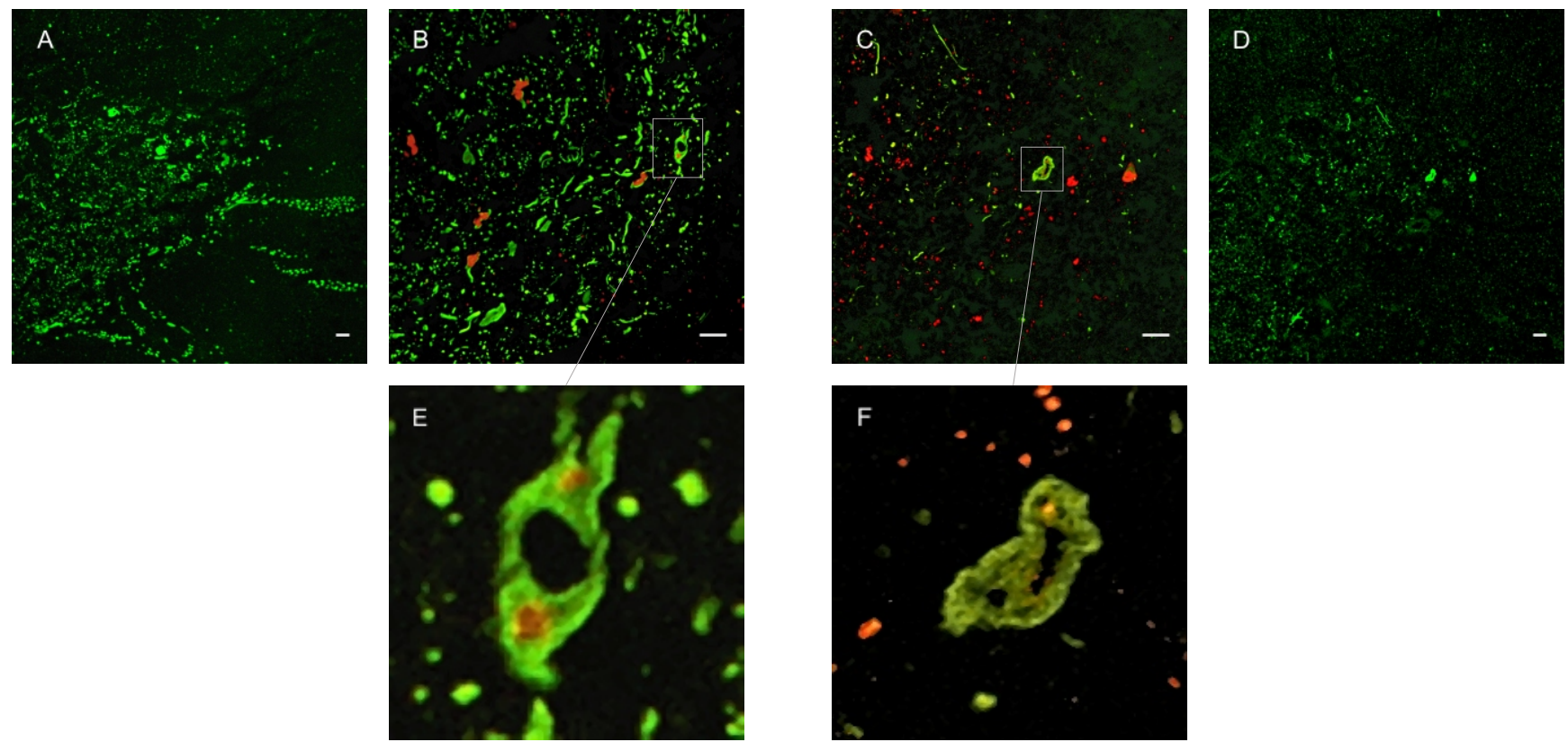

Abb. 11 Doppelfärbung von P2X4/ SMI32 (grün) mit humanem Kontroll- (B, E) und ALS-Gewebe (C, F) sowie Übersichtsdarstellung des untersuchten Vorderhorns in der Einzelfärbung mit SMI32 $(A=$ gesund; $\mathrm{D}=$ krank) im Kryoschnitt.

Der zunehmende Verlust des SMI32-Immunosignals im kranken Gewebe im Vergleich zur Kontrolle wird hier als Ausdruck fortgeschrittener Zelldegeneration ebenso deutlich (B vs. C) wie die offensichtliche morphologische Veränderung der Zellstruktur betroffener Neurone ( E vs. F).

In den Abbildungen $11 \mathrm{C}$ und $11 \mathrm{~F}$ ist das sog. Overlay des Signals beider hier verwendeter Antikörper im Vergleich zur gesunden Nervenzelle (B, E) deutlich dargestellt, resultierend aus der hochregulierten Expression des P2X4Rezeptors auf degenerierten Nervenzellen (C, F).

Skalierung $=50 \mu \mathrm{m}$
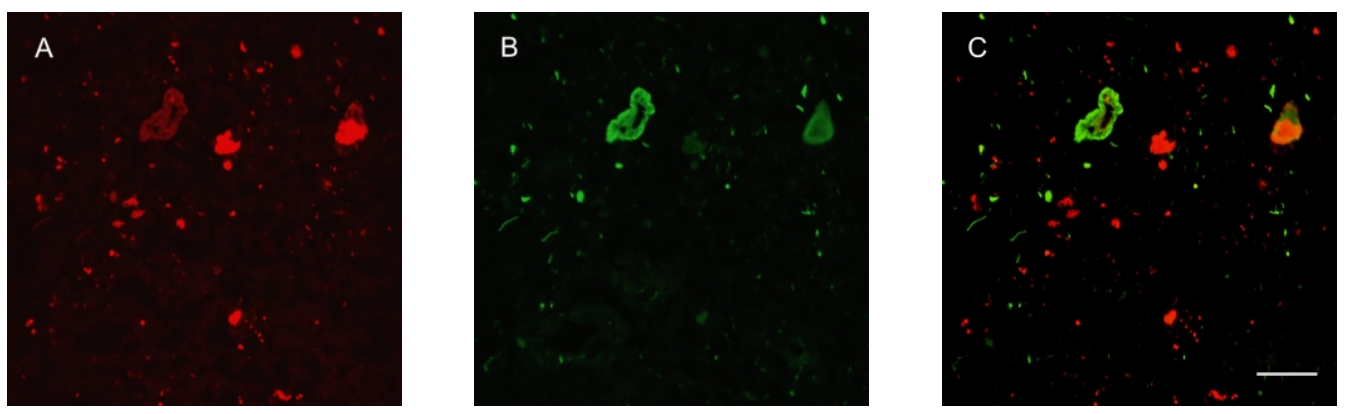

Abb. 12 Exemplarische Darstellung der Expression und Hochregulation des Purin-Rezeptors P2X4 auf der individuellen und offensichtlich von Degeneration betroffenen motorischen Nervenzelle des kranken humanen Gewebes im Kryoschnitt. Zusätzlich fällt hier die verbleibende Hochregulation des P2X4-Immunosignals (rot) im Neuropil und auf Zell-Debris auf.

Skalierung $=50 \mu \mathrm{m}$

Das Material wurde uns freundlicherweise von Frau Prof. Petri, Medizinische Hochschule Hannover, Abt. Neurologie, zur Verfügung gestellt. 


\section{Mikroglia}

Mit der Anwendung des Ki-M1P-Antikörpers wurden die Mikrogliazellen sowohl im gesunden als auch im kranken humanen Gewebe detektiert.

Bei niedriger Zellzahl im Kontrollgewebe fand sich im ALS-Gewebe eine deutliche Vermehrung der Mikrogliazellen (Abb. 13D, E, F und 14C, D).

Die Mikroglia unterschieden sich auch zytomorphologisch von den Gliazellen des Kontrollgewebes. Sie stellten sich im kranken humanen Gewebe größer und mit einem lockerer erscheinenden Zytoplasma dar als die Mikroglia im gesunden Gewebe.

Des Weiteren zeigten sich viele Mikrogliazellen des ALS-Gewebes gruppiert in der Nähe von Motoneuronen, bzw. degenerierten Motoneuronen gelegen dar.

In der Doppelfärbung mit Anti-P2X4-Antikörper wurde die Expression des P2X4Rezeptors auf Mikroglia nachgewiesen (Abb. 13G, H, I und 14F).

Diese Beobachtungen konnten sowohl in Kryoschnitten als auch in Paraffin eingebettetem Gewebe gemacht werden. Insgesamt waren damit die Befunde im humanen Gewebe mit denen des Mausmodells übereinstimmend. 

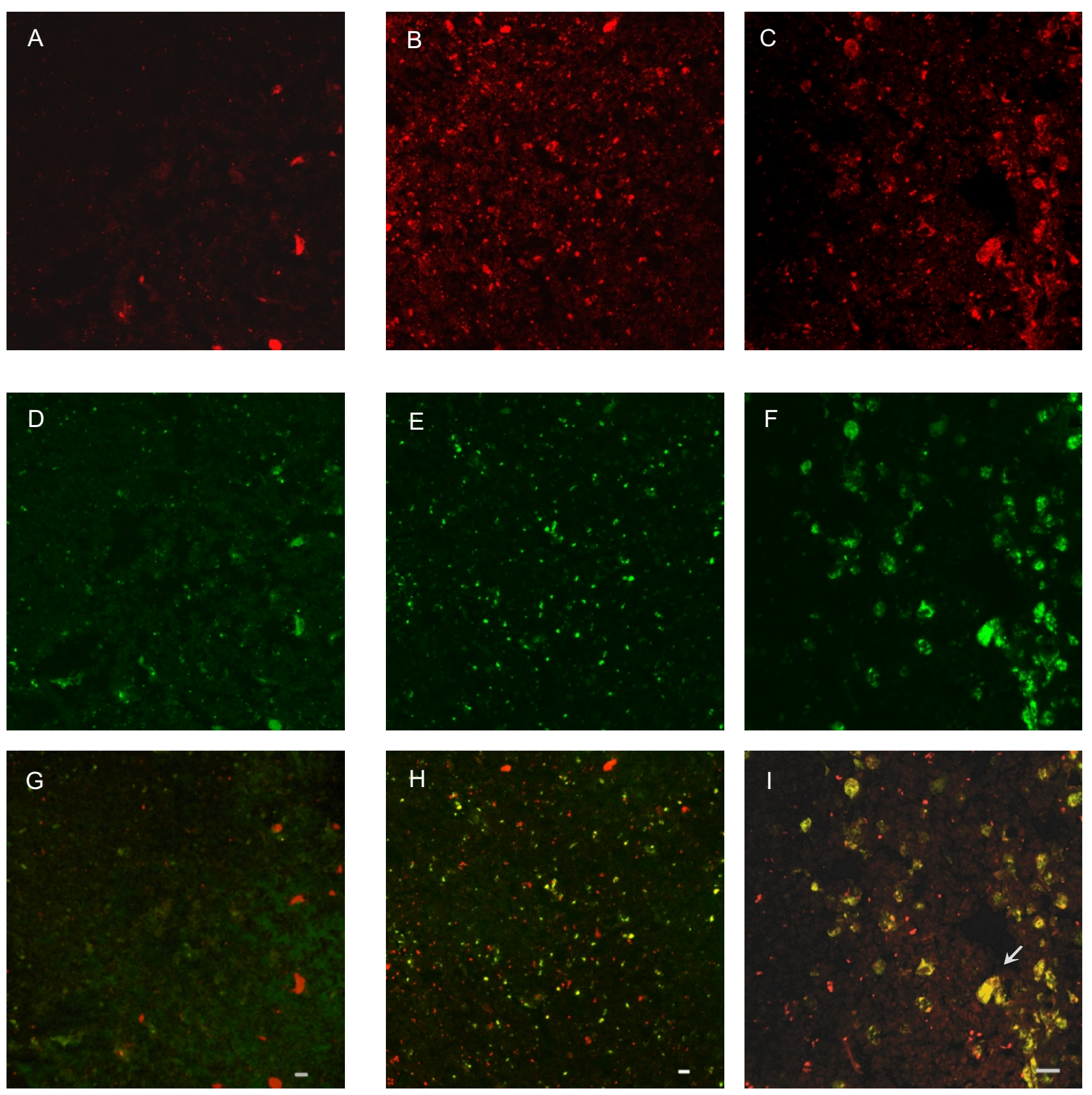

Abb 13 Doppelfärbung von P2X4/ KI-M1P (grün) mit humanem Kontroll- (G) und ALS-Gewebe $(H, I)$ im Kryoschnitt zur vergleichenden Darstellung der Mikrogliose (E, F) sowie Kolokalisation des Purin-Rezeptors P2X4 (B, C) auf Mikroglia.

Die Abbildungen 9C, F und I stellen zur eindeutigeren Veranschaulichung die Kolokalisation in der Vergrößerung 40x im ALS-Gewebes dar.

Die Färbung erreicht die Darstellung der aktivierten Mikrogliazellen und starken Mikrogliose im ALSGewebe, während die Kontrollprobe nur ein schwaches Ki-M1P-Immunosignal aufweist.

Die hier nachgewiesene Kolokalisation und im Vergleich zum Kontrollgewebe Hochregulation des P2X4-Rezeptos auf aktivierten Mikroglia (Pfeil) ließ sich im in Paraffin eingebetteten humanen Rückenmarksgewebe reproduzieren (s. Abb. 14).

Skalierung $=50 \mu \mathrm{m}$ 

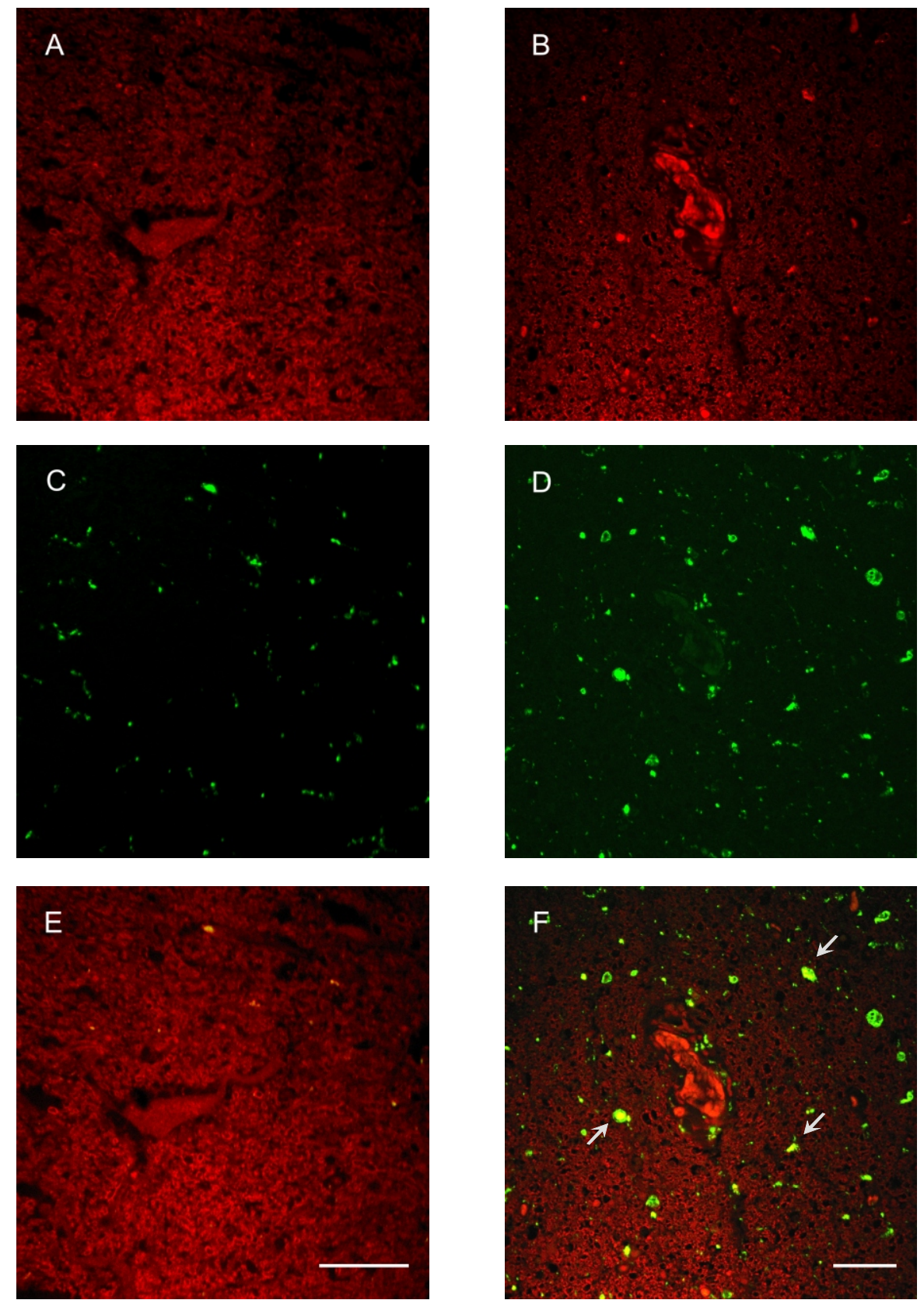

Abb. 14 Doppelfärbung von P2X4/ KI-M1P (grün) mit humanem Kontroll- (A, C, E) und ALS-Gewebe (B, D, F) im Paraffinschnitt.

Die Darstellung des kranken Gewebes zeigt die starke Mikrogliose sowie die Kolokalisation des Purin-Rezeptors P2X4 auf Mikrogliazellen (B-F; s. Pfeil). Außerdem lässt die Färbung der Mikroglia die räumliche Assoziation der Gliazellen zu morphologisch veränderten Neuronen erkennen sowie die amöboide Transformation der aktivierten Gliazellen. Die Hochregulation des P2X4-Rezeptors auf morphologisch geschädigten Motoneuronen (B) konnte auch hier eindeutig reproduziert werden (A vs. B).

Skalierung $=50 \mu \mathrm{m}$ 
Die Expression und Regulation des P2X4-Rezeptors auf den Motoneuronen zeigte einen Verlauf, der mit der Degeneration der motorischen Nervenzelle korreliert:

In dem frühen Krankheitsstadium „frühsymptomatisch“, Stadium 1 im Mausmodell waren entsprechend die Motoneurone nur gering degeneriert, in der P2X4-Färbung erschien ein leicht erhöhtes Signal. Es bestand keine räumliche Assoziation zwischen Nervenzellen und Mikroglia.

Anders im Stadium 2. Hier fand sich ein starkes P2X4-Signal auf den Neuronen. Sie schienen jedoch noch nicht irreversibel geschädigt, da sie noch durch den neuronalen SMI32-Marker detektiert wurden. Außerdem ließ sich hier durch die Färbung der Mikroglia deren Aktivierung darstellen und die Expression des P2X4Rezeptors auf Mikrogliazellen nachweisen.

Im Endstadium nahm das P2X4-Signal auf den Motoneuronen insgesamt wieder ab, besonders die Zellen, die das SMI32-Signal verloren hatten, exprimierten keine P2X4-Rezeptoren mehr auf ihrer Oberfläche.

Neben der Hochregulation des Purin-Rezeptors auf Zellkörpern gelang durch Doppelmarkierung der Nachweis der P2X4-Expression auf Axonen und Dendriten im transgenen Mausgewebe.

In den Kryo- sowie Paraffinschnitten des humanen Rückenmarksgewebes von ALS-Patienten sowie der gesunden Kontrolle waren die Befunde mit der Expressionsanalyse von P2X4 aus dem Mausmodell übereinstimmend. Auch hier fand sich im betroffenen Rückenmarksgewebe eine verstärkte Expression des P2X4-Rezeptors auf Nervenzellen des Vorderhorns sowie auf aktivierten Mikrogliazellen im Gegensatz zu dem Gewebe der gesunden Kontrollen. 

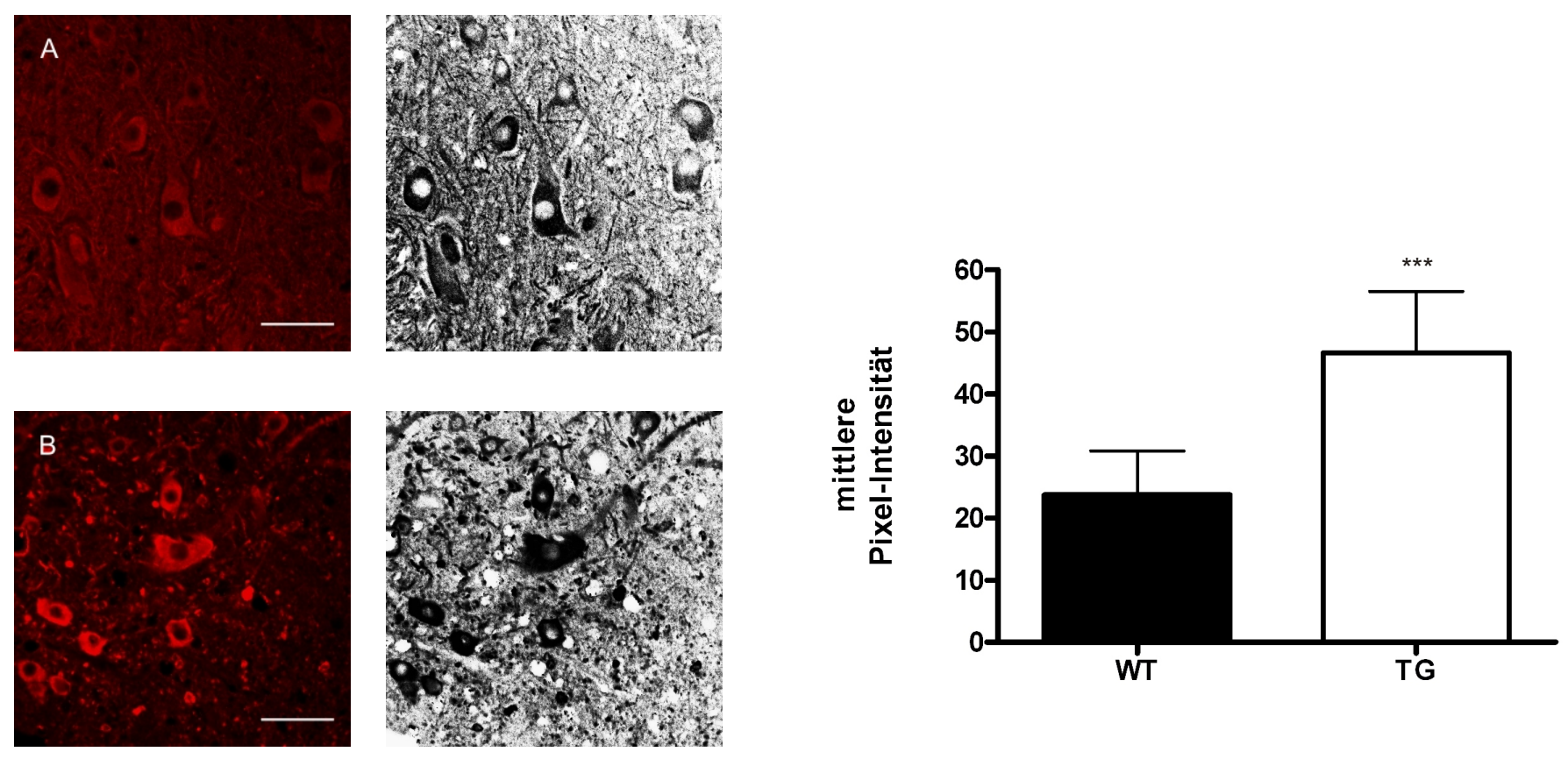

Abb. 15 Graphische Darstellung der Fluoreszenzintensität des P2X4-Signals im Wildtyp (WT) gegenüber dem transgenen (TG)Tier.

Mittels Fluoreszenzintensitätsmessung erfolgte die Quantifizierung der immunhistochemischen Hochregulation von P2X4. Es wurden jeweils 70 (WT) und 100 (TG, Stadium 2) Motoneurone (Somata) des Vorderhorns mittels des Computerprogramms Scion Image Alpha 4.0.3.2. analysiert und das Ergebnis als Mittelwert \pm Standardabweichung dargestellt. Für die statistische Auswertung der Mittelwerte wurde der unpaired T-Test verwendet (GraphPad Prism). Die Abbildungen 14.A und B zeigen exemplarisch Motoneurone des Wildtyp- (A) und Transgen-Gewebes (B).

*** $p<0.0001$

Skalierung $=50 \mu \mathrm{m}$ 


\subsection{WESTERN-BLOT-ANALYSE DES P2X4- REZEPTORS IN WILDTYP- UND TRANSGEN- GEWEBE}

Die in der Immunhistochemie angestellten Beobachtungen spiegelt die WesternBlot-Analyse auf der Proteinebene wider, die zur semiquantitativen Bestimmung von P2X4-Rezeptoren durchgeführt wurde. Als Extrakte wurden die nativen lumbalen Rückenmarksabschnitte von Wildtyp- und transgenen Mäusen (Stadium 1) verwendet (s. Material und Methoden).

Nach Inkubation mit dem Anti-P2X4-Antikörper zeigte sich sowohl im Wildtyp- als auch im Transgen-Gewebe jeweils eine Hauptbande bei etwa 58kD. Diese stellte sich im TG-Gewebe stärker ausgebildet dar und bestätigt die Hochregulation des P2X4-Rezeptors im kranken Tier. Zusätzlich fanden sich im TG-Gewebe eine fast gleichstarke Bande bei $20 \mathrm{kD}$ sowie weitere schwächere Banden bei etwa 60 und $75 \mathrm{kD}$. Die 58kD-Bande entspricht der homotrimeren Form des Purin-Rezeptors. Die Banden 58 und 75kD sind vermutlich auch Bestandteil des P2X4-Homomers, da wir sie auch in WT-Mausgewebe bei jungen (P15, P60) Tieren gefunden haben (Abb. 5). Es kann vermutet werden, dass die Expression des P2X4-Rezeptors im WT-Mausgewebe nur zeitweilig auftritt oder eine verstärkte Expression nur in jungen Tieren vorkommt und im Verlauf wieder herunterreguliert wird sowie es andernorts auch bei GABA-Rezeptoren teilweise beschrieben wurde (Laurie et al. 1992, Santhakumar et al. 2010). Das in der vergleichenden WB-Analyse (s. Abb. 16) verwendete WT-Gewebe stammt von adulten Tieren (P 120). Die Kontinuität und Zunahme der Proteinbande bei 58kD in WT- und TG-Gewebe erklärt sich durch die Pathophysiologie: der krankheitsbedingte nummerische Verlust von Motoneuronen und Verlust an spezifischem Protein wird durch die Hochregulation des Rezeptors auf den verbliebenen Zellen ausgeglichen bzw. überkompensiert.

Da der Anti-P2X4-AK an der intrazellulär gelegenen C-Domäne des Rezeptors bindet, könnte es sich bei der im TG-Gewebe detektierten Bande von 20kD um ein durch den Prozess der Degeneration freigelegtes Monomer des Kanals handeln. Die Degeneration und der Zellzerfall der den P2X4-Rezeptor exprimierenden Motoneurone impliziert ebenfalls den Zerfall des Purin-Kanals, so dass die intrazellulär gelegene Untereinheit frei liegt und separat detektiert werden kann. 


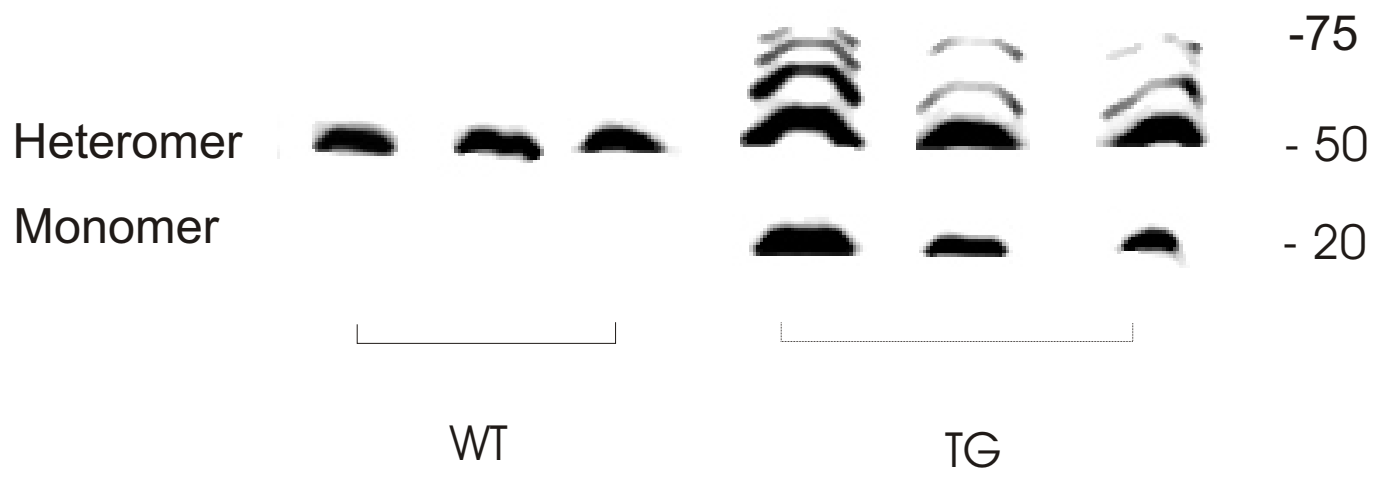

Abb. 16 Vergleichende Western-Blot-Analyse zwischen Wildtypgewebe (WT) und transgenen Tieren (TG) des Stadium 1.

Dargestellt sind Proteinbanden von mit Anti-P2X4-Antikörper inkubierten Rückenmarksproben des lumbalen Segments. In der Analyse des transgenen Gewebes zeigt sich - genau wie im Wildtyp - die Heteromerbande bei ca. 58kD. Die Kontinuität dieser Bande spricht für das Gleichgewicht zwischen Zelldegenereation und Hochregulation des P2X4Rezeptors im kranken Gewebe sowie Mikro- und Astrogliose und anderen Gewebsreaktionen. Daneben finden sich in den transgenen Proben weitere Banden, die von dem Anti-P2X4-Antikörper detektiert wurden und vermutlich ebenfalls aus dem Gewebszerfall resultieren.

Bemerkenswert ist hier die bei ca. 20 kD gelegene Proteinbande im transgenen Gewebe. Vermutlich steht sie für eine Unterform der mutierten Superoxid-Dismutase, die ähnliche Epitope aufweist wie der P2X4-Rezeptor; es entsteht eine Kreuzreaktion mit dem Anti-P2X4-Antikörper. Im Wildtyp-Gewebe zeigt sich diese Bande nicht. 


\section{DISKUSSION}

Die ALS ist gekennzeichnet durch den selektiven Untergang von Motoneuronen des Rückenmarks, des Hirnstamms und des motorischen Kortex. Neben den in der Einleitung bereits diskutierten Hypothesen der ursächlichen Pathomechanismen wie Störungen der extrazellulären Homöostase, Bildung intrazellulärer Proteinaggregate (Shaw und Ince 1997, Watanabe et al. 2001, Shigetomi und Kato 2004) oder mitochondriale Schädigung von Neuronen wird zusätzlich in der neueren Literatur in glialen Veränderungen ein weiterer pathogenetischer Faktor der ALS vermutet. Damit würde es sich nicht ausschließlich um eine autonome Degeneration der Motoneurone handeln (Übersicht bei Boillée et al. 2006a, Boillée 2006b).

P2X4 ist ein wichtiger Purin-Rezeptor im ZNS (Tsuda et al. 2003, Trang et al. 2006) und wurde auf Neuronen und Gliazellen nachgewiesen (Übersicht Abbracchio und Burnstock 1994).

Die vorliegende Arbeit beschäftigt sich mit der Hypothese, dass eine fehlerhafte interzelluläre Kommunikation zwischen Neuronen und Gliazellen als Resultat einer gestörten Expression oder Aktivität des P2X4-Rezeptors für die progrediente Neurodegeneration im Rahmen der ALS mitverantwortlich sein könnte. Es wurde die Expression dieses Rezeptors auf Neuronen und Gliazellen im transgenen Mausmodell der ALS immunhistologisch und im Western Blot untersucht. Das Expressionsmuster wurde in räumlichen und zeitlichen Zusammenhang mit der fortschreitenden Neurodegeneration im Vorderhorn des Rückenmarks gestellt. In einem weiteren Schritt wurden die gewonnenen Ergebnisse mit den Befunden an Autopsiematerial von an ALS-verstorbenen Patienten und gesunden humanen Rückenmarkskontrollen verglichen. 


\subsection{EXPRESSIONSMUSTER DES P2X4- REZEPTORS IM ALS-MAUSMODELL UND HUMANEN ALS-GEWEBE}

In der vorliegenden Arbeit wurde durch immunhistochemische Untersuchungen eine P2X4-Expression auf Motoneuronen des Vorderhorns (Lamina 9; s. Abb. 3) sowie Vorderwurzelabschnitten im Transgen-Gewebe jeden Krankheitsstadiums nachgewiesen. Gesunde adulte Tiere zeigten keine oder nur vereinzelt ein schwaches P2X4-Immunosignal der Motoneurone. Dieses Expressionsmuster im Mausmodell ist mit den Befunden von Casanovas et al. 2008 im transgenen Rattenmodell übereinstimmend. Der prinzipiell subjektive mikroskopische Befund konnte in der vorliegenden Arbeit in Anlehnung an die Veröffentlichung von Varma et al. (2009) durch die semiquantitative Methode der Fluoreszenzintensitätsmessung objektiviert werden. Man kann begründet annehmen, dass diese P2X4Expression eine spezifische Veränderung bei ALS darstellt. Diese Annahme wird dadurch gestützt, dass die Stärke des P2X4-Immunosignal mit morphologischen Schädigungszeichen der einzelnen Nervenzelle korreliert sowie im chronologischen Krankheitsverlauf abhängig vom Krankheitsstadium zunimmt, wobei die Motoneurone des Krankheitsstadium 3 ein schwächeres P2X4Immunosignal zeigten; dieses lässt sich durch den Zellverlust im Rahmen der fortgeschrittenen Degeneration erklären. Auch diese Beobachtung ist übereinstimmend mit den Ergebnissen am Rattenmodell von Casanovas et al. (2008). Nach diesen Befunden ist der zeitliche Verlauf der P2X4-Expression mit dem Voranschreiten der klinischen Symptomatik positiv korrelierend.

Die von uns erhobenen Befunde der Hochregulation im Krankheitsverlauf und im Vergleich zum WT-Gewebe sind gleichsinnig im Western Blot erhoben worden (s. Kapitel 4.3.). Entsprechend dem Stadienverlauf zeigte die spezifische Bande bei $58 \mathrm{kD}$ einen zunehmenden Verlauf. Die Tatsache, dass sich die Hochregulation des Rezeptors nicht durch ein deutlich stärkeres Bandensignal darstellte, entsprechend der Signalexpression der einzelnen Nervenzelle in der immunhistochemischen Untersuchung, ist vermutlich der parallel ablaufenden neuronalen Degeneration und gesamten Reduktion der Zellzahl geschuldet. Naturgemäß handelt es sich hierbei um Summations-Banden von Motoneuron- und Glia-Signal. 
Neben den Neuronen zeigten auch Gliazellen eine Hochregulation des P2X4Rezeptors in der Immunhistochemie. Diese Veränderung war beschränkt auf die "region of interest" (Lamina 9; s. Abb. 3), d.h. auf die unmittelbarer Nähe von P2X4-positiven Motoneuronen. Überwiegend handelte es sich um P2X4-positive Mikroglia, wie durch Doppelmarkierung nachgewiesen werden konnte. Mit GFAP markierte Astrozyten zeigten nur selten eine Detektion durch den Anti-P2X4Antikörper, fanden sich jedoch auch in der Umgebung von positiven Motoneuronen. Hernandez et al. konnten ebenfalls eine Gliose, also eine Vermehrung von Gliazellen in räumlicher Nähe von P2X4-positiven Motoneuronen zeigen, jedoch stellten sich dort die Mikroglia ohne P2X4-Immunosignal dar (Hernandez et al. 2010). Der fehlende Nachweis des positiven P2X4-Imunosignals auf Mikroglia könnte durch Verwendung eines anderen Antikörpers verursacht sein. Auf die Bedeutung dieser räumlichen Beziehung wird weiter unten in der Diskussion eingegangen (s. Kapitel 5.3.).

Entsprechend dem Tierversuch ist der Befund der vorliegenden Arbeit am humanen Material. In der untersuchten Kasuistik zeigten sich numerisch reduzierte Motoneurone mit deutlich positivem P2X4-Signal. In räumlicher Nähe befanden sich aktivierte Mikrogliazellen, welche ebenfalls ein positives P2X4-Signal zeigten. Das Rückenmarks-gesunde Probenmaterial zeigte keine spezifische P2X4Markierung.

Vergleichsuntersuchungen der P2X4-Expression im humanen ZNS liegen in der Literatur nicht vor. Zwar wurden P2X4-Rezeptoren häufig im Tiermodell mit dem hier verwendeten Antikörper dargestellt (Yamamoto 2006, Sonin 2008). An humanem ALS-Gewebe liegen aber keine entsprechenden Untersuchungen vor. Es wäre wünschenswert, dass zukünftig bei Autopsien gezielt die Rezeptordarstellung erfolgt. 


\subsection{ZUR ROLLE DER P2X4-EXPRESSION IN DER PATHOPHYSIOLOGIE NEUROGENER SCHÄDIGUNG}

Die Beteiligung des P2X4-Rezeptors ist häufig bei zentralnervöser Schädigung/ Erkrankung nachgewiesen, überwiegend durch eine Hochregulation des Rezeptors (Franke und Illes 2006, Trang et al. 2006). Damit ist die vermehrte Expression von P2X4-Rezeptoren auf geschädigten Neuronen kein spezifisches Phänomen der Pathogenese der ALS, sondern Ausdruck einer allgemeinen Zellreaktion bei vielen ZNS-Erkrankungen. Schwab et al. (2005) halten sie für eine generelle Antwort der Nervenzelle auf pathologische Vorgänge.

Schwiebert et al. (2005) vermuten, dass P2X4-Rezeptoren eine Art Sensorfunktion für die exprimierende Zelle haben, durch die Informationen über die Beschaffenheit und eventuellen Veränderungen des extrazellulären Milieus an die Zelle weitergegeben werden. In diesem Sinne deuten Sonin et al. (2008) die vermehrte Expression des Rezeptors von Myokardischämien am Mausmodell als protektives Phänomen. Die Hochregulation des P2X4-Rezeptors scheint auch eine in der Krankheit notwendigen Aufräum- und Reparaturreaktionen, wie z.B. die Ausschüttung von Zytokinen und Mikrogliose in Gang zu setzen (s. u.). Man geht davon aus, dass die Überexpression des P2X4-Rezeptors ein frühes Zeichen einer neuronalen Stressreaktion ist (Franke und Illes 2006, Inoue 2008). Es stellt sich hier allerdings die Frage, inwiefern dieses P2X4-Signal bestimmend ist, ob die folgende Reaktion protektiv ist oder den Abbau der reagierenden Zelle einleitet. Experimentelle Befunde bei Untersuchungen an Chimären deuten auf eine aktive Rolle der Glia bei der Initiierung des Krankheitsprozesses hin (Boillée 2006b).

Da es sich bei dem Rezeptor um einen lonenkanal handelt, der auch den Calciumeinstrom reguliert, ist vorstellbar, dass es durch einen vermehrten loneneinstrom im hochregulierten Kanal $\mathrm{zu}$ einer intrazellulären CalciumAkkumulation kommt, in deren Folge der Zelltod eintritt. Die Untersuchungen dazu haben allerdings gegensätzliche Ergebnisse erbracht: Roy et al. (1998) fanden in einem in vitro-mSOD1-Modell einen intrazellulären Calciumanstieg nach Hochregulation des Rezeptors mit nachfolgendem Zelltod. Entsprechend konnten sie einen Zelluntergang durch die Zugabe eines Calciumbindenden Proteins 
verhindern. Nach ihrer Interpretation erklärt dieser Befund auch den selektiven Untergang von Motoneuronen bei ALS, da diese im Gegensatz zu im Krankheitsverlauf nicht betroffenen motorischen Hirnnervenkernen dieses Calciumbindende Protein nicht exprimieren. Andere Autoren (Schwiebert et al. 2005, Franke und Illes 2006, Trang et al. 2006) gehen davon aus, dass geschädigte Motoneurone durch die Hochregulation des P2X4-Rezeptors und durch intrazellulären $\mathrm{Ca}^{++}$-Influx zunächst ein „rescue“ versuchen als interzelluläres Signal an neuroinflammatorische Zellen. Im Verlauf dieses Prozesses rücken jedoch pro-degenerative Aspekte in den Vordergrund, die insbesondere einen ungesteuerten $\mathrm{Ca}^{++}$-load beinhalten .

Im Widerspruch dazu stehen die bzgl. dieser Fragestellung kürzlich gewonnenen Befunde von Hernandez et al. (2010). In Messungen mit Hilfe der Patch-ClampMethode an Motoneuronen mit hochreguliertem P2X4-Rezeptor konnte kein erhöhter intrazellulärer Calciumspiegel gemessen werden. Sie schließen aus dieser Beobachtung, dass es sich bei dem hochregulierten P2X4-Rezeptor um einen dysfunktionalen lonenkanal handelt.

Unabhängig von dieser unsicheren Datenlage bezüglich der Pathophysiologie ist der morphologische Befund gesichert. Alle Arbeitsgruppen haben eine Hochregulation des P2X4-Rezeptors im SOD ${ }^{\mathrm{G} 93 \mathrm{~A}}$-Maus- und Rattenmodell gefunden. In der vorliegenden Arbeit konnte dieser Befund erstmals auch in der humanen Kasuistik erhoben bzw. bestätigt werden. Diese P2X4-Hochregulation kann als zellulärer Marker für die Affektion des Motoneurons im Rahmen der ALS gelten, auch wenn ihr Stellenwert in der ALS-Pathogenese noch unklar bleibt. Damit steht sie in einer Reihe mit der SOD1-Mutation des SOD-Enzyms und den Eiweiß-Praezipitaten in erkrankten Ganglienzellen (z.B. Bunina-Körperchen). 


\subsection{ZUR BEDEUTUNG DER HOCHREGULATION VON P2X4-REZEPTOREN AUF MIKROGLIA- ZELLEN}

Mikrogliazellen und Makrophagen spielen die Schlüsselrolle in den Vorgängen der Chemotaxis und Phagozytose. Ihre pathophysiologische Bedeutung ist insbesondere bei Erkrankungen wie der peripheren Neuropathie und der Schmerzentstehung untersucht (Simard und Rivest 2006, Trang et al. 2006).

Es ist mehrfach gezeigt worden, dass neuroinflammatorische Prozesse u. a. durch die ATP-Stimulation von Purin-Rezeptoren auf Motoneuronen und Gliazellen initiiert bzw. vermittelt werden (Gu und Macdermott 1997. Fricker-Gates 2006, Dibaj et al. 2010). Besondere Bedeutung hat die Neuron-Glia-Interaktion im Rahmen der Tripartite-Synapsen, bei der ATP von Astrozyten-Fortsätzen an Synapsen freigesetzt wird und die Glia damit direkten Einfluss auf die synaptische Aktivität nehmen kann. Dies stellt eine neue Form der neuronalen-glialen Interaktion und Kommunikation dar.

Im SOD1-Modell der ALS wird allgemein angenommen, dass die Krankheit durch die Mutation des Enzyms im Motoneuron initiiert wird, in dem folgenden Prozess der neuronalen Degeneration und des motoneuronalen Untergangs aber nichtneuronale Zellen involviert sind. In der vorliegenden Arbeit konnten wir zeigen, dass aktivierte Mikrogliazellen ein positives P2X4-Immunosignal exprimierten und sich zu der Zeit der stärksten neuronalen P2X4-Expression, im Stadium 2, in amöboider, aktivierter Morphologie und in räumlicher Nähe zu den betroffenen, P2X4-positiven Nervenzellen darstellten (Mikrogliose). Die Anzahl der markierten Gliazellen erhöhte sich korrelierend mit dem chronologischen Krankheitsverlauf und war im Stadium 3 am höchsten. Neben den durch Anti-P2X4-Antikörper markierten Mikroglia fanden sich auch vereinzelt P2X4-positive Astrozyten. Diese Beobachtung bestätigt die Vermutung, dass die Hochregulation des P2X4Rezeptors im kranken Gewebe im Zusammenhang mit Mikro- sowie Astrogliose zum selben Zeitpunkt steht. Unsere Arbeitsgruppe konnte in einem in-vivo Ansatz des mSOD1-Mausmodells zeigen, dass hier eine Mikroglia-vermittelte Inflammation des ZNS vorliegt und diese in zwei Phasen unterteilt werden kann: während die Mikrogliazellen im präklinischen Stadium mit morphologischen 
Veränderungen und der verstärkten Migration zu einer Laser-induzierten axonalen Läsion im lumbalen Rückenmark (anders als die Mikroglia im WT-Gewebe) reagierten, konnte in klinischen Stadien beobachtet werden, dass Mikroglia die zielgerichtete Antwort verloren; allerdings wurde eine unkontrollierte Aktivität wie Phagozytose von nicht-betroffenem Gewebe beobachtet (Dibaj et al. 2011). Auch andere Untersucher bestätigen, dass eine fortschreitende MotoneuronDegeneration bei ALS von den Mikroglia beeinflusst wird (Clement et al. 2003, Beers et al. 2006, Boillee et al. 2006b, Fricker-Gates 2006, Moisse und Strong 2006).

Mikroglia exprimieren v. a. die ATP-Rezeptoren P2X4, P2X7 und P2Y12 und sind durch die Ausschüttung von neurotrophen Zytokinen wie NGF (neurotrophic growth factor), BDNF (brain-derived neurotrophic factor) oder Plasminogen an der Reparation und Heilung von geschädigtem Gewebe des ZNS beteiligt. Insbesondere Plasminogen (Nakajima und Kohsaka 1993) und Interleukin-6 (II-6) haben einen großen Einfluss auf die Regulation und Erhaltung der Neurone (Umegaki et al. 1996).

Aktivierte Mikroglia sezernieren allerdings auch toxische Stoffe wie Stickstoffmonoxid (NO), die die Apoptose in geschädigten Nervenzellen induzieren können (Beers et al. 2006, Dibaj et al. 2010).

Die Untersuchungen von Inoue (2002) zeigten, dass ATP in unterschiedlichen Konzentrationen protektive als auch neurotoxische Reaktionen der Mikroglia induziert und die Vorbehandlung der Mikrogliazellen mit oxidiertem ATP, welches als selektiver P2X7-Antagonist fungiert, sowohl den ATP-vermittelten CalciumEinstrom als auch die Aktivierung der Mikroglia verhindert. In die gleiche Richtung weist die Blockade-Untersuchung von Hollopeter et al., die zeigen konnte, dass der Anstoß zur amöboiden Bewegung ebenfalls durch die Reaktion von ATP mit einem Purin-Rezeptor vermittelt zu sein scheint, denn bei den Zellen, die mit einem P2Y12-Blocker wie Pertussistoxin vorbehandelt wurden blieb die morphologische Veränderung aus (Hollopeter et al. 2001). Man kann also begründet annehmen, dass diese Reaktionen durch glial exprimierte Purin-Rezeptoren vermittelt werden. Ebenso scheint die durch NO-induzierte Mikroglia-Reaktion, die von unserer Arbeitsgruppe nachgewiesen wurde (Dibaj 2010) ATP- und Purin-Rezeptor vermittelt.

Auch die Untersuchungen von Boilée et al. (2006a, 2006b) zeigten, dass die 
aktivierte Mikroglia einen großen Anteil am neuronalen Zelltod und an der Pathogenese der ALS hat, die durch Reduktion von mSOD1 in der Mikroglia positiv verändert werden kann. In Übereinstimmung damit sind die Untersuchungen von Beers et al. (2006), dass die mikrogliale Expression von mSOD1 in einer Zellaktivierung und erhöhten Produktion von neurotoxischen Stoffen resultierte.

Andere Untersucher weisen dagegen auf eine mögliche protektive Funktion der Glia-Reaktion im mSOD1-Modell hin, da sie zeigen konnten, dass das Überleben von mSOD1-Motoneuronen verlängert wird wenn sie mit WT-Gliazellen zusammen gebracht werden (Clement et al. 2003, Yamanaka et al. 2008). Allerdings muss man sich fragen, ob die Glia-Reaktion einen wirklichen protektiven Charakter hat oder die Überlebenszeit der Nervenzellen sich nur durch die Abwesenheit von einer aus der Mutation resultierten schädigenden Reaktion verlängert.

Die Ergebnisse der o. g. Studien weisen insgesamt auf einen negativen Einfluss einer frühen und verstärkten Neuroinflammation im ALS-Maus- und Rattenmodell auf das motoneuronale Überleben hin. Es ist anzunehmen, dass Gliazellen durch die Freisetzung von Zytokinen und Enzymen aktiv am neurodegenerativen Prozess teilnehmen. Dies ergänzt das Wissen über die Pathophysiologie der ALS um die Tatsache, dass neben dem neurodegenerativen Geschehen eine inflammatorische Reaktion vorliegt (Almer 2003, Dhib-Jalbut et al. 2006).

Sowohl im menschlichen kranken Gewebe als auch im entsprechenden MausModell konnte in der vorgelegten Arbeit die Kolokalisation des P2X4-Rezeptors auf Mikrogliazellen und Subpopulationen von Astrozyten nachgewiesen werden. Es wird hier erstmals gezeigt, dass dem P2X4-Rezeptor in dem Prozess der Neurodegeneration eine Rolle zukommen könnte.

Im Widerspruch zu unseren Beobachtungen stehen die kürzlich veröffentlichten Untersuchungen von Hernandez et al., die keine P2X4-Expression auf Mikroglia nachweisen konnten (Hernandez et al. 2010). Da es sich bei unserem Untersuchungsansatz um einen qualitativ immunhistologischen Befund handelt, haben wir zur funktionellen Bedeutung bzw. Pathophysiologie des glial exprimierten P2X4-Rezeptors in der ALS keine Befunde.

Das tiefere Verständnis dieser funktionalen Rolle des glial exprimierten P2X4Rezeptors, sei sie neuroprotektiver oder zelltoxischer Art, könnte ein möglicher Ansatzpunkt in der therapeutischen Beeinflussung des Krankheitsverlaufs sein unabhängig von der auslösenden Krankheitsursache. 


\subsection{DIE P2X4-EXPRESSION IN HUMANEM ALS- GEWEBE}

P2X4-Rezeptoren sind ubiquitär im ZNS sowohl auf Neuronen als auch auf Gliazellen vorhanden (Burnstock und Knight 2004). Der Rezeptor ist vorzugsweise auf postsynaptischen Strukturen lokalisiert. Dort formt er homomere sowie heteromere Kanäle, die auf die synaptische Aktivität und Transmission Einfluss nehmen (Rubio und Soto 2001, Roberts et al. 2006). Die Calciumpermeabilität des

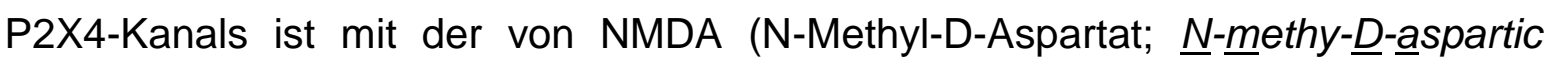
acid)-Kanälen, Glutamatkanälen, vergleichbar. Deren Beteiligung an pathologischen zentralen Prozessen und Erkrankungen ist weitläufig bekannt und lässt die Vermutung zu, dass auch die im ZNS lokalisierten Purin-Rezeptoren eine wichtige Rolle in der Regulation des neuronalen Überlebens haben (Koshimizu et al. 2000). Tatsächlich häufen sich die Hinweise dafür, dass dysfunktionale PurinRezeptoren am neuronalen Zelltod beteiligt sind (Cavaliere et al. 2001a und 2001b, Casanovas et al. 2008). Bisher gibt es allerdings kaum Untersuchungen zur Beteiligung von P2X-Rezeptoren an neurologischen Krankheitsbildern in humanem Gewebe.

Erstmals wurde in dieser Arbeit humanes ALS-Autopsiematerial auf die Expression des Purin-Rezeptors P2X4 mit dem humangängigen P2X4-Antikörper immunhistologisch untersucht. Es wurden Rückenmarksquerschnitte von an ALSverstorbenen Patienten mit Rückenmarks-Gesunden verglichen. In der humanen Untersuchung zeigte sich prinzipiell dasselbe Ergebnis wie im Tierversuch: Im ALS-Gewebe stellte sich ein deutliches P2X4-Immunosignal auf degenerierenden Motoneuronen und beteiligten Mikrogliazellen dar, während das Kontrollgewebe kein entsprechendes Signal aufwies. Eine weitergehende topographische Zuordnung der Signalexpression ist leider aufgrund autoptischer Artefaktbildung im humanen Gewebe nicht gelungen. Die eindeutige Verteilung des Signals spricht jedoch dafür, dass es sich um die gleichen spezifischen Veränderungen handelt, wie im SOD1-Mausmodell gezeigt werden konnte.

Untersuchungen des Zusammenhangs zwischen der P2X4-Expression und neurodegenerativen Erkrankungen gibt es bis jetzt nur an Alzheimer-Patienten. Varma et al. untersuchten die Beteiligung des P2X4-Rezeptors an dem neuronalen 
Zelltod i. R. der Alzheimer-Krankheit (Varma et al. 2009). Tatsächlich berichtet die erwähnte Veröffentlichung über erniedrigte P2X4-Werte im Gyrus frontalis medius und Gyrus temporalis medius von schwer betroffenen Alzheimer-Patienten. $\beta$ Amyloid beeinträchtigt u. a. die Depolarisationsschwelle und erhöht die Vulnerabiliät von Neuronen durch Erhöhung des Glutamat-vermittelten Calciumeinstroms. Es kann vermutet werden, dass auch andere Calcium-Kanäle, z. B. P2X4, zu dem $\beta$-Amyloid-induzierten Zelltod beitragen. Diese Annahme konnten Varma et al. im Tierversuch in einem in vitro-Ansatz belegen. Auf Hippocampus-Neuronen führte Amyloid- $\beta$ zunächst zu einer signifikanten Zunahe des P2X4-Signals (Hochregulation). Dieser Befund wurde in der Pixelintensitätsmessung quantifiziert und im Western Blot bestätigt. Basierend auf dem Wissen darüber, dass $\beta$-Amyloid in der Lage ist, die Aktivität der Caspase-3 zu induzieren sowie darüber, dass der P2X4-Rezeptor der einzige P2X-Subtyp ist, der eine "Caspase-cleavage-site" , also einen Angriffspunkt auf dem C-Terminus (AS 271-274) aufweist, konnte die Arbeitsgruppe des Weiteren im Rattenmodell beobachten, dass $\beta$-Amyloid durch Aktivierung der Caspase-3 die Aktivierung durch bzw. Reaktion des Purin-Rezeptors mit dem Agonisten ATP reduzierte.

Funktionell zeigte sich eine $\beta$-Amyloid-induzierte Modifikation der molekularen Struktur des P2X4-Kanals, die zu einer verlängerten Öffnungsphase und damit zu einer erhöhten, letztendlich neurotoxischen, zytosolischen Calciumkonzentration führte. Durch Experimente mit P2X4-knockout-Zellkulturen konnten Varma et al. gegenteilig beobachten, dass der neurotoxische Effekt von $\beta$-Amyloid in diesem Gewebe reduziert wurde.

Dieses Ergebnis konnte für das ALS-Modell bisher nicht reproduziert werden. Eine erhöhte P2X4-Expression zeigte sich nicht korrelierend mit einer erhöhten Calciumkonzentration (Hernandez et al. 2010).

Die erwähnten Untersuchungen belegen die Bedeutung des P2X4-Rezeptors in der Pathogenese einer neurodegenerativen Erkrankung bei Menschen und unterstützen den von uns am humanen ALS-Gewebe erhobenen Befund. 


\subsection{IST DIE P2X4-HOCHREGULATION MIT DER MOTONEURONALEN DEGENERATION IM RAHMEN DER ALS ASSOZIIERT?}

Die Hochregulation des P2X4-Kanals auf den Somata der Motoneurone des ALSMausmodells ließ sich in der vorliegenden Dissertation schon zu frühen Zeitpunkten des klinischen Verlaufs (Stadium 1) nachweisen, was die Assoziation der Expression des Purin-Rezeptors mit motoneuronaler Dysfunktion bzw. dem Untergang von Motoneuronen nahelegt.

Untersuchungen der Motoneurone im transgenen ALS-Mausmodell ergaben andernorts, dass die von Degeneration betroffenen Nervenzellen nur selten Apoptose-typische Merkmale, also zytoplasmatische Vakuolen, kondensiertes Chromatin und/ oder Schwellung der Zellorganellen aufwiesen. Definitiv apoptotische Neurone fanden sich selbst im Zellbild von „end-stage“-Tieren nur selten (Guegan und Przedborski 2003). Auch jüngst vorausgegangene Veröffentlichungen (Martin et al. 2007, Casanovas et al. 2008) zeigten, dass der Hauptteil der betroffenen Motoneurone des mSOD1-Mausmodells keine weiteren Eigenschaften der neuronalen Degeneration (wie z. B. vermehrte CaspaseAktivität und andere Apoptose-Eigenschaften) demonstrierte.

Typische Expressionsmuster des programmierten Zelltods (PCD: programmed cell death), wie das Protein Bax, das als Ko-Faktor des Tumorsupressorgens p53 fungiert, oder die Expression von Caspasen, wichtige Enzyme der Apoptose, wurden zwar in ALS-Rückenmarksgewebe gefunden, jedoch waren diese nicht immer Motoneuronen-zugehörig (Pasinelli et al. 2000, Vukosavic 2000). Die Wichtigkeit der Beteiligung der Caspasen bei der neuronalen Degeneration wurde allerdings durch das Ergebnis einer Studie deutlich, die zeigte, dass die Blockierung des Enzyms eine Verlängerung der Überlebenszeit von mSOD1Mäusen zur Folge hatte (Li M et al. 2000).

Einige der Enzym-Unterformen wurden auch im WT-Gewebe, bzw. nichtdegenerierenden Nervenzellen nachgewiesen (Guegan und Przedborski 2003) und Gould et al. (2006) relativierten die Wichtigkeit der Apoptose im Rahmen der fALS zusätzlich, indem sie zeigten, dass die Krankheit weiter fortschritt, obwohl der neuronale Zelltod durch Hemmung des Apoptose-Proteins Bax verhindert wurde. 
Es besteht im Allgemeinen ein Konsens darüber, dass sich Zellen von ALSGewebe im Prozess des programmierten Zelltods befinden können, obwohl sie keine morphologischen Anzeichen der Apoptose aufweisen (Guegan und Przedborski 2003), was in der vorliegenden Arbeit insofern nachvollzogen werden konnte, als dass der Großteil der P2X4-exprimierenden Neurone - im mittleren Stadium des Krankheitsverlaufs - auch noch von dem hier verwendeten neuronalen Marker SMI32 detektiert wurden. Dies setzt eine gewisse Intaktheit des Zellkörpers voraus. Obwohl wir beobachten konnten, dass das Immunosignal des neuronalen Markers SMI32 im Verlauf der Erkrankung abnahm, muss der Verlust des Signals nicht notwendigerweise den motoneuronalen Zelltod bedeuten, sondern die Abnahme des Neurofilaments als entsprechendes Antigen im Rahmen eines neuronalen Schadens (Unal-Cevik et al. 2004).

Wir konnten des Weiteren zeigen, dass sogar im Endstadium Motoneurone, die nur noch ein sehr schwaches SMI32-Immunosignal präsentierten, weiterhin ein starkes P2X4-Immunosignal aufweisen können. Das passt ebenfalls zu den anderweitig gewonnen Forschungsergebnissen bezüglich dem Fehlen von Apoptose-typischen Enzymen im humanen ALS-Gewebe und seinem entsprechenden Tiermodell (Guegan und Przedborski 2003) und steht außerdem im Einklang mit einer weiteren Arbeit am ALS-Rattenmodell (Casanovas et al. 2008).

Der Anti-P2X4-Antikörper markiert also die Motoneurone, die zwar geschädigt sind, jedoch noch keine Zeichen der Apoptose aufweisen. Es stellt sich die Frage, welche pathogenetischen Mechanismen genau zu dem hier beobachteten starken P2X4-Immunosignal auf Motoneuronen und Gliazellen des ALS-Gewebes führen und inwiefern das erhöhte Immunosignal den Auswirkungen der mSOD1 unterliegt bzw. mit ihnen in Beziehung steht.

Die in der vorliegenden Arbeit durchgeführte Western-Blot-Analyse zur Detektion durch den Anti-P2X4-Antikörper im transgenen Rückenmark zeigte neben den zu erwartenden Homotrimer-Banden eine Monomerbande bei etwa $20 \mathrm{kD}$. In der jüngsten Veröffentlichung von Hernandez et al. wird diese Bande ebenso durch P2X4-Antikörperbindung nachgewiesen und nach biochemischer Analyse als eine besondere Unterform, eine fehlgefaltete Form der mSOD1, angesehen (Hernandez et al. 2010). Die beobachtete immunhistochemische Kreuzreaktion wird dadurch erklärt, dass das Peptid, das zur Herstellung des P2X4-Antikörpers verwendet 
wird, sequenziell eine ähnliche Aminosäureabfolge aufweist wie eine molekulare Region der mSOD1. Dieses Epitop scheint eine hohe Affinität zu dem Anti-P2X4Antikörper zu haben. Diese Beobachtung führt zu der Überlegung, dass das P2X4Immunosignal keine Hochregulation des Purin-Rezeptors sondern mSOD1Proteine markiert. Obwohl alle Zellen des Transgen-Gewebes die mSOD1 exprimieren, passt die in der Immunhistochemie beobachtete räumliche Spezifität des P2X4-Signals zu der bei der ALS vorliegenden Pathophysiologie, nämlich des selektiven Motoneuron-Untergangs. Die in der vorliegenden Arbeit durch WesternBlot-Analyse des Transgen-Mausgewebes erhaltenen Banden höheren Gewichts (58-70kD) könnten in diesem Sinne auch auf eine Inter- bzw. Kreuzreaktion des verwendeten P2X4-Antikörpers mit anderen TG-Proteinen hinweisen.

In Hinblick auf die in 5.4. diskutierte Veröffentlichung von Varma et al. muss die Annahme, dass die von Hernandez et al. beobachtete 20kD-Bande ein Spaltprodukt des P2X4-Rezeptors darstellt, allerdings ebenfalls in Betracht gezogen werden (Varma et al. 2009).

Es ist bekannt, dass die mSOD1 mit der Ausbildung von Proteinaggregaten assoziiert ist, denen ein neurotoxischer Einfluss zugeschrieben wird (Basso et al. 2006, Wang Q et al. 2008). Diese Aggregate konnten sowohl in Neuronen als auch in Gliazellen und im extrazellulären Gewebe nachgewiesen werden (Stieber et al. 2000, Jonsson et al. 2004). Ein Antikörper, der die hier erwähnte fehlgefaltete Unterform der mSOD1 markiert (Rakhit et al. 2007) stellt nach Inkubation degenerierender Motoneurone eine gleiche Verteilung des Immunosignals wie in der vorliegenden Arbeit mit dem Anti-P2X4-Antikörper erreicht wurde dar. Aber anders als der Anti-P2X4-Antikörper detektiert dieser sog. SEDI- ( $\underline{S} O D 1$-exposeddimer-interface) Antikörper zusätzlich intraneuronale, potentiell zytotoxische, mSOD1-Aggregate. Die oben erwähnte Veröffentlichung der Hernandez-Gruppe konnte zeigen, dass diese Aggregate weder in Motoneuronen noch Gliazellen des Transgen-Gewebes durch den Anti-P2X4-Antikörper detektiert werden. Die Markierung der mSOD1 durch Anti-P2X4-Antikörper scheint also unter anderen Umständen als im Rahmen von Proteinaggregation vorzukommen. Diese Tatsache lässt vermuten, dass unterschiedliche Aggregatzustände der mSOD1 eine unterschiedliche Verteilung im ALS-Gewebe aufweisen und vermutlich über unterschiedliche Mechanismen zur Neurodegeneration beitragen (vgl. Felbecker et al. 2010). 
Diese Beobachtung sollte in Hinblick auf die kontroversen Ergebnisse in der Diskussion der zytoprotektiven (Arrasate et al. 2004, Tanaka et al. 2004) vs. zytotoxischen (Zetterstrom et al. 2007) Wirkung von intrazellulären Aggregaten im neurodegenerativen Prozess bedacht werden. Auch den bei der ALS charakteristischen eosinophilen Bunina-Körperchen gelten diese Überlegungen.

Obwohl die SOD1 primär ein zytosolisches Protein ist, konnte mittlerweile gezeigt werden, dass die mutierte Form des Enzyms teilweise über das Endoplasmatische Retikulum (ER) und den Golgi-Apparat in den extrazellulären Raum freigesetzt wird (Turner et al. 2005, Urushitani et al. 2006 und Urushitani et al. 2008).

Jüngere Veröffentlichungen diskutieren neben den "gain-of-function" Mechanismen die Wirkung von extrazellulär befindlichen mSOD1-Molekülen. Diese Untersuchungen konnten $u$. a. zeigen, dass eine erhöhte extrazelluläre Menge an mSOD1 zu der Entstehung von neuronalen Proteinaggregaten, Schädigung der Golgi-Apparate und des Endoplasmatischen Retikulums und damit zu Störungen der neuronalen Sekretion führte (Turner et al. 2005, Urushitani et al. 2006). Umgekehrt verzögerte eine intraspinale Infusion von SOD1 die Progression der neuronalen Degeneration im Mausmodell.

Außerdem ist bekannt, dass, anders als die unmutierte Form, extrazelluläre mSOD1 mit der Aktivierung von Mikrogliazellen assoziiert ist (Urushitani et al. 2007). Auch Hernandez et al. konnten zeigen, dass die Injektion von Sekret, das aus mSOD1-Rückenmark gewonnen wurde und ein positives P2X4-Immunosignal aufwies, in gesundem Gehirngewebe eine reaktive Mikrogliose induziert (Hernandez et al. 2010).

Anders als in dieser Veröffentlichung wurde aber in der vorliegenden Arbeit neben einer starken mikroglialen Rekrution in der Nähe von Motoneuronen mit positivem P2X4-Immunosignal auch ein P2X4-Immunosignal auf Mikrogliazellen des ALSGewebes beobachtet. Die oben erwähnten P2X4-positiven Banden bei 58-70kD in der Western-Blot-Untersuchung des TG-Mausgewebes könnten ihren Ursprung in P2X4-Rezeptor-exprimierenden Gliazellen haben (s. Kapitel 4.3.).

Es bleibt zu klären, ob die extrazelluläre mSOD1 alleine für den inflammatorischen Prozess verantwortlich ist - in Betrachtung der "gain-of-function"-Theorie kann sogar die Vermutung angestellt werden, dass das mutierte Protein selber als ein sog. death-signaling-molecule fungiert - oder ob die Verbindung mit einem verstärkt exprimierten jedoch dysfunktionalem P2X4-Kanal die reaktive Mikrogliose 
und folgende Neuronophagie induziert. Obwohl nicht in allen Einzelheiten geklärt, besteht weitgehender Konsens darüber, dass die Mikrogliose ein pathogenetischer Faktor der Erkrankung ALS und ihrer Progression in späteren Stadien ist (Beers et al. 2006, Boillée et al. 2006b, Xiao et al. 2007). Die Reduktion extrazellulärer mSOD1 durch immunmodulatorische Medikamente z. B. bewirkte im ALSTiermodell schon eine verlängerte Überlebenszeit der mSOD1-Mäuse (Urushitani et al. 2008).

Die in der vorliegenden Dissertation gemachten Beobachtungen und gewonnenen Erkenntnisse über Veränderungen in Morphologie, Expressions- und Färbeverhalten von Motoneuronen und Gliazellen in Korrelation zur Expression von P2X4-Rezeptoren im ALS-Gewebe unterstützen die Annahme einer pathogenetisch relevanten Mikrogliose.

Die vorliegende Untersuchung der Expression und Regulation des P2X4Rezeptors auf Motoneuronen und Gliazellen im ALS-Rückenmark sollte der Gewinnung von Kenntnissen über die Zelldegeneration und Pathophysiologie dieser Erkrankung dienen. Das therapeutische Potential der durch PurinRezeptoren vermittelte Signaltransduktion ist hier von besonderem Interesse.

Neben den oben erläuterten Erkenntnissen zur Beteiligung des untersuchten Purin-Rezeptors an dem neuronalen Untergang sowie der reaktiven Gliose im Rahmen der ALS wurde in der vorliegenden Dissertation keine Untersuchung zur Veränderung der intrazellulären Calciumkonzentration während des Zelluntergangs durchgeführt. Die Analyse der Konzentrationsänderungen von intrazellulärem Calcium erbrachte in einer jüngeren Publikation allerdings, dass der CalciumEinstrom in mSOD1-Neuronen im Vergleich zu Kontroll-Gewebe geringer war (Hernandez et al. 2010). Sowohl in der immunhistochemischen Untersuchung als auch im Western Blot konnte in der vorliegenden Arbeit eine kontinuierliche Zunahme der P2X4-Expression im ALS-Gewebe gezeigt werden. Diese Beobachtung legt den Schluss nahe, dass eine Hochregulation des P2X4-Kanals in der Pathophysiologie der ALS andere Funktionen als die Kontrolle des CalciumEinstroms hat oder dass es sich um eine verstärkte Expression eines dysfunktionalen lonenkanals handelt. In Anlehnung an die Veröffentlichung von Hernandez et al. und Varma et al. (2009) und deren widersprüchlichen Ergebnissen bezüglich der intraneuronalen Calciumkonzentration im ALS- vs. 
Alzheimer-Tiermodell müssen weitere Untersuchungen folgen um abschätzen zu können, ob ein erhöhter zytosolischer Calciumspiegel letztendlich eine pathophysiologische Ursache des neuronalen Zelltods im Rahmen der ALS ist.

Indes konnte gezeigt werden, dass der Anti-P2X4-Antikörper zur Detektion von dysfunktionalen und untergehenden Motoneuronen sowie reaktiven Mikroglia in humanem ALS-Rückenmarksgewebe angewendet werden kann.

Die Verwendung des Anti-P2X4-Antikörpers liefert ein Instrument zur Identifikation geschädigter Motoneurone und ermöglicht damit die genauere und weiterführende Untersuchung der neuronalen Pathologie und der Rolle des purinergen Systems im Rahmen dieser Erkrankung. Diese Eigenschaft des Antikörpers macht die Darstellung der Dimension des neuronalen Schadens durch u. a. zusätzliches Anfärben der Zellfortsätze und damit die Darstellung der umfangreichen sowie weitreichenden destruierenden Wirkung schon in den Anfangsstadien der ALS möglich.

Des Weiteren konnte diese Arbeit zeigen, dass das hier beobachtete Verteilungsund Expressionsmuster des P2X4-Immunosignals im ALS-Gewebe mit der Schwere und dem Verlauf der Klinik korreliert. Das Voranschreiten der neuronalen Degeneration im Krankheitsverlauf kann so eindeutiger dokumentiert werden.

Es bleibt allerdings zu klären, inwiefern die Expression des P2X4-Kanals mit den Auswirkungen der mSOD1 in Beziehung steht bzw. innen unterliegt. Sollte sich herausstellen, dass die reaktive Mikrogliose von einer Wechselwirkung des mutierten Enzyms und dem dysfunktionalen P2X4-Rezeptor induziert wird, erscheint der Versuch gezielt in das Zusammenwirken zwischen P2X4-Kanal, Mikroglia und untergehenden Motoneuronen einzugreifen, vielversprechend. Die reaktive Mikrogliose stellt schon länger einen potentiellen Angriffspunkt zur Entwicklung von Therapiestrategien.

Die Antagonisierung des Rezeptors und die folglich ausbleibenden Gewebs- und Entzündungsreaktionen könnte das Fortschreiten der Krankheit verlangsamen bzw. die klinische Symptomatik abschwächen. 


\section{ZUSAMMENFASSUNG}

Die derzeitigen Kenntnisse zur Pathogenese der Amyotrophen Lateralsklerose (ALS) stützen sich auf Untersuchungen von transgenen Mäusen, die Mutationen im humanen Cu/Zn-Superoxid-Dismutase (mSOD1)-Gen tragen und ein etabliertes Modell für die familiäre Form der ALS darstellen. Purinerge (ATP-) Rezeptoren steuern durch intrazelluläre $(\mathrm{n}) \mathrm{Ca}^{++}$-Einstrom und -Freisetzung sowohl Aktivität und Motilität von Mikroglia-Zellen als auch $\mathrm{Ca}^{++}$-abhängige Prozesse und das Membranpotential in Motoneuronen. Die Rolle von Purin-Rezeptoren in der Pathogenese der ALS ist bisher nicht geklärt. Wir untersuchten Paraffineingebettete Rückenmarksschnitte von Wildtyp- und SOD1 ${ }^{\text {G93A-Mäusen }}$ immunhistochemisch auf die Expression des liganden-gesteuerten P2X4-PurinRezeptors zu unterschiedlichen Krankheits-Zeitpunkten. Eine Western-BlotAnalyse sowie die Messung und Auswertung der Pixelintensität wurde zur (semi-) quantitativen Bestimmung der Rezeptorexpression durchgeführt. Zusätzlich wurde humanes postmortales Rückenmarksgewebe zur Expressionsanalyse des P2X4Rezeptors untersucht. In Wildtyp-Mausgewebe fand sich eine schwache Expression von P2X4-Rezeptoren in Motoneuronen der grauen Substanz während der postnatalen Entwicklung; das entsprechende immunhistochemische Signal zeigte sich in der Folge hochreguliert. In SOD1 ${ }^{\text {G93A }}$-transgenen Mäusen zeigte sich im Vergleich zu Kontrollen eine verstärkte Expression von P2X4-Rezeptoren auf Motoneuronen, Axonen sowie in der Vorderwurzel des Rückenmarks, insbesondere auf morphologisch bereits geschädigten Zellen. Eine Hochregulation auf Mikrogliazellen im Rahmen der Mikrogliose wurde ebenfalls beobachtet. In der Western-Blot-Analyse fand sich eine verstärkte Expression von P2X4-Monomeren im Krankheitsverlauf. In humanem Rückenmarksgewebe von postmortalem Kontroll- und ALS-Gewebe ließen sich die Befunde der Expressionsanalyse von P2X4 aus dem Mausmodell reproduzieren. Die Hochregulation von P2X4Rezeptoren auf Motoneuronen während des Krankheitsverlaufs korreliert mit morphologischen Schädigungszeichen von Motoneuronen und kann als Marker für geschädigte Motoneurone eingesetzt werden. Unter funktionellen Aspekten ist die Hochregulation von P2X4 möglicherweise die Folge einer lokalen, extrazellulären ATP-Erhöhung mit konsekutiver Membrandepolarisation und intrazellulärem $\mathrm{Ca}^{++}$Influx und in einen vermutlich vorliegenden inflammatorischen Aspekt der neuronalen Degeneration i. R. der ALS involviert. 


\section{ANHANG}

\subsection{ABKÜRZUNGSVERZEICHNIS}

$\AA \AA$ Ångström ( $10^{-10}$ Meter $)$

Abb Abbildung

ADP Adenosindiphosphat

Ak Antikörper

ALS Amyotrophe Lateralsklerose

AMP Adenosinmonophosphat

APS Ammoniumperoxodisulfat

ATP Adenosintriphosphat

Aq. dest. destilliertes Wasser

BDNF Brain derived neurotrophic factor

cAMP zyklische Adenylatzyklase

cCT kraniale Computertomographie

d Tag(e); days

d. F. der Fälle

DAPI Diaminophenylindol

DNS Desoxyribonukleinsäure

DTT Dithiotreitol

ECL enhanced chemoluminescence

EMG Elektromyographie

ENG Elektroneurographie

EPSC excitatory postsynaptic currents

ER Endoplasmatisches Retikulum

EtOH Ethanol 
fALS familiäre ALS

GABA Y-Aminobuttersäure

GFAP saures Gliafaserprotein; glial fibrillary acidic protein

h Stunde (hour), human (Vorkommen z.B. in hSOD1)

HBSS Hank`s gepufferte Salzlösung; Hank`s buffered salt solution

$\mathrm{HCl} \quad$ Salzsäure (37\%ige Lösung von Chlorwasserstoff in Wasser)

HRP Meerrettich-Peroxidase; horse radish peroxidase

$\mathrm{HZ} \quad$ heterozygot

Ig Immunglobulin

IL Interleukin

iNOS inducible nitric oxide synthase

kD Kilodalton

LP Ladepuffer

M $\quad$ Molar $=\mathrm{mol} / \mathrm{l}$

M. Musculus

MCSF Monozyten-Kolonie - stimulierender Faktor

MG Mikroglia

MN Motoneuron

MSAP Muskelsummenaktionspotenzial

mSOD1 mutierte SOD1

n Anzahl

$\mathrm{NaCl} \quad$ Natriumchlorid

NANC non-adrenergic, non-cholinergic

NGS normal goat serum

NLG Nervenleitgeschwindigkeit 
P Postnataler Tag

PAGE Polyacrylamidgelelektrophorese

PBS phosphatgepufferte Salzlösung; phosphate buffered saline

PCR Polymerase-Kettenreaktion; polymerase chain reaction

$\mathrm{pH} \quad$ negativer dekadischer Logarithmus der Protonenkonzentration

PMI Postmortalintervall

RT Raumtemperatur

SALS sporadische ALS

SDS Natriumdodezylsulfat; sodiumdodecylsulfate

SOD Superoxiddismutase

Tab. Tabelle

TBS Tris(hydroxymethyl)-aminomethan, gepuffert

TBS-T Tris(hydroxy)aminomethan + Tween20

TEMED N,N,N',N'-Tetra-Methyl-Ethylen-Diamin

TG Transgen

TNF Tumornekrosefaktor

Tris Tris(hydroxymethyl)-aminomethan

Tween20 Polysorbat 20 (nichtionisches Tensid)

ÜZ Überlebenszeit

V Volumen; Volume (Gehaltsanteil)

W Gewicht; Weight (Gehaltsanteil)

WB Western-Blot

WBP Westernblot-(Lyse-) puffer

WT Wildtyp 


\subsection{ABBILDUNGSVERZEICHNIS}

Abb. 1; S. 4: Charakteristische Autopsiebefunde im humanen ALSRückenmarksgewebe (Histologie)

Abb. 2; S. 21: Schematische Darstellung des P2X4-Rezeptors

Abb. 3; S. 54: Abbildung von Rückenmarksquerschnitt (Maus, Wildtyp) (Immunhistochemie)

Abb. 4; S. 57: Zeitverlauf der P2X4-Expression im Rückenmark von WildtypMäusen (Immunhistochemie)

Abb. 5; S. 57: Western-Blot-Analyse von P2X4-inkubiertem Maus-Rückenmarksgewebe

Abb. 6; S. 57: Zeitverlauf der P2X4-Expression im Rückenmark von transgenen Mäusen (Immunhistochemie)

Abb. 7; S. 59: Hochregulation des P2X4-Kanals auf Fasern der ventralen RMWurzel sowie Illustration der Kolokalisation auf neuronenzugehörigen Fasern (Immunhistochemie)

Abb. 8; S. 61: Zellspezifische Expression des P2X4-Kanals auf Motoneuronen (Immunhistochemie)

Abb. 9; S. 63: Kolokalisation des P2X4-Kanals auf Mikroglia (Immunhistochemie)

Abb. 10; S. 65: Astrogliose im Krankheitsverlauf (Immunhistochemie) 
Abb. 11; S. 67: Zellspezifische Expression des P2X4-Kanals auf humanen Motoneuronen sowie des neuronalen Untergangs im Kryogewebeschnitt (Immunhistochemie)

Abb. 12; S. 67: Zellspezifische Expression des P2X4-Kanals auf humanen Motoneuronen sowie des neuronalen Untergangs im Kryogewebeschnitt (Immunhistochemie)

Abb. 13; S. 69: Mikrogliose in humanem Gewebe sowie der Kolokalisation des P2X4-Kanals auf humanen Mikrogliazellen im Kryogewebeschnitt (Immunhistochemie)

Abb. 14; S. 70: Mikrogliose in humanem Gewebe sowie der Kolokalisation des P2X4-Kanals auf humanen Mikrogliazellen in Paraffin-fixiertem Gewebe (Immunhistochemie)

Abb. 15; S. 72: Fluoreszenzintensität des P2X4-Signals im Mausmodell (Wildtypversus Transgengewebe)

Abb. 16; S. 74: Western-Blot-Analyse von Wildtyp- versus Transgengewebe (Stadium 1) (Rückenmark Maus) 


\subsection{TABELLENVERZEICHNIS}

Tab. 1; S. 7: El-Escorial-Kriterien zur Diagnostik der ALS

Tab. 2; S. 18: Die Purin-Rezeptoren

Tab. 3; S. 36: verwendete Verbrauchsmaterialien

Tab. 4; S. 37: verwendete Geräte

Tab. 5; S. 38: verwendete Chemikalien

Tab. 6; S. 40: verwendete Lösungen

Tab. 7; S. 40: verwendete Reaktionssysteme

Tab. 8; S. 41: verwendete Puffer

Tab. 9; S. 43: Primär-Antikörper (Immunhistochemie)

Tab. 10; S. 44: Sekundär-Antikörper (Immunhistochemie)

Tab. 11; S. 49: Primär-Antikörper (Western Blot)

Tab. 12; S. 49: Sekundär-Antikörper (Western Blot)

Tab.13; S. 50: Chemikalien zur Herstellung der Western-Blot-Gele

Tab. 14; S. 56 Verteilung der P2X4-Expression im WT- und TG-Mausgewebe 


\section{LITERATURVERZEICHNIS}

Abbracchio MP, Burnstock G (1994): Purinoceptors: Are there families of P 2 X and $P 2$ Y purinoceptors? Pharmacol Ther $\underline{64}, 445-475$

Agteresch HJ, Dagnelie PC, van den Berg JW, Wilson JH (1999): Adenosine triphosphate: established and potential clinical applications. Drugs $\underline{58}, 211-232$

Al-Chalabi A, Andersen PM, Chioza B, Shaw C, Sham PC, Robberecht W, Matthijs G, Camu W, Marklund SL, Forsgren L et al. (1998): Recessive amyotrophic lateral sclerosis families with the D90A SOD1 mutation share a common founder: evidence for a linked protective factor. Hum Mol Genet $\underline{7}$, 2045-2050

Allen NJ, Barres BH (2005): Signaling between glia and neurons: Focus on synaptic plasticity. Curr Opin Neurobiol $\underline{15}, 542-548$

Almer G (2003): Amyotrophe Lateralsklerose: Überlegungen zu Ursprung und Pathophysiologie der Erkrankung. J Neurol Neurochir Psychiatr 4, 6-12

Andersen PM (2006): Amyotrophic lateral sclerosis associated with mutations in the CuZn superoxide dismutase gene Curr Neurol Neurosci Rep. $\underline{6}$, 37-46.

Appel SH, Smith RG, Alexianu M, Siklos L, Engelhardt J, Colom LL, Stefani E (1995): Increased intracellular calcium triggered by immune mechanisms in amyotrophic lateral sclerosis. Clin Neurosci $\underline{3}, 368-374$

Aran F (1850): Recherches sur une maladie non encore décrite du système musculaire (Atrophie musculaire progressive). Arch Gén Med 24,172-214

Araque A (2006): Astrocyte-neuron signaling in the brain - implications for disease. Curr Opin Investig Drugs $\underline{7}, 619-624$ 
Araque A, Parpura V, Sanzgiri RP, Haydon PG (1999): Tripartite synapses: glia, the unacknowledged partner. Trends Neurosci 22, 208-215

Araque A, Carmignoto G, Haydon PG (2001): Dynamic signaling between astrocytes and neurons. Annu Rev Physiol 63, 795-813

Arrasate M, Mitra S, Schweitzer ES, Segal MR, Finkbeiner S (2004): Inclusion body formation reduces levels of mutant huntingtin and the risk of neuronal death. Nature $\underline{431}, 805-810$

Atkinson L, Shigetomi E, Kato F, Deuchars J (2003): Differential increases in P2X receptor levels in rat vagal efferent neurones following a vagal nerve section. Brain Res $\underline{977}, 112-118$

Baek W, Koh SH, Park JS, Kim YS, Kim HY, Kwon MJ, Ki CS, Kim SH (2011): A novel codon4 mutation (A4F) in the SOD1gene in familial amyotrophic lateral sclerosis. J Neurol Sci. , Epub ahead of print. (doi:10.1016/j.jns.2011.03.041)

Bahron RJ, Rowland LP (2002): Neurology and gulf war veterans. Neurology $\underline{59}$, 1484-1485

Basso M, Massignan T, Samengo G, Cheroni C, De Biasi S, Salmona M, Bendotti C, Bonetto V (2006): Insoluble mutant SOD1 is partly oligoubiquitinated in amyotrophic lateral sclerosis mice. J Biol Chem 281, 33325-33335

Baumann N, Pham-Dinh D (2001): Biology of oligodendrocyte and myelin in the mammalian central nervous system. Physiol Rev $\underline{81}$, 871-927

Beers DR, Henkel JS, Xiao Q, Zhao W, Wang J, Yen AA, Siklos L, McKercher SR, Appel SH (2006): Wild-type microglia extend survival in PU.1 knockout mice with familial amyotrophic lateral sclerosis. Proc Natl Acad Sci U S A 103, 16021-16026

Belin MF, Hardin H (1991): Interactions neurone-glie (Review; Abstr. in Englisch). Encephale 17, 467-473 
Bennet DW, Drury AN (1931): Further observations relating to the physiological activity of adenine compounds. J Physiol $\underline{72}, 288-320$

Bergles DE, Jahr CE (1997): Synaptic activation of glutamate transporters in hippocampal astrocytes. Neuron $\underline{19}, 1297-1308$

Bergles DE, Diamond JS, Jahr CE (1999): Clearance of glutamate inside the synapse and beyond. Curr Opin Neurobiol $\underline{9}$, 293-298

Berne RM (1963): Cardiac nucleotides in hypoxia: possible role in regulation of coronary blood flow. Am J Physiol 204, 317-322

Birve A, Neuwirth C, Weber M, Marklund SL, Nilsson AC, Jonsson PA, Andersen PM (2010): A novel SOD1 splice site mutation associated with familial ALS revealed by SOD activity analysis. Hum Mol Genet 21, 4201-4206

Blaustein MP (1988): Calcium transport and buffering in neurons. Trends Neurosci $\underline{11}, 438-443$

Bleehen T, Keele CA (1977): Observations on the algogenic actions of adenosine compounds on the human blister base preparation. Pain $\underline{3}, 367-377$

Bodin P, Burnstock G (2001): Purinergic signalling: ATP release. Neurochem Res 26, 959-969

Boillée S, Vande Velde C, Cleveland DW (2006a): ALS: a disease of motor neurons and their nonneuronal neighbors. Neuron $\underline{52}, 39-59$

Boillée S, Yamanaka K, Lobsiger C, Copeland N, Jenkins N, Kassiotis G, Kollias G, Cleveland D (2006b): Onset and progression in inherited ALS determined by motor neurons and microglia. Science $\underline{312}, 1389-1392$

Bonfanti L, Peretto P (2007): Radial glial origin of the adult neural stem cells in the 
subventricular zone. Prog Neurobiol $\underline{83}$, 24-36

Booth GE, Kinrade EF, Hidalgo A (2000): Glia maintain follower neuron survival during Drosophila CNS development. Development 127, 237-244

Brettschneider J, Widl K, Schattauer D, Ludolph AC, Tumani H (2007): Cerebrospinal fluid erythropoietin (EPO) in amyotrophic lateral sclerosis. Neurosci Lett $\underline{416}, 257-260$

Brettschneider J, Lehmensiek V, Mogel H, Pfeifle M, Dorst J, Hendrich C, Ludolph AC, Tumani H (2010): Proteome analysis reveals candidate markers of disease progression in amyotrophic lateral sclerosis (ALS). Neurosci Lett $\underline{468}, 23-27$

Brooks BR, Miller RG, Swash M, Munsat TL (2000): El Escorial revisited: revised criteria for the diagnosis of amyotrophic lateral sclerosis. Amyotroph Lateral Scler 1, 293-299

Bruening W, Roy J, Giasson B, Figlewicz DA, Mushynski WE, Durham HD (1999): Up-regulation of protein chaperones preserves viability of cells expressing toxic $\mathrm{Cu} / \mathrm{Zn}$-superoxide dismutase mutants associated with amyotrophic lateral sclerosis. J Neurochem $\underline{72}, 693-699$

Bruijn LI, Cleveland DW (1996): Mechanisms of selective motor neuron death in ALS: insights from transgenic mouse models of motor neuron disease. Neuropathol Appl Neurobiol 22, 373-387

Bruijn LI, Beal MF, Becher MW, Schulz JB, Wong PC, Price DL, Cleveland DW (1997a): Elevated free nitrotyrosine levels, but not protein-bound nitrotyrosine or hydroxyl radicals, throughout amyotrophic lateral sclerosis (ALS) - like disease implicate tyrosine nitration as an aberrant in vivo property of one familial ALSlinked superoxide dismutase 1 mutant. Proc Natl Acad Sci USA 94, 7606-7611

Bruijn LI, Becher MW, Lee MK, Anderson KL, Jenkins NA, Copeland NG, Sisodia SS, Rothstein JD, Borchelt IR, Price DL et al. (1997b): ALS-linked SOD1 mutant 
G85R mediates damage to astrocytes and promotes rapidly progressive disease with SOD1-containing inclusions. Neuron 18, 327-338

Bruijn LI, Houseweart MK, Kato S, Anderson KL, Anderson SD, Ohama E, Reaume AG, Scott RW, Cleveland DW (1998): Aggregation and motor neuron toxicity of an ALS-linked SOD1 mutant independent from wild-type SOD1. Science $\underline{281}, 1851-1854$

Bruijn LI, Miller TM, Cleveland DW (2004): Unraveling the mechanisms involved in motor neuron degeneration in ALS. Annu Rev Neurosci 27, 723-749

Burnstock G (1972): Purinergic nerves. Pharmacol Rev 24, $509-581$

Burnstock G (1976): Do some nerve cells release more than one transmitter? Neuroscience $1,239-248$

Burnstock G (1978): Do some sympathetic neurones synthesize and release both noradrenaline and acetylcholine? Prog Neurobiol 11, 205-222

Burnstock G (1996): A unifying purinergic hypothesis for the initiation of pain. Lancet $\underline{347}, 1604-1605$

Burnstock G (2006): Purinergic signalling - an overview. Novartis Found Symp $\underline{276}$, 26-48, discussion 48-57, 275-281

Burnstock G, Knight GE (2004): Cellular distribution and functions of P2 receptor subtypes in different systems. Int Rev Cytol 240, 31-304

Burnstock G, Fredholm BB, North RA, Verkhratsky A (2010): The birth and postnatal development of purinergic signalling. Acta Physiol (Oxf) 199, 93-147; Übersicht

Bush TG, Puvanachandra N, Horner CH, Polito A, Ostenfeld T, Svendsen CN, Mucke L, Johnson MH, Sofroniew MV (1999): Leukocyte infiltration, neuronal 
degeneration, and neurite outgrowth after ablation of scar-forming, reactive astrocytes in adult transgenic mice. Neuron $\underline{23}, 297-308$

Casanovas A, Hernández S, Tarabal O, Rosselló J, Esquerda JE (2008): Strong P2X4 purinergic receptor-like immunoreactivity is selectively associated with degenerating neurons in transgenic rodent models of amyotrophic lateral sclerosis. J Comp Neurol $\underline{506}, 75-92$

Cavaliere F, D'Ambrosi N, Ciotti MT, Mancino G, Sancesario G, Bernardi G, Volonté C (2001a): Glucose deprivation and chemical hypoxia: neuroprotection by P2 receptor antagonists. Neurochem Int $\underline{38}, 189-197$

Cavaliere F, D'Ambrosi N, Sancesario G, Bernardi G, Volonté C (2001b): Hypoglycaemia-induced cell death: features of neuroprotection by the P2 receptor antagonist basilen blue. Neurochem Int $\underline{38}, 199-207$

Charcot J (1874): De la sclérose latérale amyotrophique. Prog Med 2, 325-327

Charcot J, Joffreoy A (1869): Deux cas d' atrophie musculaire progressive avec lésions de la substance grise et des faisceaux anterolatereaux de la moelle épiniére. Arch Physiol Norm Path $\underline{354}$, 629-744

Charles AC, Merrill JE, Dirksen ER, Sanderson MJ (1991): Intercellular signaling in glial cells: calcium waves and oscillations in response to mechanical stimulation and glutamate. Neuron $\underline{6}, 983-992$

Chessell IP, Hatcher JP, Bountra C, Michel AD, Hughes JP, Green P, Egerton J, Murfin M, Richardson J, Peck WL et al. (2005): Disruption of the P2X7 purinoceptor gene abolishes chronic inflammatory and neuropathic pain. Pain $\underline{114}$, 386-396

Chio A, Benzi G, Dossena M, Mutani R, Mora G (2005): Severely increased risk of amyotrophic lateral sclerosis among Italian professional football players. Brain (Oxford) $128,472-476$ 
Clement AM, Nguyen MD, Roberts EA, Garcia ML, Boillée S, Rule M, Mc Mahon AP, Doucette W, Siwe KD, Ferrante RJ et al. (2003): Wild-type nonneuronal cells extend survival of SOD1 mutant motor neurons in ALS mice. Science $\underline{302}, 113-117$

Cockayne DA, Hamilton SG, Zhu QM, Dunn PM, Zhong Y, Novakovic S, Malmberg AB, Cain G, Berson A, Kassotakis L et al. (2000): Urinary bladder hyporeflexia and reduced pain-related behaviour in P2X3-deficient mice. Nature 407, 1011-1015

Cornell-Bell AH, Finkbeiner SM, Cooper MS, Smith SJ (1990): Glutamate induces calcium waves in cultured astrocytes: long-range glial signaling. Science $\underline{247}, 470-$ 473

Cotrina ML, Nedergaard M (2002): Astrocytes in the aging brain. J Neurosci Res $\underline{67}, 1-10$

Coull JA, Beggs S, Boudreau D, Boivin D, Tsuda M, Inoue K, Gravel C, Salter MW, De Koninck $Y$ (2005): BDNF from microglia causes the shift in neuronal anion gradient underlying neuropathic pain. Nature $\underline{438}, 1017-1021$

Cox PA, Sacks OW (2002): Cycad neurotoxins, consumption of flying foxes, and ALS-PDC disease in Guam. Neurology $\underline{58}, 956-959$

Dal Canto MC, Gurney ME (1995): Neuropathological changes in two lines of mice carrying a transgene for mutant human $\mathrm{Cu}, \mathrm{Zn} \mathrm{SOD}$, and in mice overexpressing wild type human SOD: a model of familial amyotrophic lateral sclerosis (FALS). Brain Res $\underline{676}, 25-40$

Danbolt NC (2001): Glutamate uptake. Prog Neurobiol $\underline{65}, 1-105$

Davalos D, Grutzendler J, Yang G, Kim JV, Zuo Y, Jung S, Littman DA, Dustin ML, Gan WB (2005): ATP mediates rapid microglial response to local brain injury in vivo. Nat Neurosci $\underline{8}, 752-758$

De Groot CJ, Montagne L, Janssen I, Ravid R, Van Der Valk P, Veerhuis R (2000): 
Isolation and characterization of adult microglial cells and oligodendrocytes derived from postmortem human brain tissue. Brain Res Brain Res Protoc $\underline{5}$, 85-94

Deitmer JW, Verkhratsky AJ, Lohr C (1998): Calcium signalling in glial cells. Cell Calcium 24, 405-416

Delisle MB, Carpenter S (1984): Neurofibrillary axonal swellings and amyotrophic lateral sclerosis. J Neurol Sci $\underline{63}, 241-250$

Dengler R, Zierz S, Jerusalem F: Amyotrophe Lateralsklerose. Georg Thieme, Stuttgart 2000

Dhib-Jalbut S, Arnold DL, Cleveland DW, Fisher M, Friedlander RM, Mouradian MM, Przedborski S, Trapp BD, Wyss-Coray T, Yong VW (2006): Neurodegeneration and neuroprotection in multiple sclerosis and other neurodegenerative diseases. J Neuroimmunol $\underline{176}, 198-215$

Dibaj P, Kaiser M, Hirlinger J, Kirchhoff F, Neusch C (2007): Kir4.1 channels regulate swelling of astroglial processes in experimental spinal cord edema. $\mathrm{J}$ Neurochem 103, 2620-2628

Dibaj P, Nadrigny F, Steffens H, Scheller A, Hirrlinger J, Schomburg ED, Neusch $C$, Kirchhoff $F$ (2010): NO mediates microglial response to acute spinal cord injury under ATP control in vivo. Glia $\underline{58}, 1133-1144$

Dibaj P, Steffens H., Zschüntzsch J, Nagrigny F, Schomburg E D, Kirchhoff F, Neusch C. (2011): In vivo imaging reveals Distinct Inflammatory Activitiy of CNS Microglia versus PNS Macrophages in a mouse model for ALS. PLoS One 18, 6 (3), e17910

Doctor RB, Matzakos T, McWilliams R, Johnson S, Feranchak AP, Fitz JG (2005): Purinergic regulation of cholangiocyte secretion: identification of a novel role for P2X receptors. Am J Physiol Gastrointest Liver Physiol 288, 779-786 
Doetsch F (2003): The glial identity of neural stem cells. Nat Neurosci $\underline{6}, 1127-$ 1134

Donato R, Rodrigues RJ, Takahashi MC, Tsai MC, Soto D, Miyagi K, Villafuertes RG, Cunha RA, Edwards FA (2008): GABA release by basket cells onto Purkinje cells, in rat cerebellar slices, is directly controlled by presynaptic purinergic receptors, modulating Ca2+ influx. Cell Calcium 44, 521-532

Drury AN, Szent-Györgyi A (1929): The physiological activity of adenine compounds with especial reference to their action upon the mammalian heart. $J$ Physiol $\underline{68}, 213-237$

Durham HD, Roy J, Dong L, Figlewicz DA (1997): Aggregation of mutant Cu/Zn superoxide dismutase proteins in a culture model of ALS. J Neuropathol Exp Neurol $\underline{56}, 523-530$

Edwards FA, Gibb AJ, Colquhoun D (1992): ATP receptor-mediated synaptic currents in the central nervous system. Nature $\underline{359}, 144-147$

Estévez AG, Crow JP, Sampson JB, Reiter C, Zhuang Y, Richardson GJ, Tarpey MM, Barbeito L, Beckman JS (1999): Induction of nitric oxide--dependent apoptosis in motor neurons by zinc-deficient superoxide dismutase. Science $\underline{286}$, 2498-2500

Fauci A, Isselbacher J, Wilson D, Root R, Martin J, Petersdorf R: Harrison's Principles of Internal Medicine. McGraw-Hill Professional, New York, NY, USA 1998.

Faulkner JR, Herrmann JE, Woo MJ, Tansey KE, Doan NB, Sofroniew MV (2004): Reactive astrocytes protect tissue and preserve function after spinal cord injury. $J$ Neurosci 24, 2143-2155

Felbecker A, Camu W, Valdmanis PN, Sperfeld AD, Waibel S, Steinbach P, Rouleau GA, Ludolph AC, Andersen PM (2010): Four familial ALS pedigrees 
discordant for two SOD1 mutations: are all SOD1 mutations pathogenic? J Neurol Neurosurg Psychiatry $\underline{81}$, 572-577

Franke H, Illes P (2006): Involvement of P2 receptors in the growth and survival of neurons in the CNS. Pharmacol Ther $\underline{109}, 297-324$

Fricker-Gates RA (2006): Radial glia: a changing role in the central nervous system. Neuroreport 17, 1081-1084

Fyffe RE, Perl ER (1984): Is ATP a central synaptic mediator for certain primary afferent fibers from mammalian skin? Proc Natl Acad Sci USA $\underline{81}$, 6890-6893

Garcia ML, Singleton AB, Hernandez D, Ward CM, Evey C, Sapp PA, Hardy J, Brown RH jr., Cleveland DW (2006): Mutations in neurofilament genes are not a significant primary cause of non-SOD1-mediated amyotrophic lateral sclerosis. Neurobiol Dis $\underline{21}, 102-109$

Gonzales EB, Kawate T, Gouaux E (2009): Pore architecture and ion sites in acidsensing ion channels and P2X receptors. Nature $\underline{460}, 599-604$

Gould TW, Buss RR, Vinsant S, Prevette D, Sun W, Knudson CM, Milligan CE, Oppenheim RW (2006): Complete dissociation of motor neuron death from motor dysfunction by Bax deletion in a mouse model of ALS. J Neurosci 26, 8774-8786

Grass D, Pawlowski PG, Hirrlinger J, Papadopoulos N, Richter DW, Kirchhoff F, Hülsmann S (2004): Diversity of functional astroglial properties in the respiratory network. J Neurosci 24, 1358-1365

Gros-Louis F, Gaspar C, Rouleau GA (2006): Genetics of familial and sporadic amyotrophic lateral sclerosis. Biochim Biophys 1762, 956-972

Grosskreutz J, Peschel T, Unrath A, Dengler R, Ludolph AC, Kassubek J (2008): Whole brain-based computerized neuroimaging in ALS and other motor neuron disorders. Amyotroph Lateral Scler $\underline{9}$, 238-248 
Gu JG, MacDermott AB (1997): Activation of ATP P2X receptors elicits glutamate release from sensory neuron synapses. Nature $\underline{389}, 749-753$

Guégan C, Przedborski S (2003): Programmed cell death in amyotrophic lateral sclerosis. J Clin Invest 111, 153-161

Guégan C, Vila M, Rosoklija G, Hays AP, Przedborski S (2001): Recruitment of the mitochondrial-dependent apoptotic pathway in amyotrophic lateral sclerosis. J Neurosci 21, 6569-6576

Guimaraes JS, Freire MA, Lima RR, Souza-Rodrigues RD, Costa AM, dos Santos CD, Picanco-Diniz CW, Gomes-Leal W (2009): Mecanismos de degeneracíon secundaria en el sistema nervioso central durante los trastornos neuronales agudos y el dano en la sustancia blanca (englische Übersetzung). Rev Neurol $\underline{48}$, 304-310

Guo H, Lai L, Butchbach ME, Stockinger MP, Shan X, Bishop GA, Lin CL (2003): Increased expression of the glial glutamate transporter EAAT2 modulates excitotoxicity and delays the onset but not the outcome of ALS in mice. Hum Mol Genet 12, 2519-2532

Gurney ME, Cutting FB, Zhai P, Doble A, Taylor CP, Andrus PK, Hall ED (1996): Benefit of vitamin $\mathrm{E}$, riluzole, and gabapentin in a transgenic model of familial amyotrophic lateral sclerosis. Ann Neurol $\underline{39}, 147-157$

Hafezparast M, Klocke R, Ruhrberg C, Marquardt A, Ahmad-Annuar A, Bowen S, Lalli G, Witherden AS, Hummerich H, Nicholson $S$ et al. (2003): Mutations in dynein link motor neuron degeneration to defects in retrograde transport. Science $\underline{300}, 808-812$

Halliwell B, Gutteridge J (1992): Letter to the editor - Comments on review of free radicals in biology and medicine, second edition. Free radical Biology and Medicine $\underline{12}, 93-94$ 
Hamilton SG, Warburton J, Bhattacharjee A, Ward J, McMahon SB (2000): ATP in human skin elicits a dose-related pain response which is potentiated under conditions of hyperalgesia. Brain $\underline{123}, 1238-1246$

Harrison TR, Al. E: Harrison's Principles of Internal Medicine. The McGraw-Hill, New York, NY, USA 2005

Hashimoto K, Engberg G, Shimizu E, Nordin C, Lindstrom LH, lyo M (2005): Reduced D-serine to total serine ratio in the cerebrospinal fluid of drug naive schizophrenic patients. Prog Neuropsychopharmacol Biol Psychiatry 299, 767-769

Haydon PG (2001): GLIA: listening and talking to the synapse. Nat Rev Neurosci 2 , $185-193$

Haynes SE, Hollopeter G, Yang G, Kurpius D, Dailey ME, Gan WB, Julius D (2006): The P2Y12 receptor regulates microglial activation by extracellular nucleotides. Nat Neurosci $\underline{9}, 1512-1519$

Hedlund E, Hefferan MP, Marsala M, Isacson O (2007): Cell therapy and stem cells in animal models of motor neuron disorders. Eur J Neurosci $\underline{26}, 1721-1737$

Hernández S, Casanovas A, Piedrafita L, Tarabal O, Esquerda JE (2010): Neurotoxic species of misfolded SOD1G93A recognized by antibodies against the P2X4 subunit of the ATP receptor accumulate in damaged neurons of transgenic animal models of amyotrophic lateral sclerosis. J Neuropathol Exp Neurol $\underline{69}, 176-$ 187

Hirrlinger J, Hülsmann S, Kirchhoff F (2004): Astroglial processes show spontaneous motility at active synaptic terminals in situ. Eur J Neurosci $\underline{20}, 2235$ 2239

Ho BK, Alexianu ME, Colom LV, Mohamed AH, Serrano F, Appel SH (1996): Expression of calbindin-D28K in motoneuron hybrid cells after retroviral infection with calbindin-D28K cDNA prevents amyotrophic lateral sclerosis IgG-mediated 
cytotoxicity. Proc Natl Acad Sci U S A 무, 6796-6801

Hollopeter G, Jantzen HM, Vincent D, Li G, England L, Ramakrishnan V, Yang RB, Nurden P, Nurden A, Julius D, Conley PB (2001): Identification of the platelet ADP receptor targeted by antithrombotic drugs. Nature $\underline{409}, 202-207$

Holton P (1959): The liberation of adenosine triphosphate on antidromic stimulation of sensory nerves. J Physiol $\underline{145}, 494-504$

Howland DF, Liu J, She Y, Goad B, Maragakis NJ, Kim B, Erickson J, Kulik J, Devito L, Psaltis G et al. (2002): Focal loss of the glutamate transporter EAAT2 in a transgenic rat model of SOD1 mutant-mediated amyotrophic lateral sclerosis (ALS). Proc Natl Acad Sci U S A $\underline{99}, 1604-1609$

Hufschmidt A, Lücking $\mathrm{CH}$, Rauer S (Hrsg.): Neurologie compact. Für Klinik und Praxis. Georg Thieme, Stuttgart 1999

Hugel S, Schlichter R (2000): Presynaptic P2X receptors facilitate inhibitory GABAergic transmission between cultured rat spinal cord dorsal horn neurons. J Neurosci $\underline{20}, 2121-2130$

Inoue K (2002): Microglial activation by purines and pyrimidines. Glia $\underline{40}, 156-163$

Inoue K (2008): Purinergic systems in microglia. Cell Mol Life Sci $\underline{65}$, 3074-3080

Jaiswal MK, Keller BU (2009): Cu/Zn superoxide dismutase typical for familial amyotrophic lateral sclerosis increases the vulnerability of mitochondria and perturbs Ca2+ homeostasis in SOD1G93A mice. Mol Pharmacol $\underline{75}$, 478-489

Jaiswal MK, Zech WD, Goos M, Leutbecher C, Ferri A, Zippelius A, Carri MT, Nau $\mathrm{R}$, Keller BU (2009): Impairment of mitochondrial calcium handling in a mtSOD1 cell culture model of motoneuron disease. BMC Neurosci 10, 64; (doi 10:1186/1471-2202-10-64) 
Johnston JM, Burnett P, Thomas AP, Tezapsidis N (2006): Calcium oscillations in type-1 astrocytes, the effect of a presenilin 1 (PS1) mutation. Neurosci Lett $\underline{395}$, 159-164

Jonsson PA, Ernhill K, Andersen PM, Bergemalm D, Brannstrom T, Gredal O, Nilsson P, Marklund SL (2004): Minute quantities of misfolded mutant superoxide dismutase-1 cause amyotrophic lateral sclerosis. Brain 127, 73-88

Kaiser M, Maletzki I, Hülsmann S, Holtmann B, Schulz-Schaeffer W, Kirchhoff F, Bähr M, Neusch C (2006): Progressive loss of a glial potassium channel (KCNJ10) in the spinal cord of the SOD1 (G93A) transgenic mouse model of amyotrophic lateral sclerosis. J Neurochem $\underline{99}, 900-912$

Kang N, Xu J, Xu Q, Nedergaard M, Kang J (2005): Astrocytic glutamate releaseinduced transient depolarization and epileptiform discharges in hippocampal CA1 pyramidal neurons. J Neurophysiol $\underline{94}, 4121-4130$

Kawate T, Michel JC, Birdsong WT, Gouaux E (2009): Crystal structure of the ATPgated P2X(4) ion channel in the closed state. Nature $\underline{460}, 592-598$

Khakh BS, Henderson G (1998): ATP receptor-mediated enhancement of fast excitatory neurotransmitter release in the brain. Mol Pharmacol $\underline{54}, 372-378$

Khakh BS, North RA (2006): P2X receptors as cell-surface ATP sensors in health and disease. Nature $\underline{442}, 527-532$

Khakh BS, Gittermann D, Cockayne DA, Jones A (2003): ATP modulation of excitatory synapses onto interneurons. J Neurosci $\underline{23}, 7426-7437$

Kofuji P, Newman EA (2004): Potassium buffering in the central nervous system. Neuroscience $\underline{129}, 1045-1056$

Kong J, Xu Z (1998): Massive mitochondrial degeneration in motor neurons triggers the onset of amyotrophic lateral sclerosis in mice expressing a mutant 
SOD1. J Neurosci $\underline{18}, 3241-3250$

Koshimizu TA, Van Goor F, Tomíc M, Wong AO, Tanoue A, Tsujimoto G, Stojilkovic SS (2000): Characterization of calcium signaling by purinergic receptorchannels expressed in excitable cells. Mol Pharmacol $\underline{58}$, 936-945

Krieger C, Jones K, Kim SU, Eisen AA (1994): The role of intracellular free calcium in motor neuron disease. J Neurol Sci 124 , suppl. 27-32

Krieger C, Lanius RA, Pelech SL, Shaw CA (1996): Amyotrophic lateral sclerosis: the involvement of intracellular $\mathrm{Ca} 2+$ and protein kinase $\mathrm{C}$. Trends Pharmacol Sci $\underline{17}, 114-120$

Kuffler SW, Nicholls JG, Orkand RK (1966): Physiological properties of glial cells in the central nervous system of amphibia. J Neurophysiol 29, 768-787

Kunita R, Otomo A, Mizumura H, Suzuki K, Showguchi-Miyata J, Yanagisawa Y, Hadano S, Ikeda JE (2004): Homo-oligomerization of ALS2 through its unique carboxyl-terminal regions is essential for the ALS2-associated Rab5 guanine nucleotide exchange activity and its regulatory function on endosome trafficking. $J$ Biol Chem 279, 38626-38635

Largo C, Cuevas P, Somjen GG, Martin Del Rio R, Herreras O (1996): The effect of depressing glial function in rat brain in situ on ion homeostasis, synaptic transmission, and neuron survival. J Neurosci 16, 1219-1229

Laurie DJ, Wisden W, Seeburg PH (1992): The distribution of thirteen GABAA receptor subunit mRNAs in the rat brain. III. Embryonic and postnatal development. J Neurosci.,12, 4151-4172

Leigh PN, Swash M (1991): Cytoskeletal pathology in motor neuron diseases. Adv Neurol $\underline{56}, 115-124$

Leigh PN, Whitwell H, Garofalo O, Buller J, Swash M, Martin JE, Gallo JM, Weller 
$\mathrm{RO}$, Anderton $\mathrm{BH}$ (1991): Ubiquitin-immunoreactive intraneuronal inclusions in amyotrophic lateral sclerosis. Morphology, distribution, and specificity. Brain 114, 775-788

Li M, Ona VO, Chen M, Kaul M, Tenneti L, Zhang X, Stieg PE, Lipton SA, Friedlander RM (2000): Functional role and therapeutic implications of neuronal caspase-1 and -3 in a mouse model of traumatic spinal cord injury. Neuroscience $\underline{99}, 333-342$

Logroscino G, Traynor BJ, Hardiman O, Chio A, Mitchell D, Swingler RJ, Millul A, Benn E, Beghi E (2010): Incidence of amyotrophic lateral sclerosis in Europe. J Neurol Neurosurg Psychiatry $\underline{81}, 385-390$

Ludolph AC (2000): Treatment of amyotrophic lateral sclerosis - what is the next step? J Neurol 247, 13-18

Ludolph AC, Sperfeld A, Collatz BM, Storch A (2001): Tauopathien - eine neue Kategorie degenerativer Hirnerkrankungen. Nervenarzt 72, 78-85

Ludolph AC, Bendotti C, Blaugrund E, Hengerer B, Löffler JP, Martin J, Meininger V, Meyer T, Moussaoui S, Robberecht W, Scott S, Silani V, van den Berg LH (2007): Guidelines for the preclinical in vivo evaluation of pharmacological active drugs for ALS/MND: report on the 142nd ENMC international workshop. Official publication of the World Federation of Neurology Research Group on Motor Neuron Diseases. Amyotroph lateral scler $\underline{8}, 217-223$

Ludwin SK (1984): The function of perineuronal satellite oligodendrocytes: an immunohistochemical study. Neuropathol Appl Neurobiol $\underline{10}, 143-149$

Ludwin SK (1997): The pathobiology of the oligodendrocyte. J Neuropathol Exp Neurol $\underline{56}, 111-124$

Lulé D, Ludolph AC, Kassubek J (2009): MRI-based functional neuroimaging in ALS: an update. Amyotroph Lateral Scler 10, 258-268 
Maragakis NJ, Rothstein JD (2004): Glutamate transporters: animal models to neurologic disease. Neurobiol Dis $\underline{15}, 461-473$

Maragakis NJ, Rothstein JD (2006): Mechanisms of Disease: astrocytes in neurodegenerative disease. Nat Clin Pract Neurol 2, 679-689

Martin LJ, Liu Z, Chen K, Price AC, Pan Y, Swaby JA, Golden WC (2007): Motor neuron degeneration in amyotrophic lateral sclerosis mutant superoxide dismutase-1 transgenic mice: mechanisms of mitochondriopathy and cell death. $\mathrm{J}$ Comp Neurol 500 , 20-46

März P, Gadient RA, Otten U (1996): Expression of interleukin-6 receptor (IL-6R) and gp130 mRNA in PC12 cells and sympathetic neurons. Brain Res $\underline{706}, 71-79$

Masuhr KF, Neumann M : Neurologie. Georg Thieme, Stuttgart 1996

Matthias K, Kirchhoff F, Seifert G, Hüttmann K, Matyash M, Kettenmann H, Steinhauser C (2003): Segregated expression of AMPA-type glutamate receptors and glutamate transporters defines distinct astrocyte populations in the mouse hippocampus. J Neurosci $\underline{23}$, 1750-1758

Mazzanti M, Sul JY, Haydon PG (2001): Glutamate on demand: astrocytes as a ready source. Neuroscientist $\underline{7}, 396-405$

McBurney RN, Neering IR (1985): The measurement of changes in intracellular free calcium during action potentials in mammalian neurones. J Neurosci Methods $\underline{13}, 65-76$

Moisse K, Strong MJ (2006): Innate immunity in amyotrophic lateral sclerosis. Biochim Biophys Acta, 1762 1083-1093

Morrison BM, Morrison JH (1999): Amyotrophic lateral sclerosis associated with mutations in superoxide dismutase: a putative mechanism of degeneration. Brain Res Brain Res Rev 모, 121-135 
Mourelatos Z, Hirano A, Rosenquist AC, Gonatas NK (1994): Fragmentation of the Golgi apparatus of motor neurons in amyotrophic lateral sclerosis (ALS). Clinical studies in ALS of Guam and experimental studies in deafferented neurons and in beta,beta'-iminodipropionitrile axonopathy. Am J Pathol $\underline{144}, 1288-1300$

Münch C, Ludolph AC (2001): Pharmacological treatment of ALS. Neurol Neurochir Pol 35, (1 Suppl) 41-50

Münch $\mathrm{C}$, Prechter F, Xu R, Linke P, Prudlo J, Kuzma M, Kwiecinski H, Ludolph AC, Meyer T (2005): Frequency of a tau genotype in amyotrophic lateral sclerosis. J Neurol Sci $\underline{236}, 13-16$

Nakajima K, Kohsaka S (1993): Functional roles of microglia in the brain. Neurosci Res $\underline{17}, 187-203$

Neher E (1995): The use of fura-2 for estimating $\mathrm{Ca}$ buffers and $\mathrm{Ca}$ fluxes. Neuropharmacology $\underline{34}, 1423-1442$

Neusch C, Bähr M, Schneider-Gold C (2007): Glia cells in amyotrophic lateral sclerosis: new clues to understanding an old disease? Muscle Nerve $\underline{35}, 712-724$

Newman EA (2003): New roles for astrocytes: regulation of synaptic transmission. Trends Neurosci $\underline{26}, 536-542$

Newman EA, Volterra A (2004): Glial control of synaptic function. Glia 47, 207-208

Nimmerjahn A, Kirchhoff F, Helmchen F (2005): Resting microglial cells are highly dynamic surveillants of brain parenchyma in vivo. Science $\underline{308}, 1314-1318$

North RA (2002): Molecular physiology of P2X receptors. Physiol Rev $\underline{82}$, 10131067

North RA, Surprenant A (2000): Pharmacology of cloned P2X receptors. Annu Rev Pharmacol Toxicol $\underline{40}, 563-580$ 
Ohsawa K, Irino Y, Nakamura Y, Akazawa C, Inoue K, Kohsaka S (2007): Involvement of $\mathrm{P} 2 \mathrm{X} 4$ and $\mathrm{P} 2 \mathrm{Y} 12$ receptors in ATP-induced microglial chemotaxis. Glia $\underline{55}, 604-616$

Okumura H (2003): Epidemiological and clinical patterns of western pacific amyotrophic lateral sclerosis (ALS) in Guam and sporadic ALS in Rochester, Minnesota, U.S.A. and Hokkaido, Japan: a comparative study. Hokkaido Igaku Zasshi (The Hokkaido Journal of Medical Science) $\underline{78}$, 187-195

Orkand RK, Nicholls JG, Kuffler SW (1966): Effect of nerve impulses on the membrane potential of glial cells in the central nervous system of amphibia. $J$ Neurophysiol $\underline{29}, 788-806$

Orrell RW (2007): Understanding the causes of amyotrophic lateral sclerosis. N Engl J Med 357, 822-823. Comment on: Duneckley T et al. (2007) Whole-Genome analysis of sporadic amyotrophic lateral sclerosis. N Engl J Med 357, 775-788.

Orrell RW, Habgood JJ, Malaspina A, Mitchell J, Greenwood J, Lane RJ, de Belleroche JS (1999): Clinical characteristics of SOD1 gene mutations in UK families with ALS. J Neurol Sci $\underline{169}$, 56-60

Pasinelli P, Houseweart MK, Brown RH jr., Cleveland DW (2000): Caspase-1 and 3 are sequentially activated in motor neuron death in $\mathrm{Cu}, \mathrm{Zn}$ superoxide dismutasemediated familial amyotrophic lateral sclerosis. Proc Natl Acad Sci U S A 25, 13901-13906.

Paxinos G, Watson C: The rat brain in stereotaxic coordinates. 2. Aufl., Academic Press, San Diego (1986)

Perea G, Araque A (2005): Glial calcium signaling and neuron-glia communication. Cell Calcium 38, 375-382

Phillis JW, Wu PH (1981): The role of adenosine and its nucleotides in central synaptic transmission. Prog Neurobiol $\underline{16}, 187-239$ 
Piet R, Vargová L, Syková E, Poulain DA, Oliet SH (2004): Physiological contribution of the astrocytic environment of neurons to intersynaptic crosstalk. Proc Natl Acad Sci USA 101, 2151-2155

Pinto L, Götz M (2007): Radial glial cell heterogeneity--the source of diverse progeny in the CNS. Prog Neurobiol $\underline{83}, 2-23$

Potter P, White TD (1980): Release of adenosine 5'-triphosphate from synaptosomes from different regions of rat brain. Neuroscience $\underline{5}, 1351-1356$

Puls I, Jonnakuty C, LaMonte BH, Holzbaur EL, Tokito M, Mann E, Floeter MK, Bidus K, Drayna D, Oh SJ et al. (2003): Mutant dynactin in motor neuron disease. Nat Genet 33, 455-456

Qureshi OS, Paramasivam A, Yu JC, Murrell-Lagnado RD (2007): Regulation of $\mathrm{P} 2 \mathrm{X} 4$ receptors by lysosomal targeting, glycan protection and exocytosis. $\mathrm{J}$ Cell Sci $\underline{120}, 3838-3849$

Raivich G, Reddington M, Haas CA, Kreutzberg GW (1995): Peptides in motoneurons. Prog Brain Res 104, 3-20

Raivich G, Bohatschek M, Kloss CU, Werner A, Jones LL, Kreutzberg GW (1999): Neuroglial activation repertoire in the injured brain: graded response, molecular mechanisms and cues to physiological function. Brain Res Brain Res Rev $\underline{30}, 77-$ 105

Rakhit R, Robertson J, Vande Velde C, Horne P, Ruth DM, Griffin J, Cleveland DW, Cashman NR, Chakrabartty A (2007): An immunological epitope selective for pathological monomer-misfolded SOD1 in ALS. Nat Med $\underline{13}, 754-759$

Raouf R, Chabot-Doré AJ, Ase AR, Blais D, Séguéla P (2007): Differential regulation of microglial $\mathrm{P} 2 \mathrm{X} 4$ and $\mathrm{P} 2 \mathrm{X} 7$ ATP receptors following LPS-induced activation. Neuropharmacology $\underline{53}, 496-504$ 
Reaume AG, Elliott JL, Hoffman EK, Kowall NW, Ferrante RJ, Siwek DF, Wilcox HM, Flood DG, Beal MF, Brown RH jr. et al. (1996): Motor neurons in Cu/Zn superoxide dismutase-deficient mice develop normally but exhibit enhanced cell death after axonal injury. Nat Genet $\underline{13}, 43-47$

Ridet JL, Malhotra SK, Privat A, Gage FH (1997): Reactive astrocytes: cellular and molecular cues to biological function. Trends Neurosci $\underline{20}, 570-577$

Roberts JA, Vial C, Digby HR, Agboh KC, Wen H, Atterbury-Thomas A, Evans RJ (2006): Molecular properties of P2X receptors. Pflügers Arch 452, 486-500 (doi:10.1007/s00424-006-0073-6); Übersicht

Roelofs-Iverson RA, Mulder DW, Elveback LR, Kurland LT, Molgaard CA (1984): ALS and heavy metals: a pilot case-control study. Neurology $\underline{34}$, 393-395

Rosen DR, Siddique T, Patterson D, Figlewicz DA, Sapp P, Hentati A, Donaldson D, Goto J, O'Regan JP, Deng HX et al. (1993): Mutations in Cu/Zn superoxide dismutase gene are associated with familial amyotrophic lateral sclerosis. Nature $\underline{362}, 59-62$

Rothstein JD, Kuncl RW (1995): Neuroprotective strategies in a model of chronic glutamate-mediated motor neuron toxicity. J Neurochem $\underline{65}, 643-651$

Rothstein JD, Van Kammen M, Levey AI, Martin LJ, Kuncl RW (1995): Selective loss of glial glutamate transporter GLT-1 in amyotrophic lateral sclerosis. Ann Neurol $\underline{38}, 73-84$

Roy J, Minotti S, Dong L, Figlewicz DA, Durham HD (1998): Glutamate potentiates the toxicity of mutant $\mathrm{Cu} / \mathrm{Zn}$-superoxide dismutase in motor neurons by postsynaptic calcium-dependent mechanisms. J Neurosci $\underline{18}, 9673-9684$

Rubio M, Soto F (2001): Distinct Localization of P2X receptors at excitatory postsynaptic specializations. J Neurosci 21, 641-653 
Sabatelli M, Madia F, Conte A, Luigetti M, Zollino M, Mancuso I, Lo Monaco M, Lippi G, Tonali P (2008): Natural history of young-adult amyotrophic lateral sclerosis. Neurology $\underline{71}, 876-881$

Santhakumar V, Jones RT, Mody I (2010): Developmental regulation and neuroprotective effects of striatal tonic GABAA currents. Neuroscience $\underline{167}, 644-$ 655

Sawynok J, Sweeney M (1989): The role of purines in nociception. Neuroscience $\underline{32}, 557-569$

Schipke CG, Ohlemeyer C, Matyash M, Nolte C, Kettenmann H, Kirchhoff F (2001): Astrocytes of the mouse neocortex express functional N-methyl-Daspartate receptors. FASEB $\mathrm{J} \underline{15}, 1270-1272$

Schwab JM, Guo L, Schluesener H (2005): Spinal cord injury induces early and persistent lesional P2X4 receptor expression. J Neurosci $\underline{163}$, 185-189

Schwiebert EM, Liang L, Cheng NL, Williams CR, Olteanu D, Welty EA, Zsembery A (2005): Extracellular zinc and ATP-gated P2X receptor calcium entry channels: New zinc receptors as physiological sensors and therapeutic targets. Purinergic Signal $\underline{1}, 299-310$

Schwiebert LM, Rice WC, Kudlow BA, Taylor AL, Schwiebert EM (2002): Extracellular ATP signaling and P2X nucleotide receptors in monolayers of primary human vascular endothelial cells. Am J Physiol Cell Physiol 282,C289-301

Shaw PJ (2005): Molecular and cellular pathways of neurodegeneration in motor neurone disease. J Neurol Neurosurg Psychiatry $\underline{76}$, 1046-1057

Shaw PJ, Ince PG (1997): Glutamate, excitotoxicity and amyotrophic lateral sclerosis. J Neurol 244, Suppl 2, S3-14

Shigetomi E, Kato F (2004): Action potential-independent release of glutamate by 
$\mathrm{Ca} 2+$ entry through presynaptic P2X receptors elicits postsynaptic firing in the brainstem autonomic network. J Neurosci 24, 3125-3135

Siddique T, Figlewicz DA, Pericak-Vance MA, Haines JL, Rouleau G, Jeffers AJ, Sapp P, Hung WY, Bebout J, Mckenna-Yasek D et al. (1991): Linkage of a gene causing familial amyotrophic lateral sclerosis to chromosome 21 and evidence of genetic-locus heterogeneity. N Engl J Med 324, 1381-1384

Silinsky EM, Gerzanich V, Vanner SM (1992): ATP mediates excitatory synaptic transmission in mammalian neurones. Br J Pharmacol 106, 762-763

Sim JA, Chaumont S, Jo J, Ulmann L, Young MT, Cho K, Buell G, North RA, Rassendren F (2006): Altered hippocampal synaptic potentiation in P2X4 knockout mice. J Neurosci 26, 9006-9009

Simard AR, Rivest S (2006): Les cellules souches de la moelle osseuse au secours de la maladie d'Alzheimer. Med Sci (Paris) 22, 822-824

Singh RJ, Karoui H, Gunther MR, Beckman JS, Mason RP, Kalyanaraman B (1998): Reexamination of the mechanism of hydroxyl radical adducts formed from the reaction between familial amyotrophic lateral sclerosis-associated $\mathrm{Cu}, \mathrm{Zn}$ superoxide dismutase mutants and H2O2. Proc Natl Acad Sci USA $\underline{95}$, 6675-6680

Smith RG, Hamilton S, Hofmann F, Schneider T, Nastainczyk W, Birnbaumer L, Stefani E, Appel SH (1992): Serum antibodies to L-type calcium channels in patients with amyotrophic lateral sclerosis. N Engl J Med 327, 1721-1728

Sofroniew MV (2005): Reactive astrocytes in neural repair and protection. Neuroscientist 11, 400-407

Solle M, Labasi J, Perregaux DG, Stam E, Petrushova N, Koller BH, Griffiths RJ, Gabel CA (2001): Altered cytokine production in mice lacking P2X(7) receptors. J Biol Chem 276, 125-132 
Sonin D, Zhou SY, Cronin C, Sonina T, Wu J, Jacobson KA, Pappano A, Liang BT (2008): Role of P2X purinergic receptors in the rescue of ischemic heart failure. Am J Physiol Heart Circ Physiol 295, H1191-1197

Souslova V, Cesare P, Ding Y, Akopian AN, Stanfa L, Suzuki R, Carpenter K, Dickenson A, Boyce S, Hill R et al. (2000): Warm-coding deficits and aberrant inflammatory pain in mice lacking P2X3 receptors. Nature $\underline{407}, 1015-1017$

Sperlágh B, Kittel A, Lajtha A, Vizi ES (1995): ATP acts as fast neurotransmitter in rat habenula: neurochemical and enzymecytochemical evidence. Neuroscience $\underline{66}$, 915-920

Stieber A, Gonatas JO, Gonatas NK (2000): Aggregates of mutant protein appear progressively in dendrites, in periaxonal processes of oligodendrocytes, and in neuronal and astrocytic perikarya of mice expressing the SOD1(G93A) mutation of familial amyotrophic lateral sclerosis. J Neurol Sci $\underline{177}, 114-123$

Strong MJ (2004): Amyotrophic lateral sclerosis: contemporary concepts in etiopathogenesis and pharmacotherapy. Expert Opin Investig Drugs 13, 1593-1614

Surprenant A, North RA (2009): Signaling at purinergic P2X receptors. Annu Rev Physiol 1ㅡ, 333-359

Surprenant A, Rassendren F, Kawashima E, North RA, Buell G (1996): The cytolytic P2Z receptor for extracellular ATP identified as a P2X receptor (P2X7). Science $\underline{272}, 735-738$

Süssmuth SD, Tumani H, Ecker D, Ludolph AC (2003): Amyotrophic lateral sclerosis: disease stage related changes of tau protein and $S 100$ beta in cerebrospinal fluid and creatine kinase in serum. Neurosci Lett $\underline{353}, 57-60$

Süssmuth SD, Sperfeld AD, Hinz A, Brettschneider J, Endruhn S, Ludolph AC, Tumani $H$ (2010): CSF glial markers correlate with survival in amyotrophic lateral sclerosis. Neurology $\underline{74}, 982-987$ 
Tanaka M, Kim YM, Lee G, Junn E, Iwatsubo T, Mouradian MM (2004): Aggresomes formed by alpha-synuclein and synphilin-1 are cytoprotective. J Biol Chem $\underline{279}$, 4625-4631

Teuchert M, Fischer D, Schwalenstoecker B, Habisch HJ, Böckers TM, Ludolph AC (2006): A dynein mutation attenuates motor neuron degeneration in SOD1(G93A) mice. Exp Neurol 198, 271-274

Tian GF, Azmi H, Takano T, Xu Q, Peng W, Lin J, Oberheim N, Lou N, Wang X, Zielke HR et al. (2005): An astrocytic basis of epilepsy. Nat Med 11, 973-981

Trang T, Beggs S, Salter MW (2006): Purinoceptors in microglia and neuropathic pain. Pflügers Arch $\underline{452}, 645-652$

Traynor BJ, Bruijn L, Conwit R, Beal F, O'Neill G, Fagan SC, Cudkowicz ME (2006): Neuroprotective agents for clinical trials in ALS: A systematic assessment. Neurology $\underline{67}, 20-27$

Trepel M: Neuroanatomie; Struktur und Funktion. Urban \& Fischer/Elsevier, München 2006

Trotti D, Rolfs A, Danbolt NC, Brown RH Jr, Hediger MA (1999): SOD1 mutants linked to amyotrophic lateral sclerosis selectively inactivate a glial glutamate transporter. Nat Neurosci 2,427-433; Erratum in: Nat Neurosci 1999, 2, 848

Tsuda M, Shigemoto-Mogami Y, Koizumi S, Mizokoshi A, Kohsaka S, Salter MW, Inoue K (2003): P2X4 receptors induced in spinal microglia gate tactile allodynia after nerve injury. Nature $\underline{424}, 778-783$

Turner BJ, Atkin JD, Farg MA, Zang DW, Rembach A, Lopes EC, Patch JD, Hill $A F$, Cheema SS (2005): Impaired extracellular secretion of mutant superoxide dismutase 1 associates with neurotoxicity in familial amyotrophic lateral sclerosis. $J$ Neurosci $\underline{25}, 108-117$ 
Umegaki H, Yamada K, Naito M, Kameyama T, Iguchi A, Nabeshima T (1996): Protective effect of interleukin-6 against the death of PC12 cells caused by serum deprivation or by the addition of a calcium ionophore. Biochem Pharmacol $\underline{52}, 911$ 916

Unal-Cevik I, Kilinc M, Gürsoy-Ozdemir Y, Gurer G, Dalkara T (2004): Loss of NeuN immunoreactivity after cerebral ischemia does not indicate neuronal cell loss: a cautionary note. Brain Res $\underline{1015}, 169-174$

Unrath A, Ludolph AC, Kassubek J (2007): Brain metabolites in definite amyotrophic lateral sclerosis. A longitudinal proton magnetic resonance spectroscopy study. J Neurol 254, 1099-1106

Urushitani M, Sik A, Sakurai T, Nukina N, Takahashi R, Julien JP (2006): Chromogranin-mediated secretion of mutant superoxide dismutase proteins linked to amyotrophic lateral sclerosis. Nat Neurosci $\underline{9}, 108-118$

Urushitani M, Ezzi SA, Julien JP (2007): Therapeutic effects of immunization with mutant superoxide dismutase in mice models of amyotrophic lateral sclerosis. Proc Natl Acad Sci U S A 104, 2495-2500

Urushitani M, Ezzi SA, Matsuo A, Tooyama I, Julien JP (2008): The endoplasmic reticulum-Golgi pathway is a target for translocation and aggregation of mutant superoxide dismutase linked to ALS. FASEB J 22, 2476-2487

Usarek E, Kuzma-Kozakiewicz M, Schwalenstocker B, Kazmierczak B, Münch C, Ludolph AC, Baranczyk-Kuzma A (2006): Tau isoforms expression in transgenic mouse model of amyotrophic lateral sclerosis. Neurochem Res $\underline{31}, 597-602$

Van Den Bosch L, Van Damme P, Bogaert E, Robberecht W (2006): The role of excitotoxicity in the pathogenesis of amyotrophic lateral sclerosis. Biochim Biophys Acta $1762,1068-1082$

Van Es MA, Dahlberg C, Birve A, Veldink JH, van den Berg LH, Andersen PM 
(2010): Large-scale SOD1 mutation screening provides evidence for genetic heterogeneity in amyotrophic lateral sclerosis. J Neurol Neurosurg Psychiatry $\underline{81}$, 562-566

Varma R, Chai Y, Troncoso J, Gu J, Xing H, Stojilkovic SS, Mattson MP, Haughey NJ (2009): Amyloid-beta induces a caspase-mediated cleavage of P2X4 to promote purinotoxicity. Neuromolecular Med 11, 63-75

Verkhratsky A, Orkand RK, Kettenmann H (1998): Glial calcium: homeostasis and signaling function. Physiol Rev $\underline{78}, 99-141$

Vukosavic S, Stefanis L, Jackson-Lewis V, Guégan C, Romero N, Chen C, DuboisDauphin M, Przedborski S (2000): Delaying caspase activation by Bcl-2: A clue to disease retardation in a transgenic mouse model of amyotrophic lateral sclerosis. $J$ Neurosci. 20, 9119-9125

Walker DG, Lue LF (2005): Investigations with cultured human microglia on pathogenic mechanisms of Alzheimer's disease and other neurodegenerative diseases. J Neurosci Res $\underline{81}$, 412-425

Walker DG, Lue LF, Beach TG (2001): Gene expression profiling of amyloid beta peptide-stimulated human post-mortem brain microglia. Neurobiol Aging $\underline{22}$, 957966

Wallraff A, Odermatt B, Willecke K, Steinhauser C (2004): Distinct types of astroglial cells in the hippocampus differ in gap junction coupling. Glia $\underline{48}, 36-43$

Wang J, Slunt H, Gonzales V, Fromholt D, Coonfield M, Copeland NG, Jenkins NA, Borchelt DR (2003): Copper-binding-site-null SOD1 causes ALS in transgenic mice: aggregates of non-native SOD1 delineate a common feature. Hum Mol Genet $\underline{12}$, 2753-2764

Wang Q, Johnson JL, Agar NY, Agar JN (2008): Protein aggregation and protein instability govern familial amyotrophic lateral sclerosis patient survival. PLoS Biol $\underline{6}$, 
e170 (doi: 10.1371/journal.pbio.0060170)

Watanabe M, Dykes-Hoberg M, Culotta VC, Price DL, Wong PC, Rothstein JD (2001): Histological evidence of protein aggregation in mutant SOD1 transgenic mice and in amyotrophic lateral sclerosis neural tissues. Neurobiol Dis $\underline{8}, 933-941$

Williamson TL, Corson LB, Huang L, Burlingame A, Liu J, Bruijn LJ, Cleveland DW (2000): Toxicity of ALS-linked SOD1 mutants. Science 288, 399 (Comment on: Science 1999, 286, 2498-2500) DOI: 10.1126/science.288.5465.399a; Übersicht

Woulikainen A, Moritz T, Marklund SL, Antti H, Andersen PM (2011): Diseaserelated changes in the cerebrospinal fluid metablome in amyotrophic lateral sclerosis detected by GC/TOFMS. PLos One 6, e17947 research article 04 April 2011

Wroe R, Wai-Ling Butler A, Andersen PM, Powell JF, Al-Chalabi A (2008): ALSOD: the amyotrophic lateral sclerosis online database; the amyotrophic lateral sclerosis associated with mutations in CuZn superoxide dismutase gene. Amyotroph Lateral Scler $\underline{9}, 249-250$

Wu PH, Phillis JW (1978): Distribution and release of adenosine triphosphate in rat brain. Neurochem Res $\underline{3}, 563-571$

Xiao Q, Zhao W, Beers D, Yen AA, Xie W, Henkel J, Appel S (2007): Mutant SOD1(G93A) microglia are more neurotoxic relative to wild-type microglia. J Neurochem 102, 2008-2019

Yamamoto K, Sokabe T, Matsumoto T, Yoshimura K, Shibata M, Ohura N, Fukuda T, Sato T, Sekine K, Kato $S$ et al. (2006): Impaired flow-dependent control of vascular tone and remodeling in P2X4-deficient mice. Nat Med $\underline{12}, 133-137$

Yamanaka K, Boillée S, Roberts EA, Garcia ML, McAlonis-Downes M, Mikse OR, Cleveland DW, Goldstein LS (2008): Mutant SOD1 in cell types other than motor neurons and oligodendrocytes accelerates onset of disease in ALS mice. Proc Natl 
Yang Y, Hentati A, Deng HX, Dabbagh O, Sasaki T, Hirano M, Hung WY, Ouahchi K, Yan J, Azim AC et al. (2001): The gene encoding alsin, a protein with three guanine-nucleotide exchange factor domains, is mutated in a form of recessive amyotrophic lateral sclerosis. Nat Genet $\underline{29}, 160-165$

Yeung D, Zablocki K, Lien CF, Jiang T, Arkle S, Brutkowski W, Brown J, Lochmüller H, Simon J, Barnard EA et al. (2006): Increased susceptibility to ATP via alteration of $\mathrm{P} 2 \mathrm{X}$ receptor function in dystrophic $\mathrm{mdx}$ mouse muscle cells. FASEB J $\underline{20}, 610-620$

Zenker W: Feinstruktur des Nervengewebes (2). Benninghoff Anatomie Urban und Schwarzenberg, München, Wien, Baltimore 1994

Zetterström P, Stewart HG, Bergemalm D, Jonsson PA, Graffmo KS, Andersen PM, Brännström T, Oliveberg M, Marklund SL (2007): Soluble misfolded subfractions of mutant superoxide dismutase-1s are enriched in spinal cords throughout life in murine ALS models. Proc Natl Acad Sci U S A $\underline{104}, 14157-14162$

Zhang Q, Haydon PG (2005): Roles for gliotransmission in the nervous system. J Neural Transm 112, 121-125 


\section{DANKSAGUNG}

Als erstes möchte ich mich bei Herrn Prof. Bähr, dem Ärztlichen Direktor der Abteilung Neurologie des Universitätsklinikums Göttingen bedanken, der mir die Möglichkeit gab meine Dissertation in seiner Abteilung zu erstellen.

Meinem Doktorvater Herrn PD Dr. med. C. Neusch danke ich für Bereitstellung des Themas und die ausgezeichneten Möglichkeiten, es zu bearbeiten.

Frau Dr. Zschüntzsch danke ich für die Hilfsbereitschaft und Geduld, die sie mir, trotz ihrer Belastung in Klinik und Forschung, entgegenbrachte.

Des Weiteren danke ich Frau Dr. Dr. med. Wegner, Institut für Neuropathologie, Universitätsmedizin Göttingen und Frau Prof. Petri aus der Abteilung für Neurologie der Medizinischen Hochschule Hannover für die Bereitstellung des humanen Gewebes.

Bedanken möchte ich mich auch bei Frau Maruschak, technische Mitarbeiterin der Abteilung Neuropathologie der UMG, die mir bei der Bearbeitung des humanen Gewebes mit Rat und Tat bei Seite stand und immer ein persönliches und warmherziges Wort für mich hatte.

Des Weiteren danke ich dem MPI für experimentelle Medizin für die Erlaubnis und Möglichkeit an dem Konfokalmikroskop zu arbeiten.

Ebenso danke ich Martin Brand für die Durchsicht meiner Arbeit und die vielen Hinweise, die zur Vollendung derselben notwendig waren.

Ich danke Alexander Buschmin für seine unermüdliche Unterstützung und Motivation und das zu jeder Tages- und Nachtzeit offene Ohr und Herz für meine langweiligen und frustrierten Laborgeschichten.

Der meiste Dank gilt meinen Eltern. Sie haben mir diese Universitätsausbildung ermöglicht, mir ermöglicht ein Dr.med. zu werden! Meine Familie hat mir jederzeit und in jeder Hinsicht zur Seite gestanden, mich getröstet, mich aufgefangen, motiviert, angefeuert, mir zugehört und zugestimmt und widersprochen und geholfen. Allein dieser Glaube an mich und das Projekt ist der Grund, warum diese Arbeit fertig geworden ist.

Besonderer Dank gilt auch meinen Leidensgenossen, also Göttinger ExKommilitonen und Kollegen für das Gefühl "nicht alleine zu sein“, für wichtige gedankliche Anstöße, den stetigen Austausch und immer möglichen gegenseitigen Aufbau. 


\section{Lebenslauf}

Ich, Karoline Dorothea Ostertag, wurde am 17.11.1981 als erstes Kind von Gabriele Gisela Ostertag, geb. Wittke und Prof. Dr. med. Helmut Ostertag in Hannover, Niedersachsen geboren:

Dort besuchte ich von 1988 - 1992 die Grundschule Auf dem Loh und anschließend von 1992 - 1994 die Orientierungsstufe Meldaustraße. Von 1994 - 2001 war ich Schülerin des Gymnasiums Goetheschule Hannover und beendete meine Schulausbildung im Juni 2001 mit dem Abitur. Anschließend verbrachte ich drei Monate als Au Pair in Kalifornien, USA.

Es folgte von 10/2001 - 03/2003 das Studium der Geschichte und Neueren deutschen Literatur (Magister) an der Freien Universität Berlin. Im Oktober 2003 konnte ich endlich das Medizinstudium an der Humboldt-Universität zu Berlin, Charité beginnen.

Die ärztliche Vorprüfung (Physikum) absolvierte ich erfolgreich im März 2005. Anschließend wechselte ich an die Georg-August Universität Göttingen, um das Hauptstudium der Humanmedizin aufzunehmen. Während des Studiums erfolgten mehrere Auslandsaufenthalte im Rahmen der zu verrichtenden Famulaturen und Praktika, u.a. in Wien und Stockholm. Zwischen Oktober und Dezember 2009 folgte der schriftliche und mündliche Abschnitt der Zweiten Ärztlichen Prüfung. Am 02.12.2009 wurde mir die Approbation als Ärztin erteilt. Während des Hautstudiums entstand meine Dissertation: "Analyse der Rolle des Purin-Rezeptors P2X4 in der Pathophysiologie der Amyotrophen Lateralsklerose durch vergleichende Untersuchung seiner Expression im ALS-Mausmodell und humanen Gewebe ". Seit dem 16. der August 2010 bin ich als Assistenzärztin der Neurologie der UMG angestellt. Momentan arbeite ich auf der neurologischen Normalstation 3014 und bin außerdem in der Prionforschung unter der Leitung von Frau Prof. Zerr tätig. 